\title{
WestVirginiaUniversity
}

THE RESEARCH REPOSITORY @ WVU

Graduate Theses, Dissertations, and Problem Reports

2000

\section{IL -10 gene therapy for the treatment of pulmonary inflammation}

\author{
Sujatha Dokka \\ West Virginia University
}

Follow this and additional works at: https://researchrepository.wvu.edu/etd

\section{Recommended Citation}

Dokka, Sujatha, "IL -10 gene therapy for the treatment of pulmonary inflammation" (2000). Graduate Theses, Dissertations, and Problem Reports. 1242.

https://researchrepository.wvu.edu/etd/1242

This Dissertation is protected by copyright and/or related rights. It has been brought to you by the The Research Repository @ WVU with permission from the rights-holder(s). You are free to use this Dissertation in any way that is permitted by the copyright and related rights legislation that applies to your use. For other uses you must obtain permission from the rights-holder(s) directly, unless additional rights are indicated by a Creative Commons license in the record and/ or on the work itself. This Dissertation has been accepted for inclusion in WVU Graduate Theses, Dissertations, and Problem Reports collection by an authorized administrator of The Research Repository @ WVU.

For more information, please contact researchrepository@mail.wvu.edu. 


\title{
DISSERTATION
}

\section{IL-10 GENE THERAPY FOR THE TREATMENT OF PULMONARY INFLAMMATION}

\section{Sujatha Dokka}

Dissertation submitted to the School of Pharmacy at West Virginia

University in partial fulfillment of the requirements for the degree of

\author{
Doctor of Philosophy \\ In \\ Pharmaceutical Sciences \\ Yon Rojanasakul, Ph. D., Chair \\ Carl J. Malanga, Ph. D. \\ David Toledo-Velasquez, Ph. D. \\ Joseph K. H. Ma, Ph. D. \\ Xianglin Shi, Ph. D.
}

Department of Basic Pharmaceutical Sciences

Morgantown, West Virginia

2000

Keywords: IL-10, Gene Delivery, Cationic Liposomes, Toxicity, Endotoxin, ROS, Pulmonary Inflammation, Mechanism of Anti-Inflammation 


\section{ABSTRACT \\ IL-10 Gene Therapy for the Treatment of Pulmonary Inflammation}

\section{Sujatha Dokka}

Interleukin-10 (IL-10) is an anti-inflammatory cytokine that plays an important regulatory role in inflammatory diseases. The overall goal of this research is to investigate the potential therapeutic effect of IL-10 gene therapy for the treatment of pulmonary inflammation and to develop appropriate gene delivery and expression systems for efficient gene transfer to the lung. We evaluated various liposomal and non-liposomal agents including LipofectAMINE ${ }^{\circledR}$, Lipofectin $^{\circledR}$, DOTAP, DEAE-dextran, and the DNA condensing agent protamine sulfate for their ability to promote gene transfection in macrophages. We have developed an efficient transfection protocol which is at least $20-25$ fold superior to frequently used protocols for macrophage transfection. However, gene transfection in macrophages is still low. Since macrophages are known to be highly susceptible to endotoxin stimulation and endotoxin is a major contaminant of plasmid DNA preparations used in most transfection studies, we investigated the effect of endotoxin on gene transfer and the role of reactive oxygen species (ROS) in the process. Our results indicate that this decreased transfection was dependent on ROS-mediated cellular toxicity induced by endotoxin and that $\mathrm{OH}$ radicals play a major role in this process. The mechanism of antiinflammatory action of IL-10 is incompletely understood. The present study also investigates the possible role of ROS in NF- $\kappa B$ activation and $I \kappa B \alpha$ degradation and their inhibition by IL10 in macrophages. Addition of IL-10 inhibited both $\mathrm{I} \kappa \mathrm{B} \alpha$ degradation and generation of $\mathrm{OH}$ radicals in response to LPS stimulation. These results provide, for the first time, direct evidence for the role of $\mathrm{IL}-10$ in ROS-dependent NF-KB activation. The next step was to develop a protocol for in vivo gene transfer. Cationic liposomes represent a class of nonviral vectors that hold great promise as gene delivery vehicles. However, recent studies have shown that they may be associated with some toxicity. We tested the hypothesis that the positive charge of liposomes is a key determinant of toxicity. ROS play a key role in cationic lipid-mediated toxicity. Finally, we established an efficient gene transfer protocol that results in clinically relevant concentrations of IL-10 protein that can downregulate mouse lung inflammation in response to LPS stimulation. 


\section{Dedicated to my}

Parents and my Loving Husband 


\section{ACKNOWLEDGEMENTS}

First and foremost I would like to thank my parents for all their encouragement and support. They have always been there for me and have inspired me to pursue my graduate studies. The next most inspiring person in my life is Dr. Yon Rojanasakul. I consider myself very fortunate to have had the opportunity to work under him. His sincerity and commitment to research is remarkable and I have learnt a lot under his mentorship. I cannot thank him enough for all his guidance and for making this journey of mine a pleasurable one.

I would also like to thank my committee members, Dr. Joseph Ma, Dr. Carl Malanga, Dr. Xianglin Shi, and Dr. David Toledo-Velasquez for their invaluable contributions to my research. I was very lucky to have had the opportunity to work at the National Institute of Occupational Safety and Health (NIOSH) under the guidance of Dr. Xianglin Shi. At NIOSH I had access not only to state-of-the-art equipment but also had associations with some extremely talented researchers. Specifically, I would like to thank Stephen Leonard, Dale Porter, Vic Robinson, Jiangping Ye, Fei Chen, Suwei Wang, Liying Wang, Jim Antonini, and Navin Swaroop for all their technical help. I would like to thank Dr. Vince Castranova for supporting my in vivo studies.

Last but not the least, I would like to thank my husband, Sastry Sonti. His support and encouragement have been instrumental in the completion of my Ph. D. I could not have finished my degree without his help and support throughout. 


\section{TABLE OF CONTENTS}

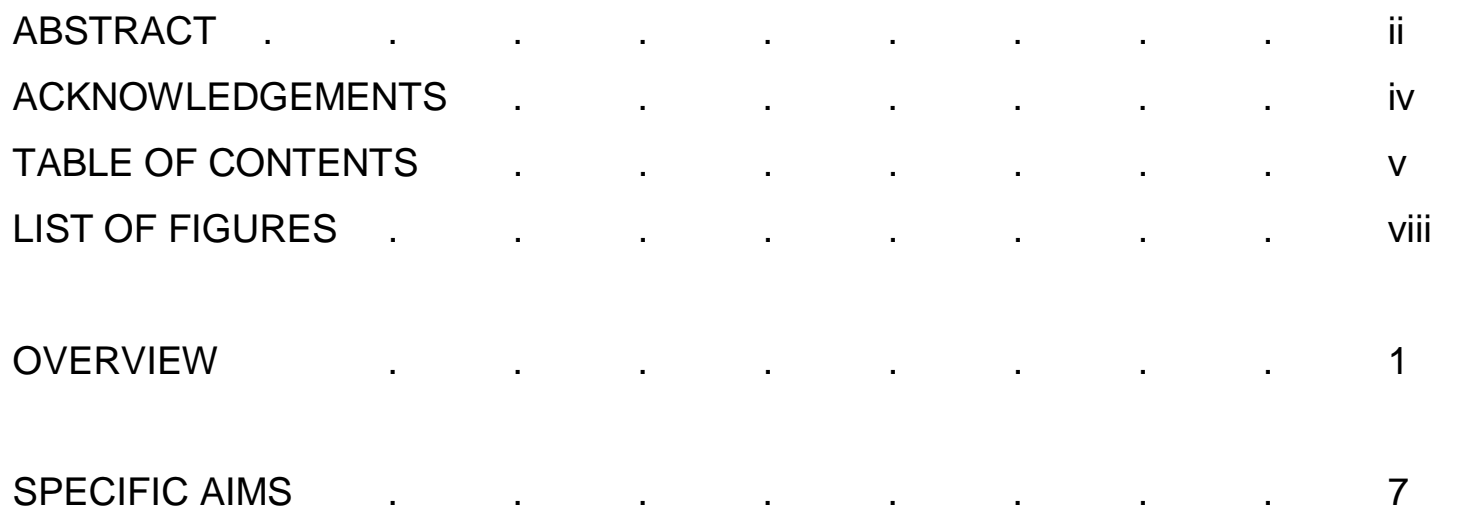

I. SECTION I : Generation of Cytoplasmic and Nuclear Expression Vectors

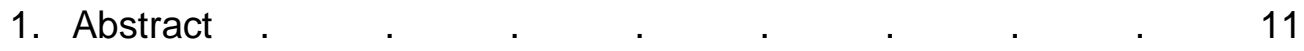

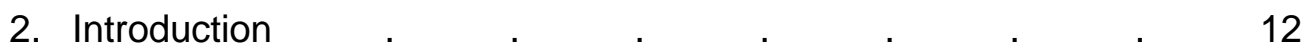

3. Materials and Methods . $\quad . \quad$. $\quad . \quad$. $\quad . \quad . \quad 14$

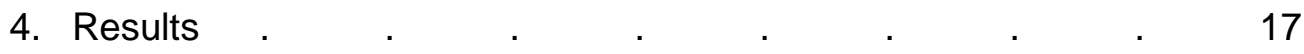

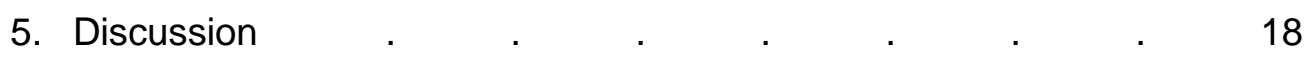

6. Figures . . . . . . . . . . . . .

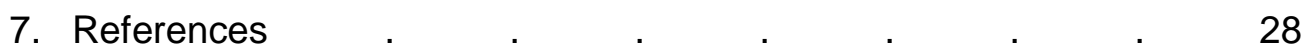

II. SECTION II : High-Efficiency Gene Transfection of Macrophages by Lipoplexes

1. Abstract . . . . . . . . . . . . . 31

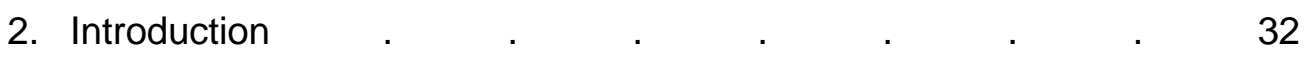

3. Materials and Methods . . . . . . . . . $\quad$. 33

4. Results and Discussion . . . . . . . . . . $\quad$. 36

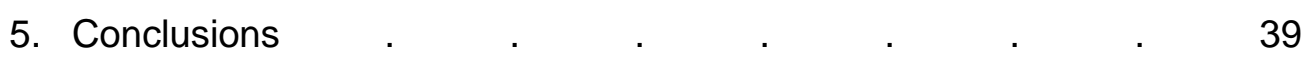

6. Figures . . . . . . . . . . . . . . 4040

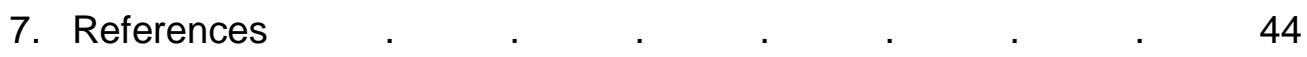

III. SECTION III : Mechanisms of Endotoxin-Induced Inactivation of Transgene Expression in Macrophages

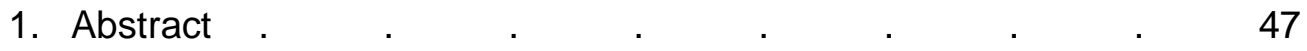

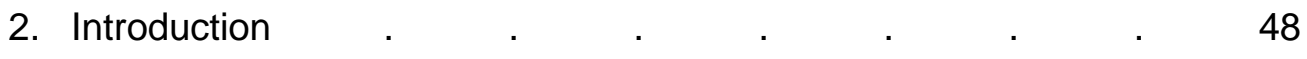

3. Materials and Methods . . . . . . . $\quad . \quad 50$ 


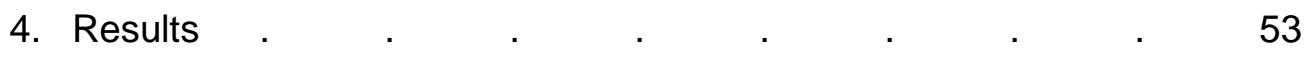

5. Discussion . . . . . . . . . . . . 56

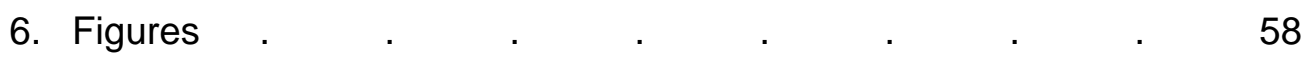

7. References . . . . . . . . . . . . 64

IV. SECTION IV : Mechanism of IL-10-Mediated Inhibition of NF- $\mathrm{kB}$ Activation in Macrophages

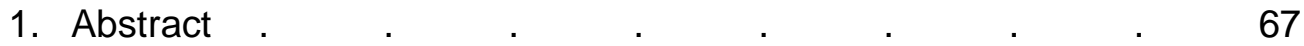

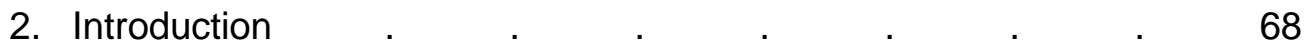

3. Materials and Methods . $\quad . \quad$. $\quad$. $\quad$. $\quad$. $\quad$. 70

4. Results . . . . . . . . . . . . . 74

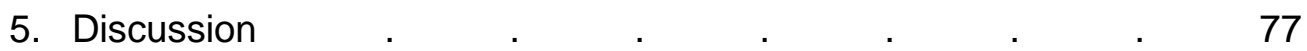

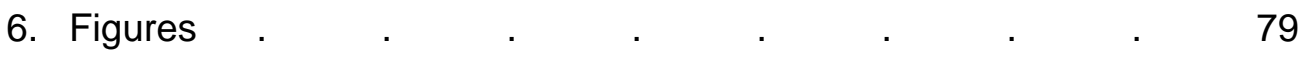

7. References . . . . . . . . . . . . 84

V. SECTION V : Oxygen Radical-Mediated Pulmonary Toxicity Induced by Cationic Liposomes

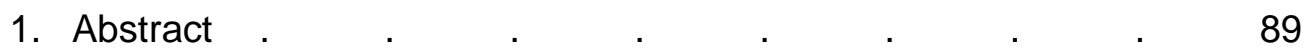

2. Introduction . . . . . . . . . . . . . 90

3. Materials and Methods . $\quad . \quad$. $\quad . \quad$. $\quad . \quad 92$

4. Results . . . . . . . . . . . . . . 95

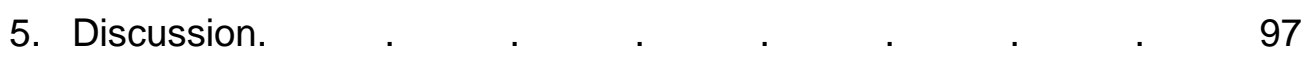

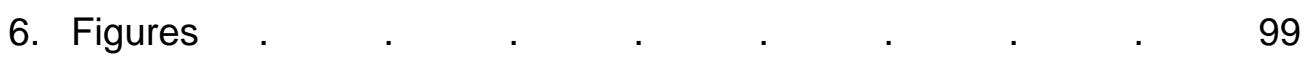

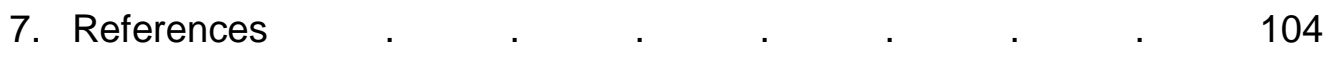

VI. SECTION VI : Inhibition of Endotoxin-Induced Lung Inflammation by IL-10 Gene Therapy

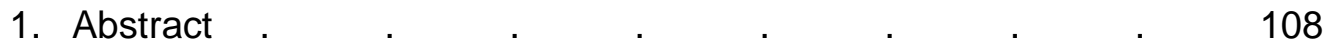

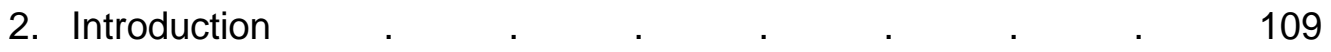

3. Materials and Methods . $\quad . \quad$. $\quad . \quad$. $\quad$. $\quad$. 111

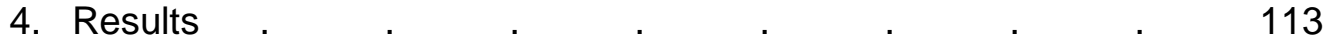

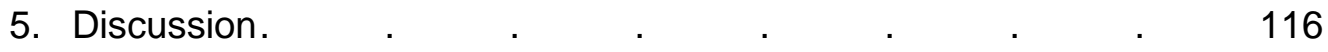

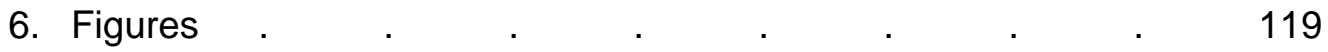

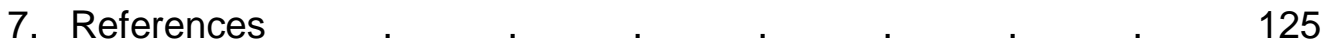


OVERALL CONCLUSIONS

CURRICULUM VITAE $\quad . \quad$. $\quad . \quad$. $\quad . \quad$. $\quad . \quad . \quad . \quad 130$ 


\section{LIST OF FIGURES}

\section{SECTION I}

1. Poor Nuclear Delivery of DNA . $\quad$. $\quad$. $\quad$. $\quad 20$

2. T7 Cytoplasmic Expression System . . . . . . 21

3. pCMV/T7-T7pol Autogene System . . . . . 22

4. Construction of pT7-mIL10 Plasmid . . . . . 23

5. Comparison of Transgene Expression of Cytoplasmic and

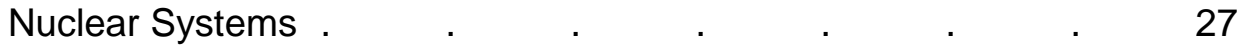

\section{SECTION II}

1. Comparison of Gene Transfection in Different Cell Lines . 40

2. Effects of DEAE-dextran and LipofectAMINE Concentration on .
(A) Transfection Efficiency
(B) Cellular Toxicity of Macrophage RAW 264.7 Cells

3. Effect of Protamine Sulfate on LipofectAMINE-Mediated Gene Transfection

4. Comparison of Transfection Activity of Different Liposomal Formulations in Macrophage RAW 264.7 Cells .

\section{SECTION III}

1. Comparison of Gene Transfection in Different Cell Lines . 58

2. Comparison of Gene Transfection of Different DNA Preparations 59

3. Effects of Endotoxin on (A) Transfection Efficiency and

(B) Cellular Toxicity in Different Cell Lines

4. Effects of Polymyxin B and PBN on (A) LPS-Induced Toxicity and

(B) Transfection Efficiency

5. Effects of ROS Scavengers on (A) LPS-Induced Toxicity and

(B) Transfection Efficiency

6. ESR Measurements of LPS-Induced ROS Generation .

\section{SECTION IV}

1. Inhibition of TNF $\alpha$ Production by IL-10 
2. EMSA studies of NF-kB Binding Activity in LPS-Treated Macrophages . $\quad$. $\quad$. $\quad$. $\quad$. $\quad$. $\quad$. 80

3. Effect of IL-10 on NF-kB-Dependent Gene Expression and IאB $\alpha$

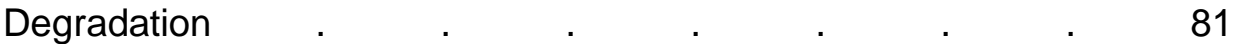

4. Effect of Oxygen Radical Scavengers on NF-kB-Dependent Gene Expression and $\mathrm{I} k \mathrm{~K} \alpha$ Degradation $\quad$. $\quad$. $\quad$. $\quad$. $\quad 82$

5. ESR Measurements of LPS-Induced ROS Generation . 83

\section{SECTION V}

1. Comparison of Toxicity Induced by Differently Charged Liposomes 99

2. Dose-Dependent Toxicity Induced by LipofectAMINE . . 100

3. Role of the Headgroup Spermine in LipofectAMINE-Induced Lung Toxicity .

4. (A) Comparison of ROS Production by Differently Charged Liposomes (B) Dose-Dependent Induction of ROS by LipofectAMINE 102

5. Effect of Pretreatment of Mice with PBN before Instillation with LipofectAMINE . . . . . . . . . . 103

\section{SECTION VI}

1. LPS-Induced Lung Inflammation in Mice .

2. Effect of Pretreatment of Mice with rlL-10 before Instillation

3. Delivery of IL-10 Plasmid with LipofectAMINE . $\quad$. $\quad 121$

4. Optimization of DNA-DOTAP Delivery System . . . 122

5. Time Profile of IL-10 Expression Following DNA-DOTAP Administration . $\quad . \quad$. $\quad . \quad$. . . . 123

6. Effect of IL-10 Gene Transfer on LPS-Induced Lung Inflammation 124 


\section{OVERVIEW}

Recent advances in molecular and cellular biology have identified the cellular mediators that regulate many disease processes. One such mediator, Interleukin-10 (IL-10), has been identified as an important negotiator between the immune and inflammatory systems (de Vries, 1995; Moore et al., 1993). IL-10 is an anti-inflammatory cytokine that is regularly produced during inflammatory processes in vivo, usually by the same cells (e.g., monocytes, $T$ cells) that release inflammatory mediators. It inhibits the production of inflammatory cytokines such as IL-1, IL-6, and tumor necrosis factor (TNF- $\alpha$ ) by macrophages stimulated with lipopolysaccharide (LPS) and interferon. The overall goal of this study is to investigate the regulatory effect of IL-10 and to employ gene strategies to deliver IL-10 in vivo.

\section{Development of Efficient IL-10 Expression Vectors}

Protein expression is a multi-step process. One key step is the transcription of the corresponding gene in the nucleus. Although many vectors are efficient in delivering DNA into the cytoplasm of cells, expression of the DNA is still hindered by inefficient transport of DNA into the nucleus where the transcription machinery resides. Less than $1 \%$ of the DNA enters the nucleus and is transcribed (Capecchi, 1980), leaving a significant amount of DNA untranscribed in the cytoplasm. Cytoplasmic gene expression systems have been developed to overcome this obstacle (Brisson et al., 1999; Gao and Huang, 1991). The advantage of cytoplasmic systems is the capacity to induce gene transcription and protein expression in the cytoplasm, thereby circumventing the problem of inefficient nuclear entry.

The goal of this study (Section I) is to construct and evaluate cytoplasmic and nuclear vectors containing IL-10 gene, for their ability to express IL-10 protein.

\section{Gene Transfection In Macrophages}

Altered cytokine expression in macrophages has been implicated in a number of pathologic disorders such as endotoxemia and sepsis. Hence, macrophages have been identified as a key target for pharmacologic intervention via plasmid mediated gene transfer. Our results show that macrophages are difficult to transfect relative to other cell types, and 
therefore there is a need for an efficient delivery system. The purpose of this study (Section II) was to develop a safe, noninvasive, and reproducible delivery system for macrophages.

A number of non-viral gene transfer methods have been developed to improve transfection (Burkholder et al., 1993; Economou et al., 1989; Mack et al., 1998; Roussel et al., 1988). However, these methods are associated with low transfection efficiency or high cellular toxicity. The DEAE-dextran method of transfection is a well-established protocol that has been shown to be superior to most other methods of transfection for macrophages (Mack et al., 1998). To develop an efficient gene delivery system for macrophages, we evaluated various liposomal and non-liposomal agents including LipofectAMINE ${ }^{\circledR}$, Lipofectin $^{\circledR}$, DOTAP, DEAE-dextran, and the DNA condensing agent protamine sulfate for their ability to promote gene transfection.

\section{Decreased Transfection in Macrophages: A Role for Endotoxin?}

Over the years, numerous efforts have been made to improve gene transfection of macrophages, however their transfection is still poor. The lack of understanding of the causes that contribute to the refractory nature of macrophages during gene transfection is partly responsible for this limited success. Since macrophages are known to be highly susceptible to endotoxin stimulation and endotoxin is a major contaminant of plasmid DNA preparations used in most transfection studies, we hypothesized that the presence of contaminating endotoxin may contribute to this low transfection.

Endotoxin is known to activate macrophages and induce the production of various cellular mediators including reactive oxygen species (ROS) (Guthrie et al., 1984; Raetz, 1990). Transfection was greately reduced in macrophages in the presence of endotoxins. Decreased transfection also correlated with increased cellular toxicity. Our hypothesis was further confirmed by the fact that neutralizing the endotoxin, reversed LPS-induced cellular toxicity and increased transfection.

Since ROS have been implicated in a variety of pathological processes and LPS is known to stimulate ROS production in macrophages (Guthrie et al., 1984), we examined the effect of different ROS scavengers on LPS induced cellular toxicity and decreased gene transfection. Supporting our hypothesis, ROS scavengers decreased cellular toxicity and 
increased gene transfection in LPS induced macrophages. By choosing specific ROS scavengers, we were also able to identify that hydroxyl radicals $(\cdot \mathrm{OH})$ maybe the principal oxidative species responsible for the observed effects induced by LPS. Our ESR data also confirmed that $\mathrm{OH}$ radicals were indeed formed.

This is the first study reporting the role of ROS in causing decreased transfection in macrophages.

\section{Role of IL-10 as an Anti-Inflammatory Molecule in the Signal Transduction Pathway Triggered by Endotoxin in Macrophages}

While the role of IL-10 as an anti-inflammatory molecule has been well established, the mechanism by which it exerts its action is still not well understood and the experimental results are controversial. Macrophages are known to generate reactive oxygen species (ROS) in response to stimuli (Rojanasakul et al., 1993). Because ROS have been implicated as the common messenger involved in NF- $\mathrm{KB}$ activation by diverse stimuli (Baeuerle and Henkel, 1994), we hypothesized that IL-10 may exert its effect on NF-kB activation by changing the redox status of stimulated cells through an ROS-dependent pathway.

The results of our study (Section IV) show that ROS are involved in the signal transduction pathway leading to NF- $\mathrm{kB}$ activation and $\mathrm{I} \mathrm{KB} \alpha$ degradation. The data from ESR studies shows that IL-10 inhibits LPS-induced $\mathrm{OH}$ production. Based on these results we proposed a mechanism of action of IL-10 which involved the modulation of ROS production.

This study provides a new insight into the mechanism of the inhibitory effects of IL10.

\section{Cationic Liposomes as Non-Viral Gene Delivery Systems In Vivo}

After the role of IL-10 as an anti-inflammatory cytokine was established, the next step was to develop an efficient gene transfer protocol for IL-10 gene therapy. Cationic lipids represent a class of non-viral vectors that have been used successfully in both in vitro (Behr et al., 1989; Felgner and Holm, 1989; Gao and Huang, 1991) and in vivo (Brigham et al., 1989; Lee et al., 1996) gene transfer. Since we established a gene transfer protocol for 
macrophages in vitro, we tested the same system in vivo. The polyvalent cationic liposome, LipofectAMINE, which was efficient and non-toxic in vitro, was found to be very toxic in vivo.

The origin of toxicity caused by cationic liposomes is not well understood. We hypothesized that the positive charge of liposomes plays an important role in lung toxicity. To test this hypothesis, we instilled differently charged liposomes into mice lungs and tried to elucidate the mechanism of pulmonary toxicity (Section V). The results from this study show that positively charged liposomes caused an increase in the number of inflammatory cells in the lung which are responsible for the release of inflammatory mediators such as cytokines and ROS. To confirm that ROS are responsible for the toxicity observed, mice were pretreated with ROS scavenger, PBN. Pretreatment with PBN decreased cationic liposome-mediated inflammation and toxicity.

We report in this study, for the first time, the role of ROS in cationic lipid-mediated toxicity. The results of this study have great significance in the development of cationic lipidbased gene delivery systems.

\section{IL-10 Gene Therapy for the Treatment of Lung Inflammation}

Our final and ultimate goal was to evaluate the therapeutic potential of IL-10 gene therapy for the treatment of lung inflammation. Most studies to date have used recombinant IL-10 protein (Howard et al., 1993; Kuhn et al., 1993). Recombinant protein has the disadvantage of being short-lived and expensive. Gene therapy, on the other hand, offers a cheaper more economical alternative and has the additional advantage of a possible prolonged expression. To study the effect of IL-10 gene therapy, we utilized a murine lung inflammation model. IL-10 plasmid delivery was optimized using a monovalent cationic liposome, DOTAP. We report here, for the first time, that intratracheal administration of pDNA/cationic liposome complexes results in clinically relevant concentrations of IL-10 protein. This IL-10 gene transfer can downregulate mouse lung inflammation and cell activation in response to LPS stimulation. The results of this study are very significant because the application of IL-10 gene therapy for lung diseases has not been reported so far. 


\section{REFERENCES}

Baeuerle, P.A. and Henkel, T. (1994) Function and activation of NF-kappa B in the immune system. Annu Rev Immunol 12, 141-179.

Behr, J.P., Demeneix, B., Loeffler, J.P., and Perez-Mutul, J. (1989) Efficient gene transfer into mammalian primary endocrine cells with lipopolyamine-coated DNA. Proc Natl Acad Sci USA 86, 6982-6986.

Brigham, K.L., Meyrick, B., Christman, B., Magnuson, M., King, G., and Berry, L.C.J. (1989) In vivo transfection of murine lungs with a functioning prokaryotic gene using a liposome vehicle. Am J Med Sci 298, 278-281.

Brisson, M., Tseng, W.C., Almonte, C., Watkins, S., and Huang, L. (1999) Subcellular trafficking of the cytoplasmic expression system. Hum Gene Ther 10, 2601-2613.

Burkholder, J.K., Decker, J., and Yang, N.S. (1993) Rapid transgene expression in lymphocyte and macrophage primary cultures after particle bombardment-mediated gene transfer. J Immunol Meth 165, 149-156.

Capecchi, M.R. (1980) High efficiency transformation by direct microinjection of DNA into cultured mammalian cells. Cell 22, 479-488.

de Vries, J.E. (1995) Immunosuppressive and anti-inflammatory properties of interleukin 10. Ann Med 27, 537-541.

Economou, J.S., Rhoades, K., Essner, R., McBride, W.H., Gasson, J.C., and Morton, D.L. (1989) Genetic analysis of the human tumor necrosis factor alpha/cachectin promoter region in a macrophage cell line. J Exp Med 170, 321-326.

Felgner, P. and Holm, M. (1989) Cationic-liposome-mediated transfection. Focus 11, 21-25.

Gao, X. and Huang, L. (1991) A novel cationic liposome reagent for efficient transfection of mammalian cells. Biochem Biophys Res Commun 179, 280-285.

Guthrie, L.A., McPhail, L.C., Henson, P.M., and Johnston, R.B.J. (1984) Priming of neutrophils for enhanced release of oxygen metabolites by bacterial 
lipopolysaccharide. Evidence for increased activity of the superoxide-producing enzyme. J Exp Med 160, 1656-1671.

Howard, M., Muchamuel, T., Andrade, S., and Menon, S. (1993) Interleukin 10 protects mice from lethal endotoxemia. J Exp Med 177, 1205-1208.

Kuhn, R., Lohler, J., Rennick, D., Rajewsky, K., and Muller, W. (1993) Interleukin-10deficient mice develop chronic enterocolitis. Cell 75, 263-274.

Lee, E.R., Marshall, J., Siegel, C.S., Jiang, C., Yew, N.S., Nichols, M.R., Nietupski, J.B., Ziegler, R.J., Lane, M.B., Wang, K.X., Wan, N.C., Scheule, R.K., Harris, D.J., Smith, A.E., and Cheng, S.H. (1996) Detailed analysis of structures and formulations of cationic lipids for efficient gene transfer to the lung. Hum Gene Ther 7, 1701-1717.

Mack, K.D., Wei, R., Elbagarri, A., Abbey, N., and McGrath, M.S. (1998) A novel method for DEAE-dextran mediated transfection of adherent primary cultured human macrophages. J Immunol Meth 211, 79-86.

Moore, K.W., O'Garra, A., de Waal, M., Vieira, P., and Mosmann, T.R. (1993) Interleukin-10. Annu Rev Immunol 11, 165-190.

Raetz, C.R. (1990) Biochemistry of endotoxins. Annu Rev Biochem 59, 129-170.

Rojanasakul, Y., Wang, L., Hoffman, A.H., Shi, X., Dalal, N.S., Banks, D.E., and Ma, J.H.K. (1993) Mechanisms of hydroxyl free radical-induced cellular injury and calcium overloading in alveolar macrophages. Am J Respir Cell Mol Biol 8, 377-383.

Roussel, M.F., Rettenmier, C.W., and Sherr, C.J. (1988) Introduction of a human colony stimulating factor-1 gene into a mouse macrophage cell line induces CSF-1 independence but not tumorigenicity. Blood 71, 1218-1225. 


\section{SPECIFIC AIMS}

1. To construct different cytoplasmic and nuclear expression vectors containing IL10 gene and to select the best expression vector for subsequent gene transfer studies (Section I).

Our first goal was to develop IL-10 expression vectors capable of expressing high levels of IL-10 protein. The potential advantages of cytoplasmic systems are higher and faster expression of gene than that of the nuclear expression system because the messenger transcribed from the cytoplasmic vector can be immediately translated into the cytoplasm. Two IL-10 expression vectors, cytoplasmic (T7 promoter driven) and nuclear (CMV promoter driven), were constructed. These plasmid vectors were transfected into macrophages and IL-10 expression was measured and compared.

\section{To develop an efficient gene delivery system for macrophages (Section II).}

A number of commercially available liposomal agents and DEAE-Dextran were tested for their transfection efficiency. CMV-luciferase and CMV- $\beta$-gal were chosen for all optimization studies. Luciferse and $\beta$-gal assays were used to quantitate gene expression and LDH assay was used to measure toxicity. Gene transfection studies were performed in various cell lines including RAW 264.7, 293, HepG2 and A549.

\section{To investigate the effect of endotoxin on gene transfection efficiency and the role of reactive oxygen species in this process (Section III).}

To investigate the cause of decreased transfection in macrophages, the effect of contaminating endotoxin in plasmid DNA preparations was studied. LDH activity was used as an indicator for cellular toxicity, and ESR was employed to study ROS generation induced by endotoxin. To confirm the role of ROS in gene transfection, ROS scavengers including PBN, catalase, superoxide dismutase and sodium formate were added to the transfection medium and cellular toxicity and gene expression were measured. 
4. To investigate the possible role of ROS and their inhibition by IL-10 in NF-KB activation and IKB $\alpha$ degradation in macrophages (Section IV).

The mechanism by which IL-10 exerts its anti-inflammatory effect is not completely understood. Hence, we studied the effect of IL-10 on different steps of the signal transduction pathway in stimulated macrophages. ELISA was employed to measure cytokine IL-10 and TNF- $\alpha$ levels. Gel-Shift assay was used to study NF-kB-DNA binding activity and Western Blot was used to measure $1 \kappa B \alpha$ degradation. A stable cell line expressing IL-10 was generated to aid mechanistic studies. ESR studies were carried out to study free radical generation and IL-10 inhibition. Specific ROS scavengers were used to determine the key species involved in the signal transduction process.

\section{To study the toxicity associated with polycationic liposomes and to elucidate the} underlying mechanism of pulmonary toxicity of polycationic liposomes in vivo (Section V).

The potential utility of any delivery system depends on its safety. The observation that the cationic liposome, LipofectAMINE, was very toxic in vivo, led to further studies into the mechanism of toxicity of cationic liposomes. To test the hypothesis that the positive charge of liposomes is responsible for toxicity, we tested the effect of intratracheal instillation of differently charged liposomes. Intratracheal administration of liposomes facilitated delivery to the lung. Polymorphonuclear (PMN) cell counts and LDH assays were performed on the bronchoalveolar lavage fluid (BALF). Free radical production was assessed by luminol-dependent chemiluminescence. To confirm the role of ROS in the development of pulmonary inflammation and toxicity, mice were preinstilled with ROS scavenger before LPS stimulation.

6. To develop an efficient gene transfer protocol for IL-10 in vivo and to study the therapeutic potential of IL-10 in the treatment of lung inflammation (Section VI).

The final goal of this study was to determine the therapeutic potential of IL-10 in pulmonary inflammation. A lung inflammation model was developed by instilling LPS 
intratracheally into mice. Since naked DNA is not efficiently expressed in our system, it was necessary to develop a delivery system. DOTAP, a monovalently charged cationic liposome, was chosen because of its relatively non-toxic nature (Section $\mathrm{V}$ ). The ratio of pDNA:DOTAP was varied and the expression of IL-10 was measured in the BALF by ELISA. The IL-10 expression was also measured at different time intervals after gene delivery to determine the time point at which expression is at the maximum. Finally, to study the therapeutic potential of IL-10 gene therapy, mice were preinstilled with the IL-10 gene delivery system before inducing lung inflammation with endotoxin. Lung inflammation was analyzed by PMN counts and TNF- $\alpha$ levels in the BALF. 


\section{SECTION I}

Development of Efficient IL-10 Expression Vectors 


\section{I.1. ABSTRACT}

Protein expression is a multi-step process. One key step is the transcription of the corresponding gene in the nucleus. Several gene delivery systems have been developed to introduce functional genes to the cell nucleus in order to induce therapeutic protein expression. However, nuclear entry of exogenously administered genes is inefficient and often results in poor protein expression. The present study investigates the feasibility of utilizing a cytoplasmic gene expression system to induce gene transcription and protein expression in the cytoplasm, thereby circumventing the problem of nuclear entry. This expression system entails genes driven by the bacteriophage $\mathrm{T} 7$ promoter to be expressed in the cytoplasm when co-delivered with T7 RNA polymerase. The overall goal of this study is to develop a gene transfer protocol for efficient expression of IL-10 protein in macrophages. To this end, we have generated both cytoplasmic and nuclear IL-10 expression vectors. RAW 264.7 cells were transfected with both cytoplasmic and nuclear vectors using cationic liposomes. Our results show that the nuclear expression system was approximately 14 fold more effective than the cytoplasmic system in expressing IL-10 protein. Based on these results the nuclear expression vector was used for all subsequent studies. 


\section{I.2. INTRODUCTION}

One of the principal barriers to effective gene therapy is the development of efficient vectors that can deliver therapeutic gene to its target site, i.e., the nucleus. Viral vectors have achieved best results so far. However, the safety concerns and the immunological profile of viral vectors have steered research towards the development of efficient non-viral carriers (Roth and Cristiano, 1997). Non-viral gene delivery systems are limited by their low transfection efficiency (Ledley, 1995). Nuclear trafficking of plasmid DNA has been identified as one of the major hurdles to efficient transfection (Capecchi, 1980; Zabner et al., 1995).

Although many vectors are efficient in delivering DNA into the cytoplasm of cells, expression of the DNA is still hindered by inefficient transport of DNA into the nucleus where the transcription machinery resides (Fig. 1) (Capecchi, 1980). To overcome this obstacle, a cytoplasmic expression system has been developed by utilizing a reporter gene driven by a bacteriophage T7 promoter (Gao and Huang, 1993). Expression of this gene is dependent on the codelivery of T7 RNA polymerase, which remains largely in the cytoplasm due to the lack of a nuclear localization signal in the molecule (Dunn et al., 1988). In this system, the T7 RNA polymerase can drive the expression of a reporter gene (e.g., pT7-CAT) in the cytoplasm (Fig. 2). Thus, cytoplasmic expression systems bypass the need for the DNA to enter the nucleus, which has been identified as the rate-limiting step for efficient DNA delivery. However, the disadvantages of this system are: 1) transient expression due to rapid degradation or inactivation of the T7 RNA polymerase enzyme, 2) potentially immunogenic because a foreign protein is being delivered, and 3) can be very expensive especially in vivo.

To overcome these problems, Brisson et al. (Brisson et al., 1999) developed a new T7 RNA polymerase expressing vector pCMV/T7-T7pol consisting of the T7 RNA polymerase gene driven by both a human CMV promoter and a bacteriophage $\mathrm{T} 7$ promoter. pCMV/T7-T7pol does not require exogenous T7 RNA polymerase to initiate the transcription. Once $\mathrm{pCMV} / \mathrm{T} 7 \mathrm{pol}$ enters the cell through endocytosis, some of the DNA is released into the cytoplasm (Fig. 3). A portion of pCMV/T7-T7pol undergoes nuclear transport where transcription is initiated at the CMV promoter. The pCMV/T7-T7pol mRNA would then be transported into the cytoplasm for translation into T7 RNA polymerase protein. This newly synthesized protein could then recognize the T7 promoter located on 
pCMV/T7-T7pol and begin transcription in the cytoplasm through a possible autoregulatory mechanism (i.e autogene mechanism). Therefore, pCMV/T7-T7pol could continuously supply the cell with a source of T7 RNA polymerase to transcribe target genes containing a T7 promoter in the cytoplasm (Fig. 3).

Since pCMV/T7-T7pol takes advantage of the large amounts of DNA that remain in the cytoplasm after transfection, theoretically this system should be more efficient in expressing delivered genes than a nuclear expression system. Thus, the potential advantages of cytoplasmic systems are higher and faster expression of gene compared to that of the nuclear expression system because the messenger transcribed from the T7 vector can be immediately translated in to the cytoplasm.

The goal of this study is to develop an expression vector that would result in maximum expression of IL-10 protein. To this end we constructed both cytoplasmic and nuclear vectors expressing IL-10. The expression of both vectors was measured in the macrophage cell line RAW-264.7 and the best vector was chosen for all further experiments. 


\section{3. MATERIALS AND METHODS}

\section{Plasmids}

Plasmid pT7-CAT, a plasmid containing the CAT reporter gene driven by the bacteriophage T7 promoter (Elroy-Stein and Moss, 1990), was a kind gift provided by Dr. L. Huang (University of Pittsburgh). pCMV-IL10 used for nuclear expression of the IL-10 gene driven by the human cytomegalovirus immediate early promoter (CMV) was a kind gift provided by Dr. H. Tahara (University of Pittsburgh). PCMV/T7-T7pol was constructed as an expression plasmid for T7 RNA polymerase gene driven by its cognate T7 promoter and the human CMV promoter (Brisson et al., 1999). A HindllI/BamHI fragment from pAR3126 (Dunn et al., 1988) containing the cDNA of T7 RNA polymerase was inserted into the corresponding sites of the pcDNA3 plasmid vector (Invitrogen Corp., San Diego, CA) to generate pCMV/T7-T7pol (Brisson et al., 1999). This vector was amplified in E. Coli DH5 $\alpha$ cells and purified using Qiagen Plasmid Maxi Kits. Plasmid pT7-mIL10, which contains an IL-10 gene driven by a T7 promoter was made in our lab by inserting a mIL-10 fragment into the plasmid pT7-CAT after deletion of the cDNA encoding CAT gene. pT7-CAT plasmid was first treated with BamHI/Ncol restriction enzymes that specifically cut out the fragment responsible for CAT expression. A BamHI/Ncol fragment from another plasmid containing mIL-10 gene was inserted into the corresponding sites of the cut pT7-vector (the new vector was designed pT7-mIL10). This vector was amplified in E. Coli DH5 $\alpha$ cells and purified using Qiagen Plasmid Maxi Kits (Qiagen, Chalsworth, CA).

\section{Cell Culture}

The macrophage cell line RAW 264.7 was obtained from the American Type Cell Culture Collection (Rockville, MD). The cells were grown in DMEM supplemented with 10\% fetal bovine serum (FBS), $2 \mathrm{mM} \mathrm{L-glutamine,} \mathrm{and} 100 \mathrm{U} / \mathrm{ml}$ penicillin-streptomycin. They were maintained at $37^{\circ} \mathrm{C}$ in a humidified atmosphere containing $5 \% \mathrm{CO}_{2}$. Prior to use, cells were briefly trypsinized or mechanically scraped and centrifuged. They were plated at $\sim 1 \times 10^{6}$ cells $/ \mathrm{ml}$ in 12-well tissue culture plates one day before transfection studies.

\section{Transfections}


For transfection of cytoplasmid vector, $0.3 \mu \mathrm{g}$ of $\mathrm{pCMV} / \mathrm{T} 7-\mathrm{T} 7 \mathrm{pol}$ per $\mu \mathrm{g}$ pT7-mIL10 were first diluted in serum-free medium before complexing with DC-Chol:DOPE liposomes (10 nmol lipid/ug DNA). These mixtures were used to transfect cells for $4 \mathrm{~h}$ at $37^{\circ} \mathrm{C}$ after which transfection medium was replaced with growth medium. Cells were incubated for an additional 2 days at $37^{\circ} \mathrm{C}$ following transfection before cell supernatants were assayed for the cytokine IL-10 level. For pCMV-mIL10, $1 \mu \mathrm{g}$ DNA was complexed with DC-Chol:DOPE liposomes (10 nmol lipid/ug DNA) for transfection. Toxicity was determined by comparing the total protein remaining in each well following transfection with the total protein remaining in untreated wells. Total protein was measured by Coomassie Plus Protein Assay Reagent (Pierce, Rockford, IL).

\section{Determination of IL-10 Protein Concentrations}

Cell-free supernatants were collected 2 days post transfection and were assayed for IL-10 protein by enzyme-linked immunosorbent assay (ELISA) kits specific for murine IL-10 and protein levels were measured as specified by the manufacturer (Endogen). The sensitivity of the assays ranged from 15 to $31 \mathrm{pg} / \mathrm{ml}$. The coefficient of variation for all cytokine assays was $<10 \%$.

\section{Restriction Digestion}

The following mixture was prepared: DNA $(0.5 \mu \mathrm{g})$, restriction buffer $(10 \mathrm{X}, 1.5 \mu \mathrm{L})$, $\mathrm{BamHI}(1 \mu \mathrm{l}), \mathrm{Ncol}(1 \mu \mathrm{l})$ and distilled water q.s. to $15 \mu \mathrm{l}$. This mixture was incubated at $37^{\circ} \mathrm{C}$ for $1 \mathrm{~h}$. The enzymes were then inactivated by heating at $65^{\circ} \mathrm{C}$ for $10 \mathrm{~min}$. The efficiency of restriction digestion was then analyzed by running the incubation mixture on a $0.8 \%$ agarose gel. Unless otherwise indicated, all enzymes used in this study were purchased from New England Biolabs.

\section{Isolation of DNA Fragments after Restriction Digestion}

The desired fragments were purified from $0.8 \%$ agarose gels by following the manufacturer's instructions (GENECLEAN II Kit, BIO 101 Inc., La Jolla, CA). Briefly, the desired band was excised from the agarose gel. Three volumes of Nal stock solution was added and was incubated at $45^{\circ}-55^{\circ} \mathrm{C}$ for $5 \mathrm{~min}$ to dissolve agarose. GLASSMILK suspension from the GENECLEAN II Kit was added and this mixture was incubated for 5 
min. The GLASSMILK/DNA complex was pelleted for $5 \mathrm{sec}$. This pellet was washed 3 times with NEW WASH buffer. The DNA was then eluted into water or low-salt buffer.

\section{Ligation of DNA Fragments}

The following mixture: DNA fragment to be inserted (mlL-10, $50 \mathrm{ng}$ ), Cut Vector (pT7, $50 \mathrm{ng}$ ), Ligase Reaction Buffer (5X, $2 \mu \mathrm{l})$, T4 ligase (1 $\mu \mathrm{l})$, and distilled water q.s. $10 \mu \mathrm{l}$, was incubated at $16^{\circ} \mathrm{C}$ overnight.

\section{Transformation}

Five microliters of ligation mixture were added to $20 \mu$ l of DH5 $\alpha$ competent cells (Life Technologies), and this mixture was incubated for $30 \mathrm{~min}$ on ice. The tubes were then placed at $37^{\circ} \mathrm{C}$ for $1 \mathrm{~min}$ and then immediately put on ice for $2 \mathrm{~min}$. One half milliliter of LB Broth was then added to the mixture and this mixture was incubated at $37^{\circ} \mathrm{C}$ with shaking for 1-2 h. Cells were then plated on ampicillin-agar plates and incubated overnight at $37^{\circ} \mathrm{C}$.

\section{Selection of Positive Colonies}

After transformation, a few colonies were picked and amplified in LB Broth containing ampicillin. Cells were then lyzed and miniprep was performed according to the protocol described in Sambrook et al. (Sambrook et al., 1989). After purification of DNA, restriction digestion was performed using $\mathrm{BamHI}$ and $\mathrm{Ncol}$ restriction enzymes. The digested mixture was then analyzed by running a $0.8 \%$ agarose gels. The colonies that exhibited the expected fragmentation pattern were then selected. DNA was extracted from these colonies and was then sent for DNA sequencing using the right primers. Sequencing data is the final confirmation of identifying the positive colony. 


\section{I.4. RESULTS}

\section{Construction of pT7-mIL10}

Fig. 4 (A, B) shows the steps involved in the construction of plasmid pT7-mIL10. First, mIL10 fragment was cut from the plasmid CMV-mIL10 using BamHI/Ncol restriction enzymes. Similarly, another plasmid, pT7-CAT, was cut using BamHI/Ncol. The restriction digestion mixture was then run on a $0.8 \%$ agarose gel. Fig. $4 \mathrm{C}$ shows agarose gel analysis after restriction digestion of both plasmids. The larger T7 fragment and the smaller mIL10 fragment were then purified from the cut gel using GENECLEAN as discussed in the Methods section. Equal concentrations of vector and fragment were then ligated at $16^{\circ} \mathrm{C}$ overnight. The next step was transformation into $\mathrm{DH} 5 \alpha$ competent cells and finally few colonies were selected. Miniprep was performed on each of these colonies to isolate DNA. The DNA was then subject to restriction digestion by BamHI/Ncol and the fragmentation pattern was analyzed by running $0.8 \%$ agarose gel. As shown in Fig. 4D, colony 6 had the potential to be a positive colony because the two fragments generated on restriction digestion had the expected molecular weights. This DNA was then sent for sequencing analysis and was found to have the desired sequences. This step concluded the preparation of plasmid pT7-mIL10.

\section{Comparison between Cytoplasmic and Nuclear Systems}

The goal here is to compare the cytoplasmic and nuclear systems and to choose the best vector for all further studies. The ratio of autogene and liposomes per $\mu \mathrm{g}$ DNA has been optimized previously (Brisson et al., 1999). RAW 264.7 macrophage cell line was

chosen because the overall goal of our project is to develop IL-10 gene transfer for macrophages. Cytoplasmic vector pT7-mIL10 expressed IL-10 (3,600-4,737 pg/ml) (Fig. 5). However, CMV-mIL10 expressed much more IL-10 protein $(50,000-71,528$ pg/ml). These results suggest that transgene expression of the nuclear expression vector is more effective than that of the cytoplasmic vector. 


\section{I.5. DISCUSSION}

Nuclear expression is the fundamental way in which proteins are expressed in cells. DNA transported to the nucleus is transcribed into mRNA which is then translated into protein in the cytoplasm. However, less than 1\% of the DNA enters the nucleus (Capecchi, 1980) and is transcribed, leaving a significant amount of DNA untranscribed in the cytoplasm. Cytoplasmic systems have been proposed as a means of bypassing the requirement of the pDNA to enter the nucleus (Brisson et al., 1999a; Brisson et al., 1999b; Chen et al., 1995; Deng and Wolff, 1994; Dubendorff and Studier, 1991; Dunn et al., 1988; Elroy-Stein and Moss, 1990; Gao and Huang, 1993; Gao et al., 1994; Lieber et al., 1989).

The cytoplasmic expression system contains a reporter gene driven by the bacteriophage T7 promoter and the purified T7 RNA polymerase (Gao and Huang, 1993). T7 RNA polymerase was chosen because it does not enter the nucleus due to the lack of a nuclear localization signal (Dunn et al., 1988). Recently, Brisson et al. (Brisson et al., 1999a) developed a novel cytoplasmic expression vector, pCMV/T7-T7pol. pCMV/T7-T7pol consists of a nuclear CMV promoter followed by a cytoplasmic T7 promoter and the T7 RNA polymerase gene. RNA polymerase II begins transcription in the nucleus via the CMV promoter on the autogene. T7 RNA polymerase is then translated in the cytoplasm. The T7 RNA polymerase produced will then begin transcription at the T7 promoter which induces T7 RNA polymerase transcription in the cytoplasm. Because of this autogene system, a continuous amount of T7 RNA polymerase is provided to the cell to transcribe pT7-reporter genes. This system obviates the need for delivering exogenous RNA polymerase which could be potentially toxic and immunogenic. Using a reporter gene assay, Brisson et al. (Brisson et al., 1999b) have shown that this cytoplasmic system is superior to nuclear expression vector, pCMV-CAT.

The overall goal of this study is to develop an efficient gene transfer protocol for the delivery of IL-10. Since, it has been claimed that cytoplasmic systems are better than nuclear systems (Brisson et al., 1999b), we constructed both cytoplasmic and nuclear vectors expressing IL-10 protein. Murine macrophages, RAW 264.7, were transfected with both the expression vectors. In our system we found that while pT7-mIL10 vector does express IL-10 protein, pCMV-mIL10 expresses IL-10 almost 14 times more. 
The discrepancy in the test results is not completely understood. However, a difference between the study of Brisson et al. (1999b) and ours is the cell line used. They used 293 cells which are kidney embryonic cells. It is possible that the T7 RNA polymerase produced by the autogene system is degraded or inactivated to a greater extent in macrophages due to their phagocytic activity. Macrophages are known to possess a high level of digestive enzymes, especially in the endosomes and lysosomes. Since the DNA complex enters the cells by endocytosis, it is likely that a substantial portion of the internalized complex is degraded in the cells. It is beyond the scope of this study to investigate the exact cause of this discrepancy. Our goal is to merely find the best available expression system for subsequent studies. Since pCMV-mIL10 showed greater transgene expression, this plasmid expression system was chosen for all further experiments. 


\section{I.6. FIGURES}

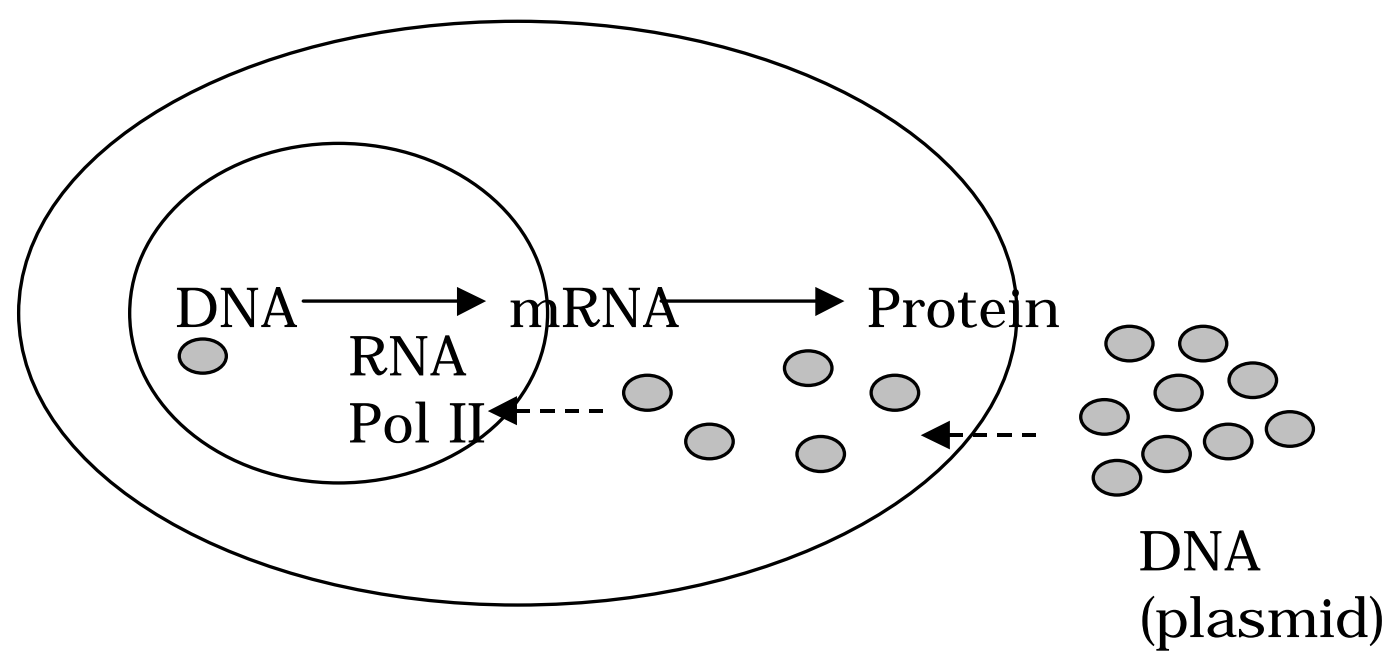

Fig. 1. Poor Nuclear Delivery of DNA. There are a number of barriers for DNA delivery. Even if the delivery system allows DNA to enter the cytoplasm, DNA has to still enter the nucleus where transcription machinery resides. The transcription of transgene completely depends on the activity of endogenous RNA polymerase (II or III) which resides in the nucleus. This step is the rate-limiting step for the current non-viral gene delivery systems. 


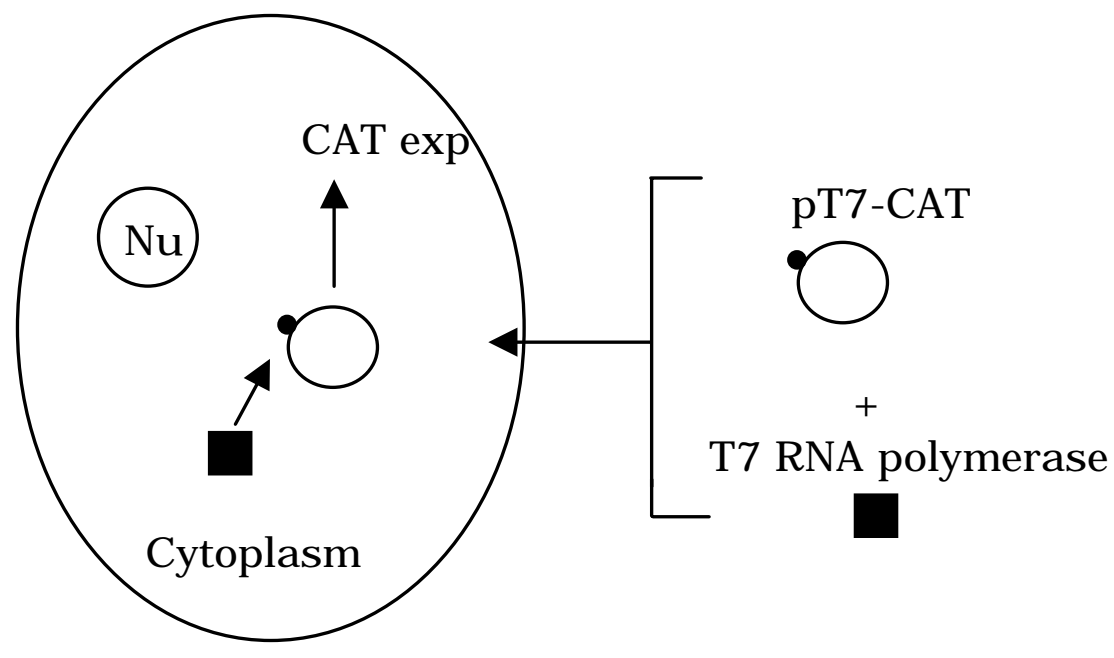

- $\mathrm{T} 7$ promoter

Fig. 2. T7 Cytoplasmic Expression System. This sytem relies on the ability of the exogenously supplied T7 RNA polymerase to drive expression of transgene under the control of T7-promoter. This system obviates the need for DNA to enter the nucleus. 


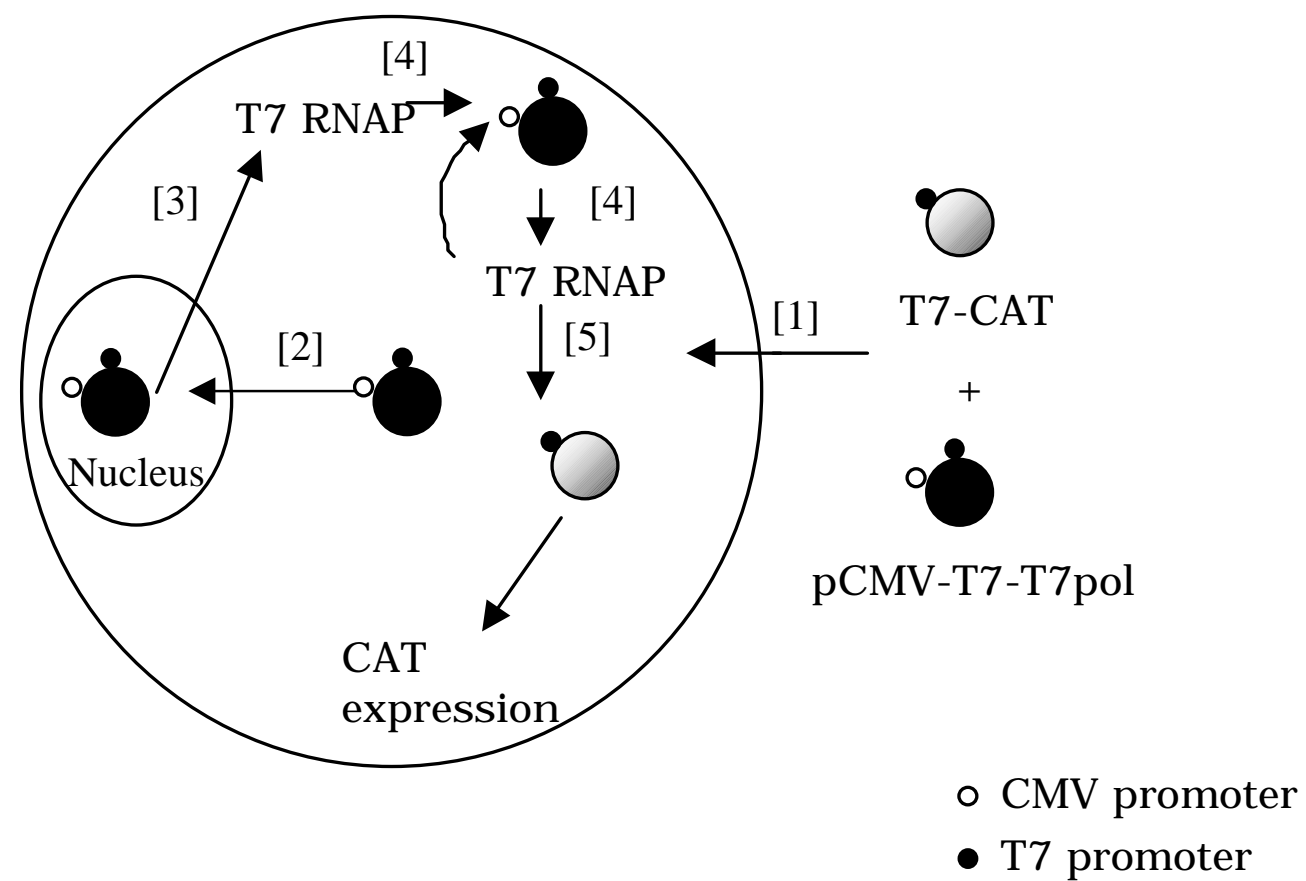

Fig. 3. pCMV/T7-T7pol Autogene System. (1) pT7-CAT and autogene codelivered into the cell (2) Some autogene enters the nucleus (3) it starts initial round of T7-RNA polymerase expression (4) This T7-RNA polymerase can drive expression of T7-polymerase due to activation of T7 promoter on the cytoplasmically present autogene. (5) T7-RNAP drives expression of T7-CAT. 


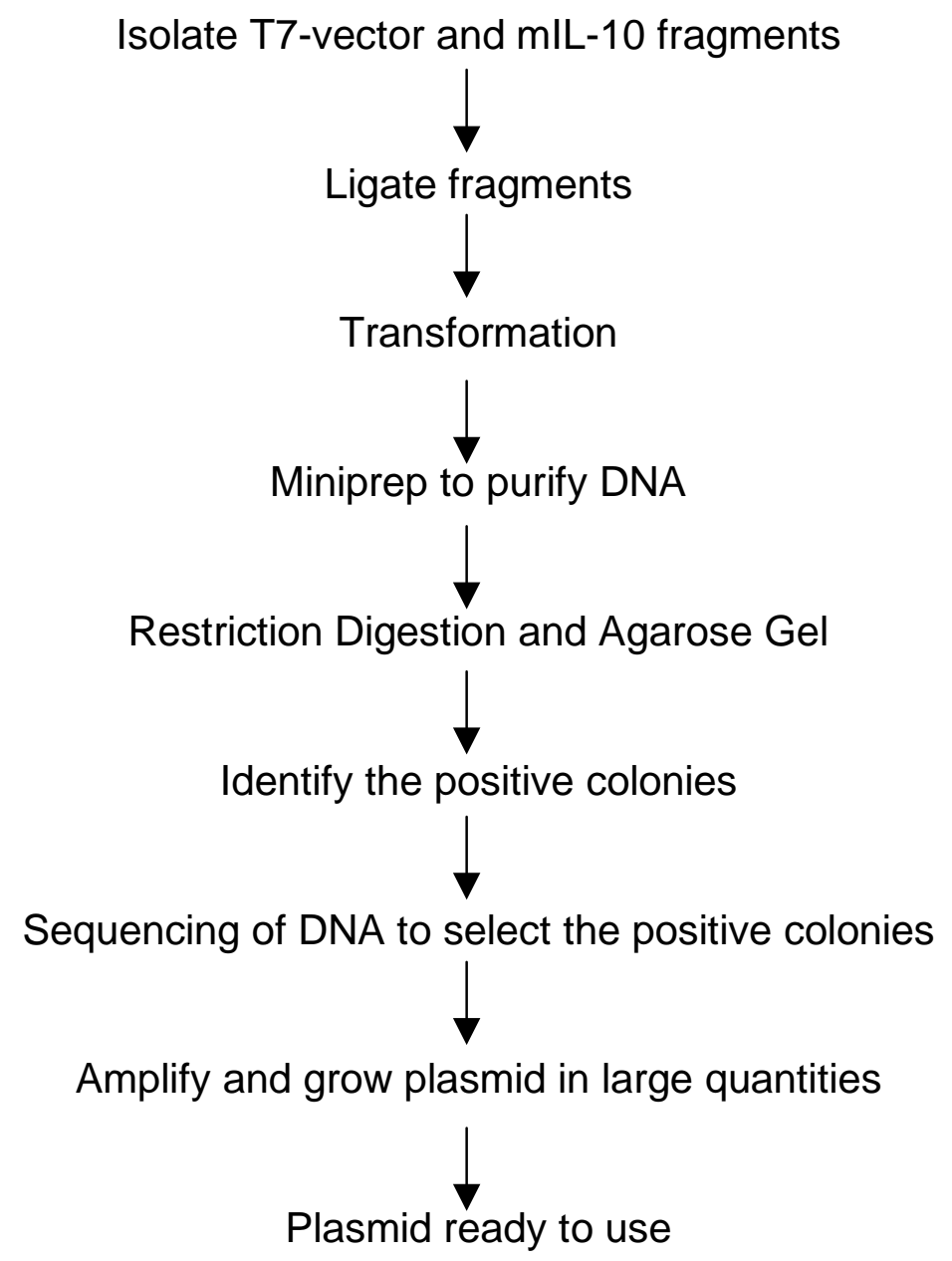

Fig. 4A. General Steps Involved in Construction of Plasmids 


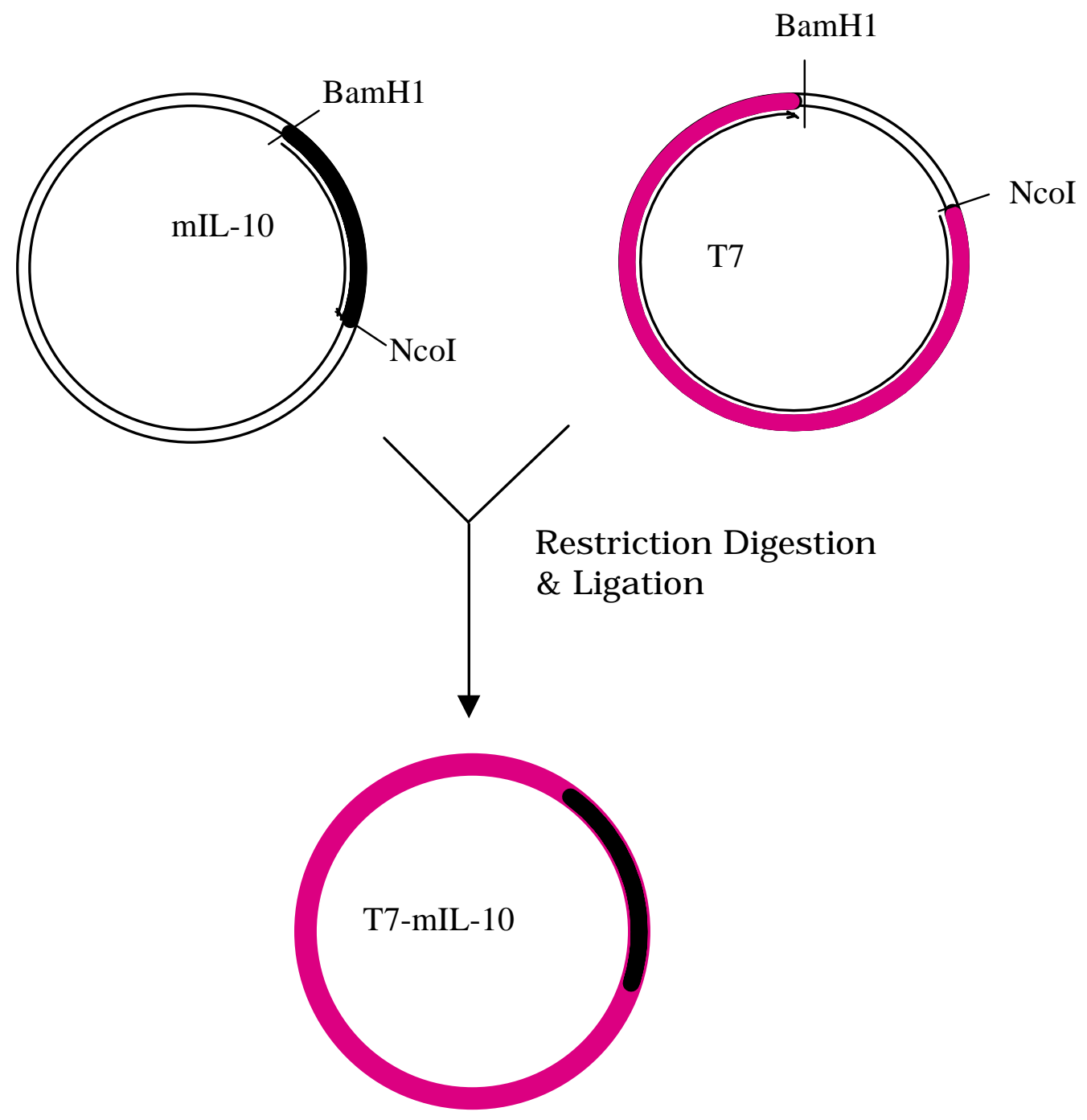

Fig. 4B. Schematic of the Generation of pT7-mIL10. mIL10 fragment is cut and isolated from a different vector and T7-vector is also digested with the same restriction enzymes. The two fragments are then ligated, transformed and pT7-mIL10 is isolated according to the scheme described above. 

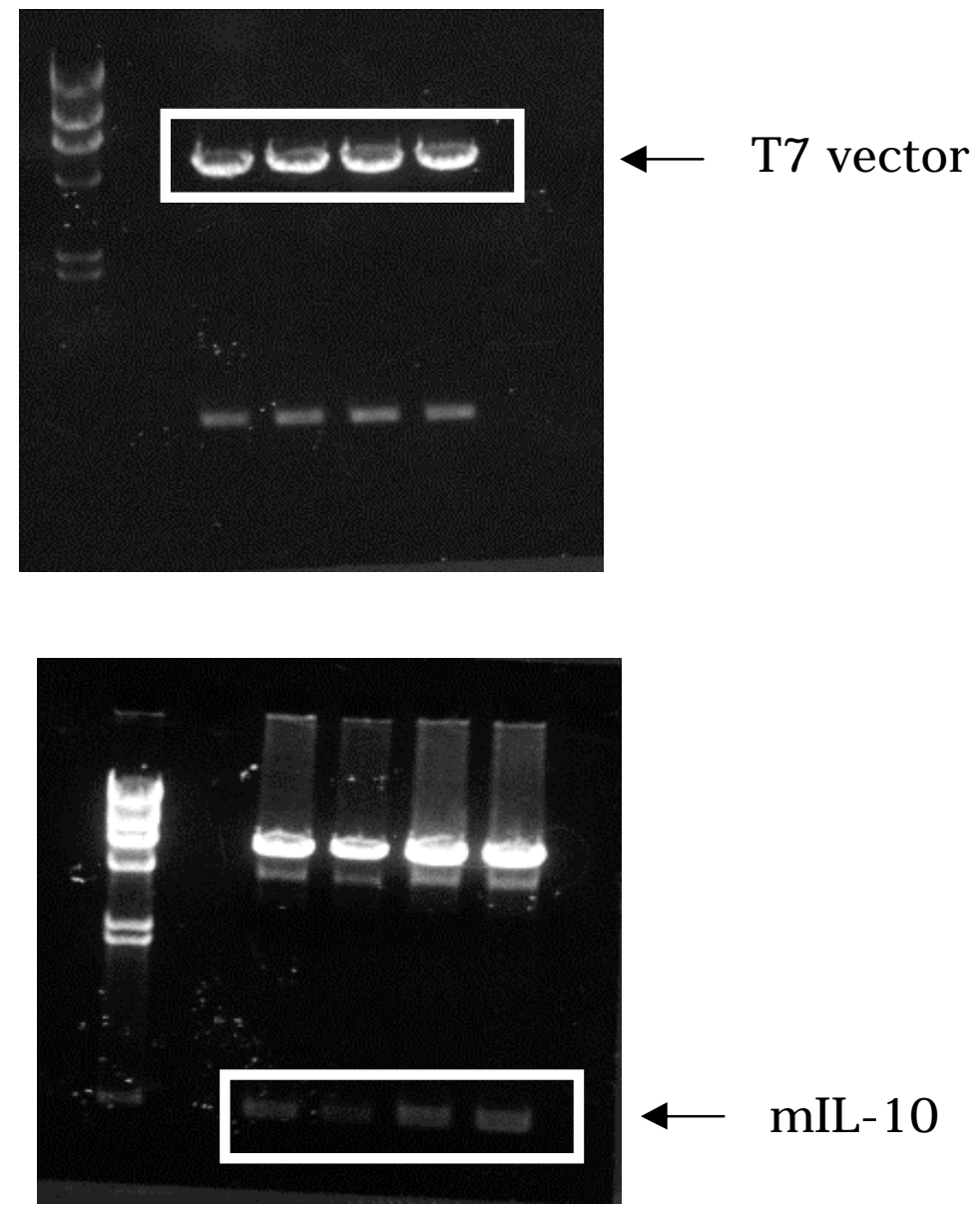

Fig. 4C. Construction of pT7-mIL10 Plasmid. T7-CAT vector is cut with BamHI/Ncol and the larger fragment (T7-vector) is separated. Similarly, mlL-10 fragment is isolated from CMV-mIL10 plasmid by BamHI/Ncol restriction digestion. 


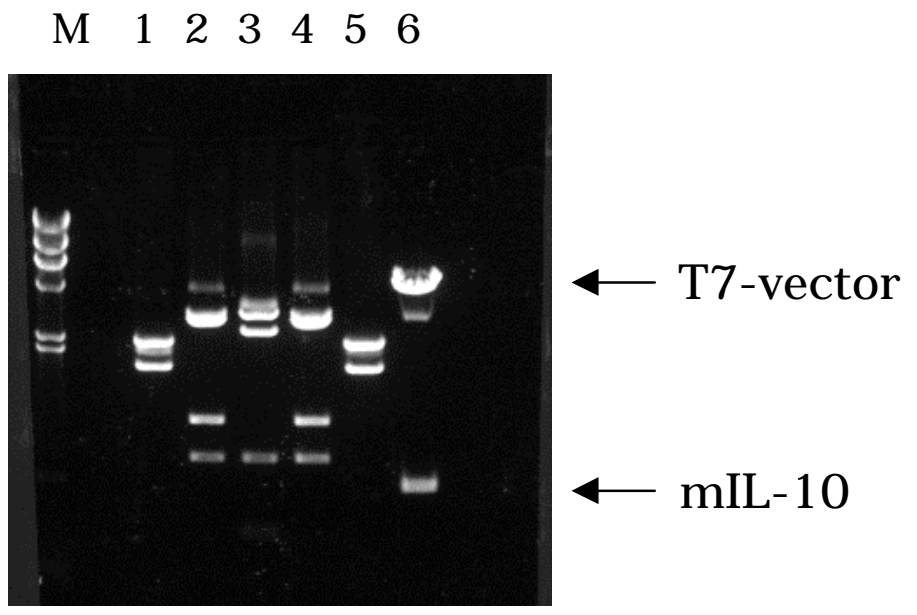

Fig. 4D. Construction of pT7-mIL10 Plasmid. After ligation of the two fragments and transformation, few colonies are selected, DNA is isolated, and then restriction digestion is performed to study the fragmentation pattern. Based on the gel analysis, colony 6 has the desired fragmentation pattern because digestion with BamHI/Ncol gives 2 fragments which correspond, in molecular weight, to the larger T7-vector and the smaller mIL10 fragments. This colony was then selected, and DNA was sent for sequencing analysis to further confirm that this is indeed the positive colony. 


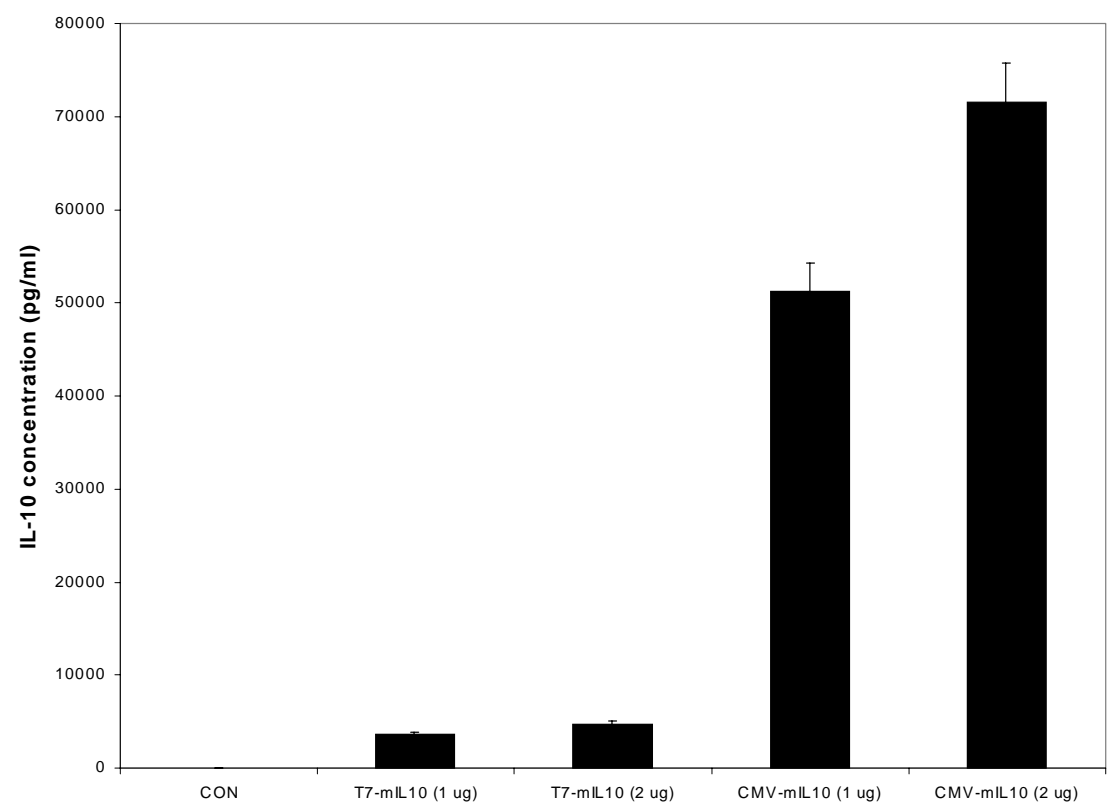

Fig. 5. Comparison of Transgene Expression of Cytoplasmic and Nuclear Systems. For transfection of cytoplasmic vector, cells $\left(1 \times 10^{6} / \mathrm{ml}\right)$, were transfected for $4 \mathrm{~h}$ at $37^{\circ} \mathrm{C}$ with $0.3 \mu \mathrm{g}$ of pCMV/T7-T7pol per $1 \mu \mathrm{g}$ pT7-mIL10 in the presence of DC-Chol:DOPE liposomes (10 nmol lipid/ug DNA). For pCMV-mlL10, $1 \mu \mathrm{g}$ DNA was complexed with DC-Chol:DOPE

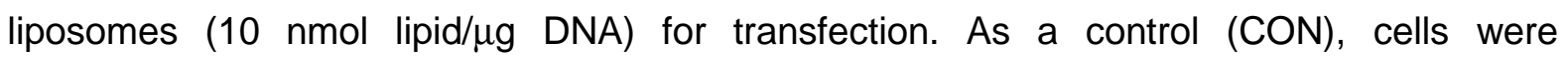
transfected with $\mathrm{pCMV}$-control vector with DC-Chol:DOPE liposomes $(10 \mathrm{nmol}$ lipid/ug DNA). Two days post-transfection, cell supernatants were assayed for cytokine IL-10 levels as described in the Methods section. Each data point represents the mean (with standard deviation) of quadruplicate samples. 


\section{I.7. REFERENCES}

Brisson, M., He, Y., Li, S., Yang, J.P., and Huang, L. (1999a) A novel T7 RNA polymerase autogene for efficient cytoplasmic expression of target genes. Gene Ther 6, 263270.

Brisson, M., Tseng, W.C., Almonte, C., Watkins, S., and Huang, L. (1999b) Subcellular trafficking of the cytoplasmic expression system. Hum Gene Ther 10, 2601-2613.

Capecchi, M.R. (1980) High efficiency transformation by direct microinjection of DNA into cultured mammalian cells. Cell 22, 479-488.

Chen, X., Li, Y., Xiong, K., Xie, Y., Aizicovici, S., Snodgrass, R., Wagner, T.E., and Platika, D. (1995) A novel nonviral cytoplasmic gene expression system and its implications in cancer gene therapy. Cancer Gene Ther 2, 281-289.

Deng, H. and Wolff, J.A. (1994) Self-amplifying expression from the T7 promoter in 3T3 mouse fibroblasts. Gene 143, 245-249.

Dubendorff, J.W. and Studier, F.W. (1991) Creation of a T7 autogene. Cloning and expression of the gene for bacteriophage T7 RNA polymerase under control of its cognate promoter. J Mol Biol 219, 61-68.

Dunn, J.J., Krippl, B., Bernstein, K.E., Westphal, H., and Studier, F.W. (1988) Targeting bacteriophage T7 RNA polymerase to the mammalian cell nucleus. Gene 68, 259266.

Elroy-Stein, O. and Moss, B. (1990) Cytoplasmic expression system based on constitutive synthesis of bacteriophage T7 RNA polymerase in mammalian cells. Proc Natl Acad Sci USA 87, 6743-6747.

Gao, X. and Huang, L. (1993) Cytoplasmic expression of a reporter gene by co-delivery of T7 RNA polymerase and T7 promoter sequence with cationic liposomes. Nucleic Acids Res 21, 2867-2872. 
Gao, X., Jaffurs, D., Robbins, P.D., and Huang, L. (1994) A sustained, cytoplasmic transgene expression system delivered by cationic liposomes. Biochem Biophys Res Commun 200, 1201-1206.

Ledley, F.D. (1995) Nonviral gene therapy: the promise of genes as pharmaceutical products. Hum Gene Ther 6, 1129-1144.

Lieber, A., Kiessling, U., and Strauss, M. (1989) High level gene expression in mammalian cells by a nuclear T7-phase RNA polymerase. Nucleic Acids Res 17, 8485-8493.

Roth, J.A. and Cristiano, R.J. (1997) Gene therapy for cancer: what have we done and where are we going? J Natl Cancer Inst 89, 21-39.

Sambrook, J., Fritsch, E., and Maniatis, T. (1989) Molecular Cloning: A Laboratory Manual (Ford, N., Nolan, C., and Ferguson M, Eds.) Cold Spring Harbor Laboratory Press, Cold Spring Harbor, NY. 56-59.

Zabner, J., Fasbender, A.J., Moninger, T., Poellinger, K.A., and Welsh, M.J. (1995) Cellular and molecular barriers to gene transfer by a cationic lipid. J Biol Chem 270, 1899719007. 


\section{SECTION II}

High-Efficiency Gene Transfection

of Macrophages by Lipoplexes 


\section{II.1. ABSTRACT}

Macrophage transfection studies are crucial to understanding gene regulation and expression. However, gene transfection in macrophages is difficult. We have shown here that macrophages are more resistant to gene transfection compared to other cell types. To further develop an efficient gene delivery system for macrophages, we evaluated various liposomal and non-liposomal agents including LipofectAMINE ${ }^{\circledR}$, Lipofectin $^{\circledR}$, DOTAP, DEAEdextran, and the DNA condensing agent protamine sulfate for their ability to promote gene transfection. CMV-luciferase was used as a reporter plasmid. Macrophage transfection was maximal at the DNA:LipofectAMINE:protamine ratio of $1: 12: 1 \mu \mathrm{g} / \mathrm{ml}$. The LipofectAMINE formulation showed a 10-12-fold increase in transfection efficiency over DOTAP and a 4-5fold increase over Lipofectin. This transfection method showed minimal toxicity at the concentrations tested and was at least 20-25-fold superior to the most frequently used DEAE-dextran method for macrophage transfection. 


\section{II.2. INTRODUCTION}

Macrophages play an important role in host defense against noxious substances and are involved in a variety of disease processes including autoimmune diseases, infections and inflammatory disorders (Pierce, 1990). Molecular analysis of macrophage functions can be accomplished by gene transfection assays. However, gene transfection in macrophages has proven difficult. A number of non-viral gene transfer methods have been developed to improve macrophage transfection, including calcium-phosphate precipitation (Roussel et al., 1988; Stief et al., 1989), DEAE-dextran (Hess et al., 1985; Mack et al., 1998; Rupprecht and Coleman, 1991), particle bombardment (Burkholder et al., 1993), and electroporation (Daumler and Zimmermann, 1989; Economou et al., 1989). These methods are however associated with low transfection efficiency or high cellular toxicity. Being non-dividing cells, macrophages are also resistant to viral-mediated gene transfection, e.g. retroviruses. Adenoviral vectors, although capable of transfecting non-dividing cells, are associated with immunogenicity, and thus their use has been limited.

The DEAE-dextran method of transfection has been described as the most efficient gene transfer method for macrophages developed thus far (Mack et al., 1998). This method was shown to be more efficient than other existing methods including the calcium phosphate, electroporation and lipofection (Mack et al., 1998). In our hand, this method provides a reasonable but still relatively low transfection efficiency. In this study, we further developed gene transfection systems for macrophages using a variety of liposomal agents. We optimized the transfection efficiency of these systems and compared them to the DEAEdextran method. In addition, we tested the effect of protamine sulfate on liposome-mediated gene transfer. Protamine is a major component of sperm nucleus with a role in DNA stabilization. This compound has been shown to cause condensation of DNA which promotes the cellular entry and gene expression of plasmid DNA (Sorgi et al., 1997). Our results showed that the optimized liposomal systems were more effective and less toxic than the DEAE-dextran and that protamine greatly enhanced the level of transgene expression mediated by liposomes. 


\section{II.3. MATERIALS AND METHODS}

\section{Cell Culture}

All cell lines including the macrophage RAW 264.7, alveolar epithelial A549, kidney embryonic 293, and liver HEPG2 were obtained from the American Type Cell Culture Collection (Rockville, MD). The cells were grown in DMEM supplemented with $10 \%$ fetal bovine serum (FBS), $2 \mathrm{mM} \mathrm{L-glutamine,} \mathrm{and} 100 \mathrm{U} / \mathrm{ml}$ penicillin-streptomycin. They were maintained at $37^{\circ} \mathrm{C}$ in a humidified atmosphere containing $5 \% \mathrm{CO}_{2}$. Prior to use, cells were briefly trypsinized or mechanically scraped and centrifuged. They were plated at $\sim 1 \times 10^{6}$ cells/ml in 12-well tissue culture plates one day before transfection studies.

\section{Plasmid DNA}

The expression vector CMV-luciferase contains the promoter-enhancer region of Cytomegalovirus upstream from the luciferase gene (kindly provided by Dr. Leaf Huang, University of Pittsburgh). The expression vector CMV- $\beta$-gal contains the promoter-enhancer region of Cytomegalo virus upstream from the $\beta$-galactosidase gene (kindly provided by $\mathrm{Dr}$. $\mathrm{Ye}, \mathrm{NIOSH}$ ). The plasmid was purified using the Qiagen Endofree plasmid kit (Qiagen, Chatsworth, CA) according to the manufacturer's instructions.

\section{Liposomal Transfection}

Approximately $1 \times 10^{6}$ cells were plated on a 12-well plate and allowed to grow for 24 hours before the transfection. The plasmid DNA $(0.5-2 \mu \mathrm{g})$ was diluted in $200 \mu$ of DMEM. In some studies, the indicated amounts of protamine sulfate were added to the DNA. The liposome was diluted in $200 \mu \mathrm{l}$ of DMEM. The diluted DNA and liposome were combined and incubated at room temperature for 15-20 min. Cells with transfection reagents were incubated for 4 hours. Transfection medium was then replaced with growth medium containing 10\% FBS. Cells were cultured for an additional 48 hours before the level of gene expression was determined. All transfections were conducted under sterile conditions and duplicate plates were tested for each condition.

\section{DEAE-dextran Transfection}


Approximately $1 \times 10^{6}$ cells were plated on a 12-well plate and allowed to grow for 24 hours before the transfection. The plasmid DNA $(1 \mu \mathrm{g} / \mathrm{ml})$ was mixed with varying concentrations of diethylaminoethyl-dextran (0-200 $\mu \mathrm{g} / \mathrm{ml})$ (Sigma, St. Louis, MO) in DMEM. The diluted DNA and DEAE-dextran were added to pre-washed cells. Wrapped plates were incubated at $37^{\circ} \mathrm{C}$ for 2 hours. The cells were then washed and incubated with growth medium containing 10\% FBS. The cells were cultured for an additional 48 hours before the level of gene expression was determined. All transfections were conducted under sterile conditions and duplicate plates were tested for each condition.

\section{Measurement of Luciferase Activity}

Luciferase synthesized during the in vitro translation was quantitated by the assay of enzyme-dependent light production using a luciferase assay kit (Promega, Madison, WI). Cells were washed twice with PBS and incubated at room temperature for $10 \mathrm{~min}$ in the presence of $250 \mu \mathrm{l}$ of lysis buffer (Promega) and then centrifuged at $12000 \mathrm{~g}$. Ten microliters of each sample was placed in a 5-ml polystyrene test tube and the tubes were then loaded into an automated luminometer (BioRad, Hercules, CA). At the time of measurement, $100 \mu \mathrm{l}$ of luciferase substrate was automatically injected into each sample, and total luminescence was measured over a 20 -sec time interval. Output is quantitated as relative light units (RLU). Protein concentration in the supernatant was determined by BCA protein assay reagent (Pierce, Rockford, IL). Luminescence detected was standardized per $\mu \mathrm{g}$ protein present in the supernatant.

\section{X-Gal Assay}

Forty-eight hours after transfection, cells were washed, fixed with $1.8 \%$ formaldehyde and $2 \%$ glutaraldehyde, and then incubated for $16-24 \mathrm{~h}$ at $37^{\circ} \mathrm{C}$ with $1 \mathrm{ml}$ of $20 \mathrm{mg} / \mathrm{ml} \mathrm{X}$-gal (5-bromo-4-chloro-3-indolyl- $\beta$-galactopyranoside) (Life Technologies) in dimethyl formamide

(Sigma, St. Louis, MO) dissolved in staining solution. Blue staining of nuclei was evaluated by light microscopy.

\section{LDH Activity}


LDH assay was performed to assess the effect of test agents on cellular toxicity. Cells were treated with plasmid DNA and transfecting agents, either individually or in combination as indicated. After the treatments, the cell supernatants were collected and assayed for LDH activity. LDH activity was determined by monitoring the oxidation of pyruvate coupled with the reduction of NAD at $340 \mathrm{~nm}$ using an LDH assay kit (Roche Diagnostic Systems, Montclair, NJ). The assay was performed on Cobas Fara II Analyzer (Roche Diagnostic Systems). One unit per liter of LDH activity is defined as the amount of enzyme that converts $1 \mu \mathrm{mol}$ of lactate to $1 \mu \mathrm{mol}$ of pyruvate with the concomitant reduction of $1 \mu \mathrm{mol}$ of NAD to $1 \mu \mathrm{mol}$ of NADH per minute per liter of sample in the assay procedure. 


\section{II.4. RESULTS AND DISCUSSION}

\section{Comparison of Gene Transfection in Different Cell Lines}

Gene transfection is known to be cell type-dependent. In our experience we found that macrophages are difficult to transfect. To substantiate this point, we carried out a comparison study in which various cell lines from different origins including the macrophage RAW 264.7, kidney embryonic 293, alveolar epithelial A549 and liver HEPG2 were transfected with the CMV-luciferase reporter plasmid. Gene transfection was carried out under the same transfection conditions using LipofectAMINE as a transfecting agent. Fig. $1 \mathrm{~A}$ shows that all four cell lines were minimally transfected in the absence of liposome. With liposome, the transfection efficiency was greatly enhanced in all cell lines tested. However, the level of enhancement was most pronounced in the HEPG2 cells, followed by the embryonic 293, epithelial A549, and macrophage RAW 264.7 cells, respectively. Similar results are seen with $\beta$-gal reporter plasmid (Fig. 1B). These results supported previous observations that different cell lines exhibit different levels of transfection and that macrophages are relatively difficult to transfect compared to other cell types. The basis for the low transfection in macrophages is not known but probably due to the presence of high enzymatic activities and the non-proliferating nature of this cell type. Macrophages are scavenging cells possessing a high level of digestive enzymes which could inactivate DNA and result in low transfection efficiency.

\section{DEAE-Dextran and LipofectAMINE-Mediated Gene Transfer}

To develop an efficient system for transfecting macrophages, we evaluated DEAEdextran and LipofectAMINE for their transfection efficiency. The DEAE-dextran method of transfection is a well-established protocol that has been shown to be superior to most other methods of transfection for macrophages (Mack et al., 1998; Rupprecht and Coleman, 1991). In the present study, we further tested DEAE-dextran in our system and compared its transfection efficiency to that of the LipofectAMINE. We optimized the two transfection methods by varying the DNA-transfecting agent ratios (Fig. 2A). The DEAE-dextran gave optimal transfection at the concentration of about $100-200 \mu \mathrm{g} / \mathrm{ml}$ per $\mu \mathrm{g}$ DNA whereas the LipofectAMINE showed optimal transfection at $12 \mu \mathrm{g} / \mathrm{ml}$ per $\mu \mathrm{g}$ DNA. At their optimal concentrations, LipofectAMINE was approximately 8-fold more effective than DEAE-dextran 
and showed minimal cellular toxicity as demonstrated by LDH assay. Higher concentrations of DEAE-dextran, i.e., $>300 \mu \mathrm{g} / \mathrm{ml}$, substantially increased cellular toxicity without significantly improving gene transfer efficiency (Fig. 2B). In all studies, no significant cytotoxicity was observed when DNA was used alone in the absence of transfecting agents. i.e., $<1 \%$.

The observation that LipofectAMINE was more effective than DEAE-dextran is contradictory to a recent report by Mack et al. (1998) who showed that LipofectAMINE was toxic to the cells and thus was less effective than DEAE-dextran. The basis for this discrepancy is not clear but may be due to the differences in transfection conditions and quality of the transfecting agents, as well as the assay methods used. In the previous study, Mack et al. (1998) did not report how cellular toxicity was detected. It appears that a direct morphologic examination of cell death was used. In our study, a sensitive LDH assay was used to assess cellular toxicity. At the level of cellular toxicity reported in this study, no apparent cell death could be directly observed. Another possibility that could contribute to the observed discrepancy is the difference in cell type used in the two studies. Previous study by Mack et al. (1998) utilized primary cultures of macrophages while our study utilized continuous macrophage cultures. While both cells are of macrophage origin, they may respond differently to gene transfection. Further studies to examine the differences in enzymatic activities and cellular responsiveness between these cells may shed light on this discrepancy.

\section{Effect of Protamine Sulfate on Transfection}

Protamine sulfate has been shown to promote lipid-based gene transfer in different cell types (Sorgi et al., 1997). However, its effect in macrophages has not been reported. In this study, we tested whether protamine can also enhance gene transfer efficiency in macrophages. Fig. 3B shows a dose-dependent increase in macrophage transfection by protamine. Maximum transfection was observed at the protamine concentration of about 1 $\mu \mathrm{g} / \mathrm{ml}$ and LipofectAMINE concentration of $12 \mu \mathrm{g} / \mathrm{ml}$ per $\mu \mathrm{g}$ DNA. Similar results are seen with $\beta$-gal reporter plasmid (Fig. 3C). This enhanced transfection was about 23-fold more effective than DEAE-dextran-mediated gene transfer (Fig. 3A). Protamine by itself or in combination with DEAE-dextran had no significant effect on gene transfection (results not 
shown). At the concentrations tested, protamine caused no significant toxic effect to the cells.

Protamine has been proposed to increase lipid-mediated gene transfection by condensing DNA into a compact structure, which promotes DNA cellular entry and enzymatic stability (Kabanov and Kabanov, 1995). Other polycationic condensing agents such as polylysine have also been shown to possess this property. However, protamine appears to be more effective than other condensing agents despite of the fact that they possess a similar condensing activity (Kabanov and Kabanov, 1995). It has been suggested that protamine, due to the presence of nuclear localization signals in its amino acid sequence, can potentiate gene expression by increasing the nuclear translocation of DNA (Sorgi et al., 1997). While we did not demonstrate such effect of protamine in this study we found that protamine can effectively enhance transfection activities of all liposomal agents tested (see below). Because of its simplicity, versatility, and ease of use, this compound could be readily used as an adjuvant in a variety of gene transfer protocols.

\section{Gene Transfer Mediated by Different Liposomal Formulations}

Different liposomal formulations including LipofectAMINE, Lipofectin, and DOTAP were further tested for their gene transfer efficiency in an attempt to determine the most efficient system for transfecting macrophages. All liposomal formulations were optimized to their best efficiency both in the presence or absence of protamine (Fig. 4A). At their optimal concentrations and in the absence of protamine, LipofectAMINE was found to be most effective, followed by Lipofectin and DOTAP. DOTAP was as equally effective as the DEAE-dextran while Lipofectin was 3-fold more effective. In the presence of protamine, LipofectAMINE showed a 4-5-fold increase in transfection efficiency over Lipofectin and at least 10- to 12-fold increase over DOTAP (Fig. 4A). Transfection with $\beta$-gal reporter plasmid also showed that LipofectAMINE was far more effective than Lipofectin or DEAE-Dextran (Fig. 4B). The increased efficiency of LipofectAMINE over other cationic liposomes may be attributed to its greater number of positively charged groups, which could condense DNA more efficiently than the monovalent lipid Lipofectin and DOTAP. 


\section{II.5. CONCLUSION}

We have developed a simple, efficient and reproducible method of transfection for macrophages. Transient transfection with our optimized delivery system resulted in a high transgene expression compared to other existing methods of transfection. The macrophages transfected with this system were $>95 \%$ viable as determined by LDH assay. We have successfully applied this technique for the stable transfection of macrophages. The transfection protocol permits the study of gene regulation in adherent macrophage cultures and may be applicable to in vivo macrophage gene transfer. 


\section{II.6. FIGURES}

Figure 1 A

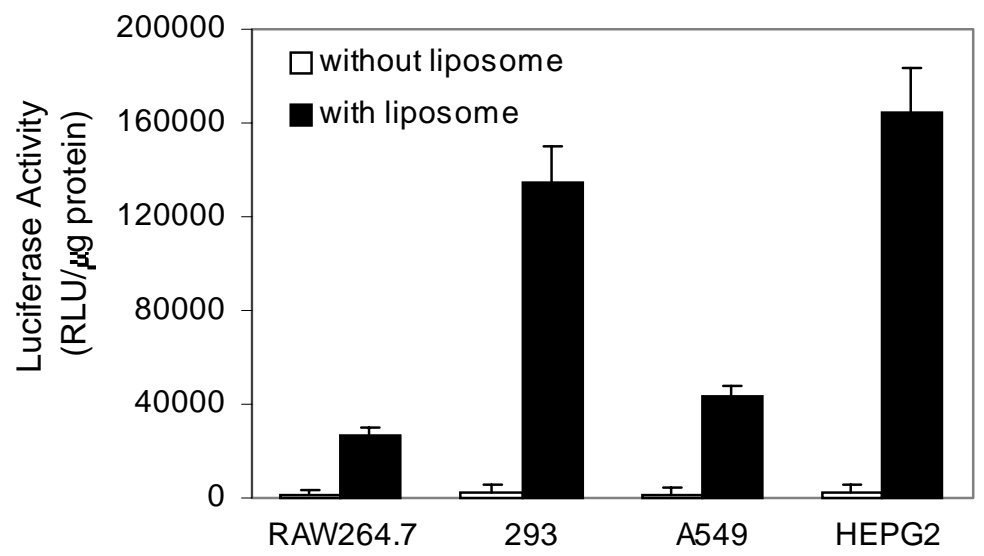

1B

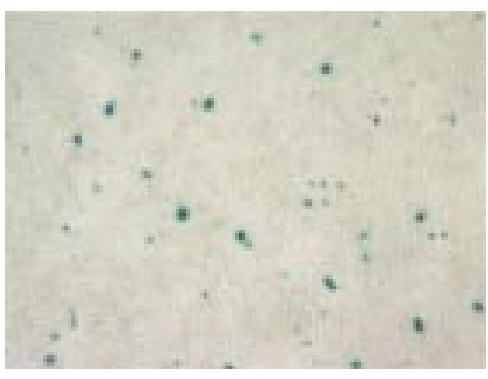

RAW 264.7

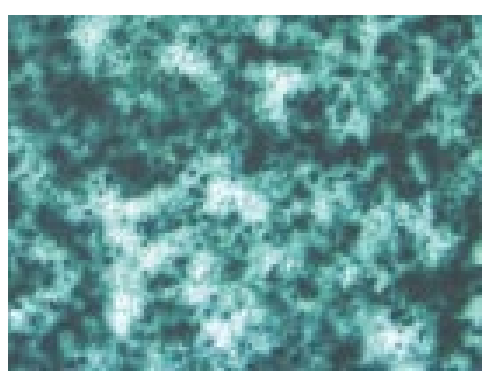

293

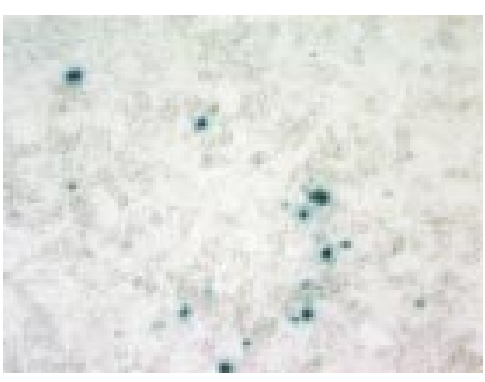

A 549

Fig. 1. Comparison of Gene Transfection in Different Cell Lines. Cells $\left(1 \times 10^{6} / \mathrm{ml}\right)$ were transfected for $4 \mathrm{~h}$ at $37^{\circ} \mathrm{C}$ with reporter gene CMV-luc (A) or CMV- $\beta$-gal (B) $(1 \mu \mathrm{g} / \mathrm{ml})$ in the presence or absence of LipofectAMINE $(12 \mu \mathrm{g} / \mathrm{ml})$. This amount of LipofectAMINE was optimized for macrophage transfection (see Fig. 2). Two days post-transfection, the cells were washed, lysed, and measured for luciferase activity or were stained for $\beta$-gal as described in the Methods section. Each data point represents the mean (with standard deviation) of quadruplicate samples and the data are normalized to protein content. 
Figure 2
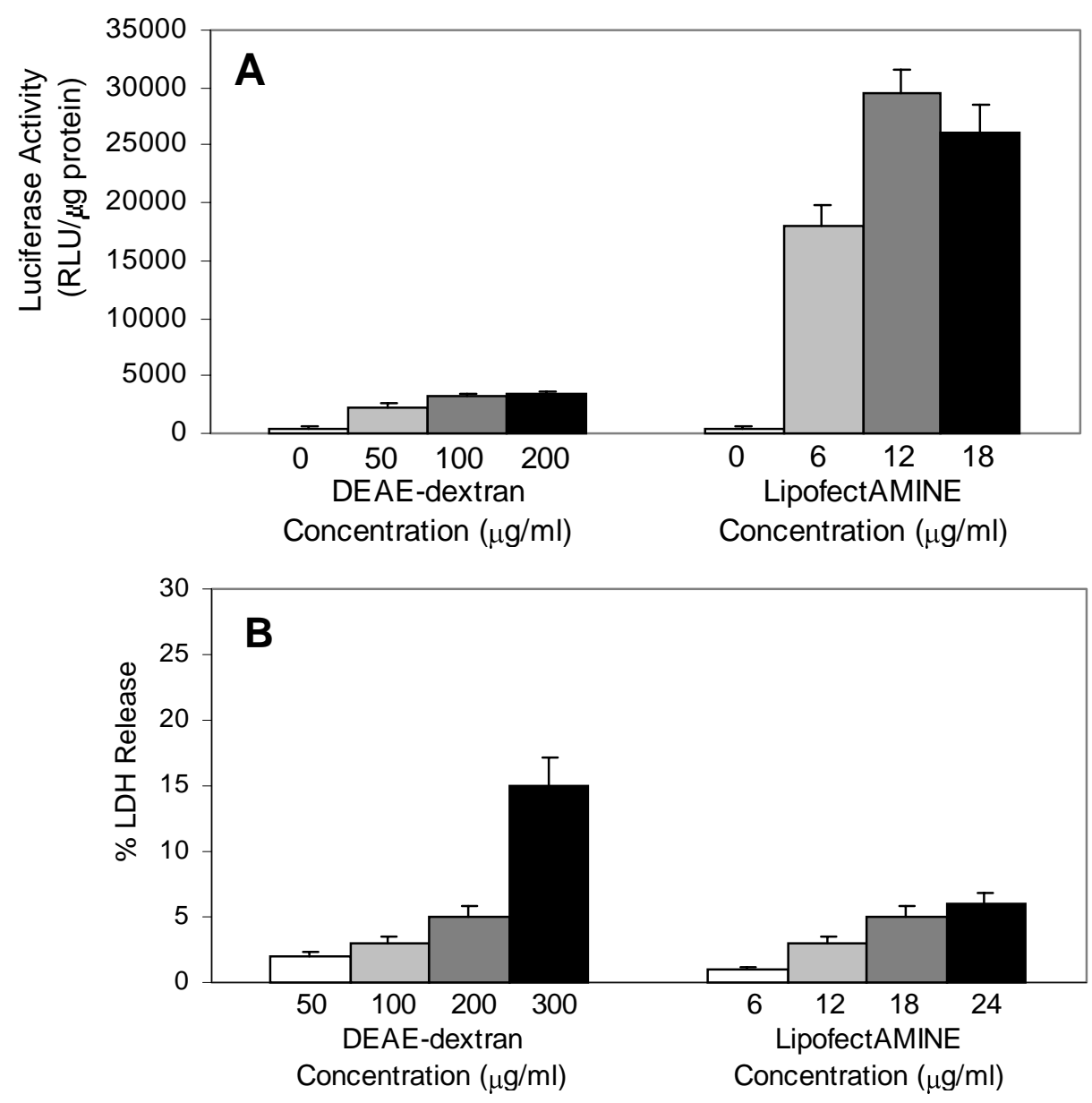

Fig. 2. Effects of DEAE-Dextran and LipofectAMINE Concentration on (A) Transfection Efficiency and (B) Cellular Toxicity of Macrophage RAW 264.7 Cells. Cells $\left(1 \times 10^{6} / \mathrm{ml}\right)$ were incubated with transfection media that contained increasing amounts of DEAE-dextran $(0-200 \mu \mathrm{g} / \mathrm{ml})$ or LipofectAMINE $(0-18 \mu \mathrm{g} / \mathrm{ml})$ in the presence of pCMV-luc $(1 \mu \mathrm{g} / \mathrm{ml})$. Two days post-transfection, the cells and supernatants were collected and analyzed for luciferase and LDH activities as noted in the Methods section. Each data point represents the mean (with standard deviation) of quadruplicate samples. 
Figure 3

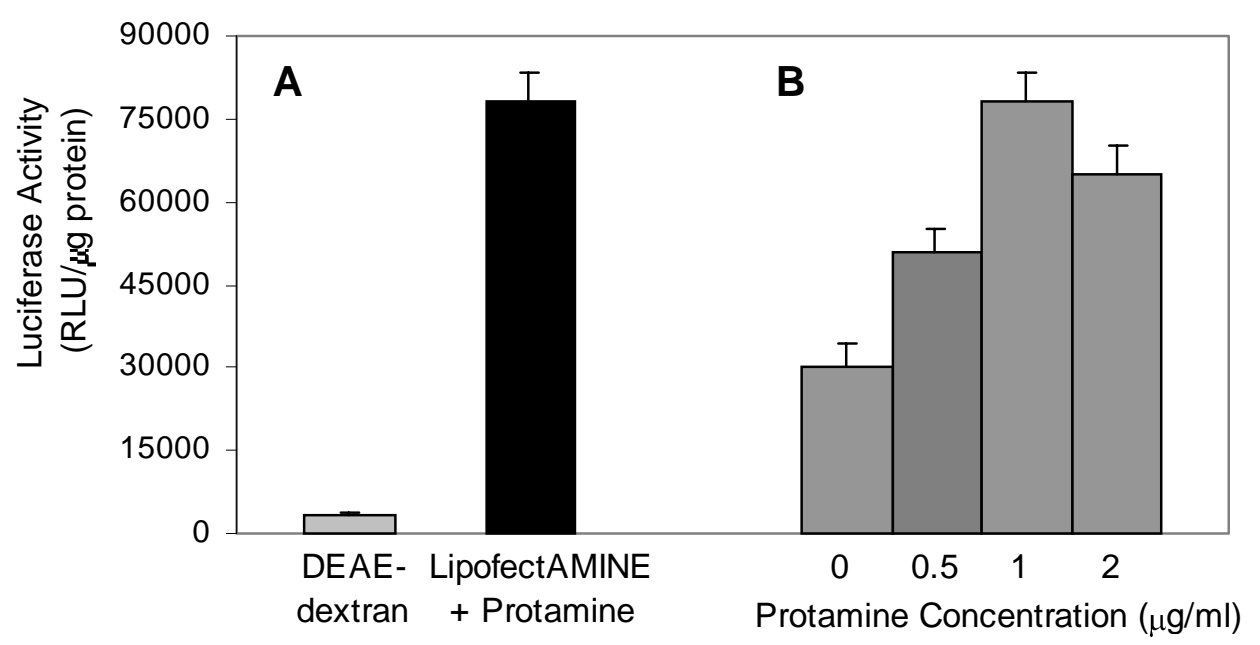

C

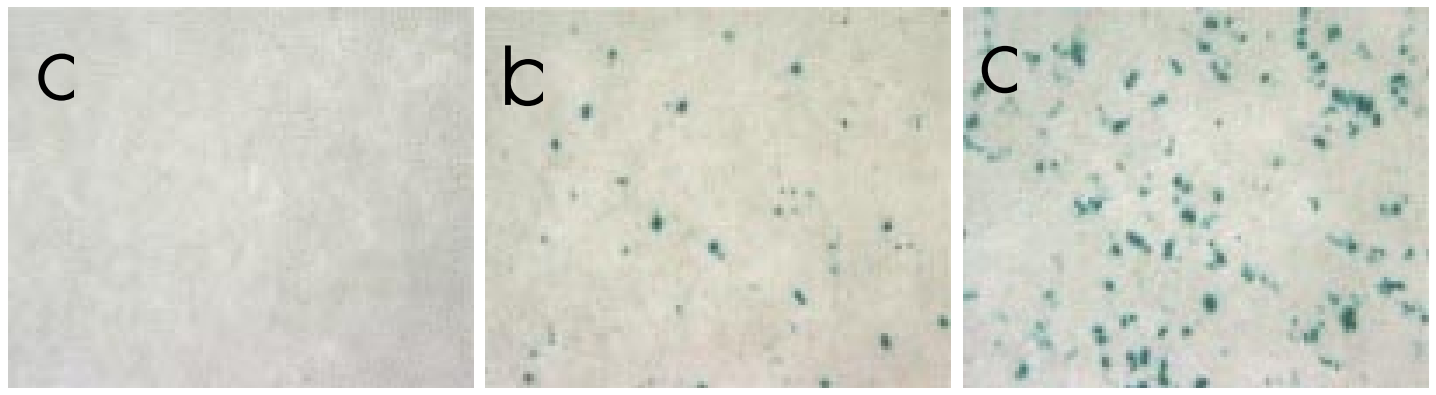

Fig. 3. Effect of Protamine Sulfate on LipofectAMINE-Mediated Gene Transfection. (A) Comparison of gene transfection mediated by DEAE-dextran $(100 \mu \mathrm{g} / \mathrm{ml})$ and LipofectAMINE/protamine $(12 / 1 \mu \mathrm{g} / \mathrm{ml})$ in macrophage RAW 264.7 cells. (B) Varying amounts of protamine sulfate $(0-2 \mu \mathrm{g} / \mathrm{ml})$ were added to transfection media containing LipofectAMINE $(12 \mu \mathrm{g} / \mathrm{ml})$ and pCMV-luc $(1 \mu \mathrm{g} / \mathrm{ml})$. Analysis of luciferase gene expression was performed as described in the Methods section. Each data point represents the mean (with standard deviation) of quadruplicate samples and the data are normalized to protein content. (C) Comparison of gene transfection mediated by (a) DNA (CMV- $\beta g a l, ~ 1 \mu \mathrm{g}$ ) alone, (b) DNA + LipofectAMINE (12 $\mu \mathrm{g} / \mathrm{ml})$ and (c) DNA + LipofectAMINE/protamine (12/1 $\mu \mathrm{g} / \mathrm{ml})$. Cells were stained with X-gal as described in the Methods section. 


\section{Figure $4 \quad \mathrm{~A}$}

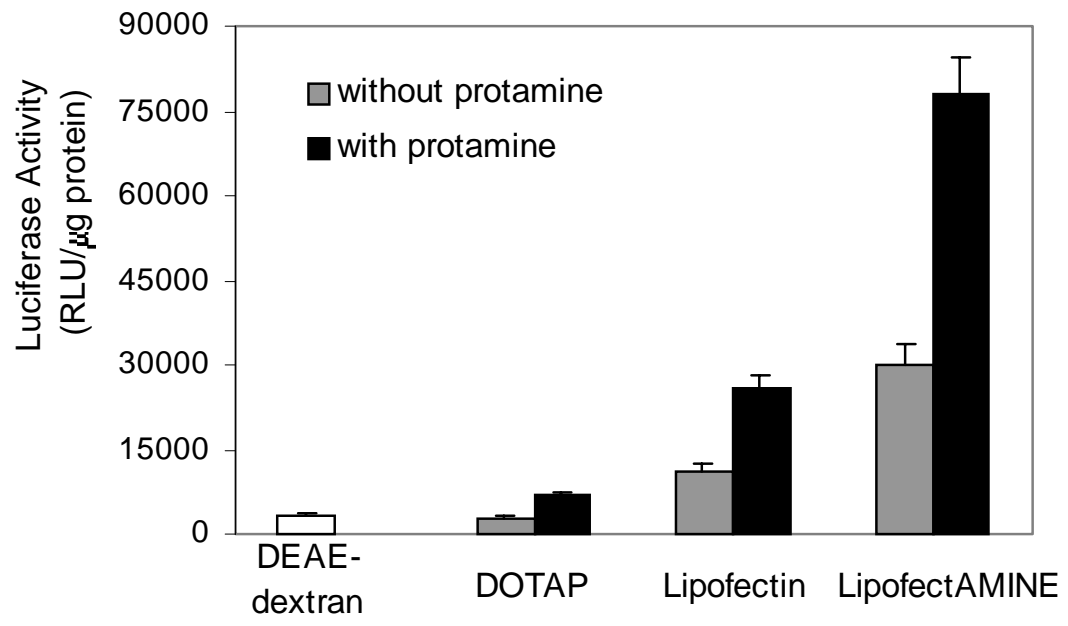

B

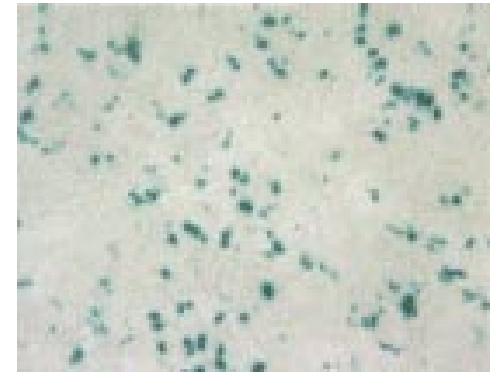

LipofectAMINE

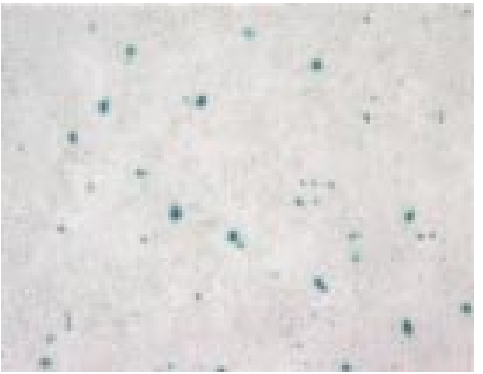

Lipofectin

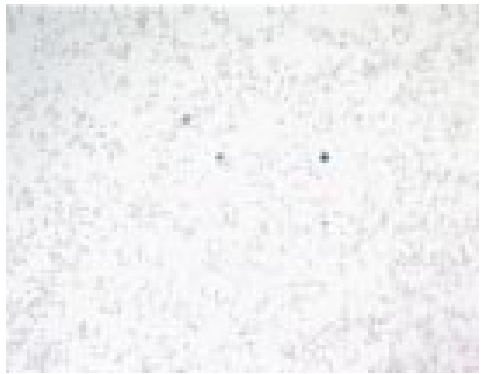

DEAE-Dextran

Fig. 4. Comparison of Transfection Activity of Different Liposomal Formulations in Macrophage RAW 264.7 Cells. Each liposomal formulation was optimized for their transfection efficiency by varying the amount of liposome per $1 \mu \mathrm{g} / \mathrm{ml}$ of DNA per well. The data represent the maximum values of gene expression for each liposomal formulation, both in the absence or presence of protamine which was similarly optimized. Transfection, luciferase and $\beta$-gal assay were performed as noted in the Methods section. Each data point represents the mean (with standard deviation) of quadruplicate samples and the data are normalized to protein content. 


\section{II.7. REFERENCES}

Burkholder, J.K., Decker, J., and Yang, N.S. (1993) Rapid transgene expression in lymphocyte and macrophage primary cultures after particle bombardment-mediated gene transfer. J Immunol Meth 165, 149-156.

Daumler, R. and Zimmermann, U. (1989) High yields of stable transformants by hypoosmolar plasmid electroinjection. $J$ Immunol Meth 122, 203-210.

Economou, J.S., Rhoades, K., Essner, R., McBride, W.H., Gasson, J.C., and Morton, D.L. (1989) Genetic analysis of the human tumor necrosis factor alpha/cachectin promoter region in a macrophage cell line. J Exp Med 170, 321-326.

Hess, J.L., Clements, J.E., and Narayan, O. (1985) Cis- and trans-acting transcriptional regulation of visna virus. Science $\mathbf{2 2 9}, \mathbf{4 8 2 - 4 8 5 .}$

Kabanov, A.V. and Kabanov, V.A. (1995) DNA complexes with polycations for the delivery of genetic material into cells. Bioconj Chem 6, 7-20.

Mack, K.D., Wei, R., Elbagarri, A., Abbey, N., and McGrath, M.S. (1998) A novel method for DEAE-dextran mediated transfection of adherent primary cultured human macrophages. J Immunol Meth 211, 79-86.

Pierce, G.F. (1990) Macrophages: important physiologic and pathologic sources of polypeptide growth factors. Am J Respir Cell Mol Biol 2, 233-234.

Roussel, M.F., Rettenmier, C.W., and Sherr, C.J. (1988) Introduction of a human colony stimulating factor-1 gene into a mouse macrophage cell line induces CSF-1 independence but not tumorigenicity. Blood 71, 1218-1225.

Rupprecht, A.P. and Coleman, D.L. (1991) Transfection of adherent murine peritoneal macrophages with a reporter gene using DEAE-dextran. $J$ Immunol Meth 144, 157163.

Sorgi, F.L., Bhattacharya, S., and Huang, L. (1997) Protamine sulfate enhances lipidmediated gene transfer. Gene Ther 4, 961-968. 
Stief, A., Winter, D.M., Stratling, W.H., and Sippel, A.E. (1989) A nuclear DNA attachment element mediates elevated and position-independent gene activity. Nature 341, 343345. 


\section{SECTION III}

\section{Mechanisms of Endotoxin-Induced Inactivation}

\section{of Transgene Expression in Macrophages}




\section{III.1. ABSTRACT}

Endotoxin, the lipopolysaccharide (LPS) component of gram-negative bacteria, is a common contaminant of plasmid DNA preparations. The present study investigates the effect of endotoxin on gene transfection efficiency and the role of reactive oxygen species (ROS) in this process. Gene transfection studies were performed in various cell types using CMV-luciferase as a reporter plasmid and cationic liposome as a transfecting agent. The presence of endotoxin in plasmid DNA preparations severely limited transgene expression in macrophages, but had little or no effect in other cell types tested. This decreased transfection was dependent on ROS-mediated cellular toxicity induced by endotoxin. Neutralizing endotoxin by the addition of polymyxin B effectively increased transfection efficiency and reduced toxicity. Electron spin resonance (ESR) studies confirmed the formation of ROS in endotoxin-treated cells and their inhibition by free radical scavengers. The ROS scavenger PBN, catalase $\left(\mathrm{H}_{2} \mathrm{O}_{2}\right.$ scavenger), and sodium formate ( $\mathrm{OH}$ scavenger) effectively inhibited endotoxin-induced effects, while superoxide dismutase (SOD) $\left(\mathrm{O}_{2}{ }^{-}\right.$ scavenger) had lesser effects. These results indicate that multiple oxidative species are involved in the transfection inactivation process, and that $\mathrm{OH}$ radicals, formed by $\mathrm{H}_{2} \mathrm{O}_{2}-$ dependent, metal-catalyzed Fenton reaction, play a major role in this process. 


\section{III.2. INTRODUCTION}

Macrophages play an important role in host defense against noxious substances and are involved in a variety of disease processes including autoimmune diseases, infections and inflammatory disorders [see (Lewis and McGee, 1992) for review]. Molecular analysis of macrophage functions can be accomplished by gene transfection assays. However, gene transfection in macrophages has proven difficult due to their refractory nature. While over the years, numerous efforts have been made to improve gene transfection of macrophages (Burkholder et al., 1993; Daumler and Zimmermann, 1989; Mack et al., 1998; Rupprecht and Coleman, 1991), their transfection is still poor. The lack of understanding of the causes that contribute to the refractory nature of macrophages during gene transfection is partly responsible for this limited success. Since macrophages are known to be highly susceptible to endotoxin stimulation and endotoxin is a major contaminant of plasmid DNA preparations used in most transfection studies, we hypothesized that the presence of contaminating endotoxin may contribute to this low transfection. The present study was undertaken to test this hypothesis and to elucidate the mechanisms underlying the cellular unresponsiveness of macrophages to gene transfection.

Endotoxin (LPS) is known to be an extremely bioactive substance and a potent stimulator of immune cells (Morrison and Ryan, 1987; Wright, 1991). LPS consists of a variable polysaccharide domain covalently attached to a lipid domain (lipid A). LPS mediates most of its effects by binding to macrophages and inducing the production of many cellular mediators, including pro-inflammatory cytokines such as TNF $\alpha$ and IL-1 (Raetz, 1990), fatty acid metabolites (Raetz, 1990), and reactive oxygen species (ROS) (Guthrie et al., 1984). ROS are known to exert multiple effects on cells and tissues and are involved in a variety of pathological processes. They can cause DNA damage, lipid peroxidation, protein modification and activation of certain nuclear transcription factors such as AP-1 and NF-kB (Meyer et al., 1994; Remacle et al., 1995). In the present study, we tested whether ROS are involved in the transfection inactivation process of macrophages.

LPS has been shown to reduce gene transfection efficiency in non-immune cells (Weber et al., 1995), however its mechanism of action is not known. We report here that cellular toxicity induced by LPS is responsible, at least in part, for the decreased transfection efficiency in macrophages. Since macrophages are the primary cellular target for LPS 
stimulation, we postulated that this cell type may be more susceptible to LPS effects. We examined the role of ROS generation by macrophages in transfection efficiency and cytotoxicity. Our hypothesis is that if ROS are responsible for such effects, then blocking these reactive species, i.e., by free radical scavengers, would increase transfection efficiency and decrease cellular toxicity. We also attempted to identify key reactive species involved in the process. The specific questions to be addressed in this study are: 1) Are macrophages more susceptible to LPS contamination of plasmid DNA than other cell types? 2) What is the underlying mechanism of LPS-induced cellular toxicity in macrophages? 3) Can free radical scavengers decrease this toxicity and do they reverse LPS-induced decrease in transfection? 4) If so, what are the key reactive species involved in the process? 


\section{III.3. METHODS}

\section{Cell Culture}

Cell lines including the macrophage RAW 264.7 and NR383, alveolar epithelial A549, kidney embryonic 293, and liver HEPG2 were obtained from the American Type Cell Culture Collection (Rockville, MD). The cells were grown in DMEM supplemented with 10\% fetal bovine serum (FBS), $2 \mathrm{mM} \mathrm{L-glutamine,} \mathrm{and} 100 \mathrm{U} / \mathrm{ml}$ penicillin-streptomycin. They were maintained at $37^{\circ} \mathrm{C}$ in a humidified atmosphere containing $5 \% \mathrm{CO}_{2}$. Prior to use, cells were briefly trypsinized or mechanically scraped and centrifuged. They were plated at $\sim 1 \times 10^{6}$ cells $/ \mathrm{ml}$ in 12-well tissue culture plates one day before transfection studies.

\section{Plasmid DNA}

The expression vector CMV-luciferase contains the promoter-enhancer region of Cytomegalovirus upstream from the luciferase gene (kindly provided by Dr. Leaf Huang, University of Pittsburgh). The plasmid was purified using the Qiagen Endofree or regular ion-exchange plasmid kits (Qiagen, Chatsworth, CA) according to the manufacturer's instructions. The content of endotoxin in plasmid DNA preparations was determined by using the chromogenic Limulus amebocyte lysate assay (Kinetic-QCL, BioWhittaker, Walkersville, MD) according to the manufacturer's instructions. In studies designed to study the effect of endotoxin on gene transfection efficiency, specified amounts of LPS (E. coli 0111:B4, $1 \mathrm{EU} / \mu \mathrm{g}$ ) (Sigma, St. Louis, MO) was added to the plasmid preparations.

\section{Liposomal Transfection}

Approximately $1 \times 10^{6}$ cells were plated on a 12-well plate and allowed to grow for 24 hours before the transfection. The plasmid DNA $(1 \mu \mathrm{g} / \mathrm{ml})$ was diluted in $200 \mu \mathrm{l}$ of DMEM (GIBCO BRL Life Technologies) and the DNA condensing agent protamine sulfate (0.1-2 $\mu \mathrm{g} / \mathrm{ml}$ ) (Sigma, St. Louis, MO) was added to the DNA. The liposome $(1-20 \mu \mathrm{g} / \mathrm{ml})$ was diluted in $200 \mu \mathrm{l}$ of DMEM. The diluted DNA and liposome samples were combined and incubated at room temperature for 15-20 min. In some studies, indicated amounts of polymyxin B sulfate, PBN, SOD, catalase, and sodium formate (Sigma) were also added to the transfection medium. Cells with transfection reagents were incubated for 4 hours. Transfection medium was then replaced with growth medium containing $10 \%$ FBS. Cells 
were cultured for an additional 48 hours before the level of gene expression was determined. All transfections were conducted under sterile conditions and duplicate plates were tested for each condition.

\section{Measurement of Luciferase Activity}

Luciferase synthesized during the in vitro translation was quantitated by the assay of enzyme-dependent light production using a luciferase assay kit (Promega, Madison, WI). Cells were washed twice with PBS and incubated at room temperature for $10 \mathrm{~min}$ in the presence of $250 \mu \mathrm{l}$ of lysis buffer (Promega) and then centrifuged at $12000 \mathrm{~g}$. Ten microliters of each sample was placed in a 5-ml polystyrene test tube and the tubes were then loaded into an automated luminometer (BioRad, Hercules, CA). At the time of measurement, $100 \mu \mathrm{l}$ of luciferase substrate was automatically injected into each sample, and total luminescence was measured over a $20-\mathrm{sec}$ time interval. Output is quantitated as relative light units $(R L U)$. Protein content in the supernatant was determined by BCA protein assay reagent (Pierce, Rockford, IL). Luminescence detected was standardized per $\mu \mathrm{g}$ protein present in the supernatant.

\section{LDH Activity}

LDH assay was performed to assess the effect of test agents on cellular toxicity. Cells were treated with plasmid DNA, LPS, and transfecting agents, either individually or in combination as indicated. After the treatments, the cell supernatants were collected and assayed for LDH activity. LDH activity was determined by monitoring the oxidation of pyruvate coupled with the reduction of NAD at $340 \mathrm{~nm}$ using an LDH assay kit (Roche Diagnostic Systems, Montclair, NJ). The assay was performed on Cobas Fara II Analyzer (Roche Diagnostic Systems). One unit per liter of LDH activity is defined as the amount of enzyme that converts $1 \mu \mathrm{mol}$ of lactate to $1 \mu \mathrm{mol}$ of pyruvate with the concomitant reduction of $1 \mu \mathrm{mol}$ of NAD to $1 \mu \mathrm{mol}$ of NADH per minute per liter of sample in the assay procedure.

\section{Free Radical Measurements}

The ESR spin trapping technique was used to detect short-lived free radical intermediates. Spin trapping is necessary because of the reactive nature of the free radicals 
to be studied. This technique involves an addition-type reaction of a short-lived radical with a diamagnetic compound (spin trap) to form a relatively long-lived free radical product, the socalled spin adduct, which can be studied by conventional ESR. The intensity of the spin adduct signal corresponds to the amount of short-lived radicals trapped, and the hyperfine splittings of the spin adduct are generally characteristic of the original, short-lived, trapped radical. All measurements were conducted with a Varian E9 ESR spectrometer and a flat cell assembly. Hyperfine splittings were measured (to $0.1 \mathrm{G}$ ) directly from magnetic field separations using potassium tetraperoxochromate $\left(\mathrm{K}_{3} \mathrm{CrO}_{8}\right)$ and 1,1-diphenyl-2picrylhydrazyl (DPPH) as standards. Reactants were mixed in test tubes in a total volume of $0.5 \mathrm{ml}$. The reaction mixture was then transferred to a flat cell for ESR measurement. All measurements were carried out using 5,5-dimethyl-1-pyrroline- $N$-oxide (DMPO)(Aldrich) as a spin trap. 


\section{III.4. RESULTS}

\section{Macrophages are Difficult to Transfect}

To evaluate the relative transfection efficiency of macrophages compared to other cell types, we transfected various cell lines from different origins including the macrophage RAW 264.7 and NR383, kidney embryonic 293, alveolar epithelial A549 and liver HEPG2 cells with the CMV-luciferase reporter plasmid. The results of this study (Fig. 1). show that maximum luciferase activity was observed in HEPG2 cells, followed by embryonic 293, epithelial A549, and macrophage RAW 264.7 cells and NR383, respectively. In the absence of transfecting agents, all four cell lines exhibited minimum luciferase activity. These results indicate that gene transfection is cell type-dependent and that macrophages are relatively difficult to transfect compared to other cell types.

\section{Endotoxin Reduces Transfection Efficiency and Increases Cellular Toxicity}

Endotoxin is known to be a frequent contaminant of plasmid DNA preparations (Cotten et al., 1994) and a potent stimulator of macrophages (Morrison and Ryan, 1987; Wright, 1991). We therefore tested whether the presence of contaminating endotoxin could contribute to the observed low transfection efficiency in macrophages. To test this possibility, we used highly purified plasmid preparations which we obtained by using the Qiagen Endofree plasmid preparation kit, and tested the effect of added LPS on gene transfer efficiency. Plasmid samples prepared by this method were found to contain $<0.1$ Endotoxin Unit (EU) per $\mu \mathrm{g}$ plasmid DNA as determined by the Limulus amebocyte lysate assay. This amount of endotoxin is typically $100-10,000$ times less than that obtained by conventional methods of DNA preparation such as anion-exchange chromatography and silica-based adsorption (Weber et al., 1995). Not surprisingly, transfection of macrophages with the Endofree plasmid was thirty times greater than that of plasmid prepared by anionexchange chromatography (Fig. 2). Fig. 2A shows that the addition of small amounts of LPS $(0-0.5 \mu \mathrm{g} / \mathrm{ml}$ or $0-5 \mathrm{EU} / \mathrm{ml})$ greatly reduced the transfection efficiency of macrophages. In contrast, LPS at the same concentration range had no significant effect on gene transfection efficiency in other cell types tested (Fig. 3A). These results suggest that macrophages are especially sensitive to LPS and that this increased susceptibility may be responsible for their poor transfection efficiency. To test whether the reduced transfection is associated with cellular toxicity potentially caused by LPS, we studied the effect of LPS on 
cellular LDH release. Fig. 3B shows that at the same concentrations used in gene transfection studies, LPS caused a significant toxic effect in macrophages but had only minimal effect in other cell types. These results suggest that the low transfection efficiency in macrophages may be caused by LPS-mediated cellular toxicity.

The role of endotoxin in macrophage toxicity is further studied by using the endotoxin neutralizing agent polymyxin B. Polymyxin B is a polycationic antibiotic that has been widely used to neutralize the effects of LPS (Storm et al., 1977). Treatment of the cells with this agent during gene transfection decreased cellular toxicity (Fig. 4A) and reversed the LPSinduced decrease in transfection (Fig. 4B). Thus, these results confirm that the observed low transfection is due to the cytotoxic effects of endotoxin.

\section{ROS are Involved in LPS-Mediated Toxicity}

LPS stimulation of macrophages has been reported to cause activation and release of ROS (Gossart et al., 1996). Since ROS are known to be involved in a number of pathological processes, we postulated that ROS may be responsible for LPS-induced toxicity and reduced transfection. To test this possibility, we treated the cells with PBN (ROS scavenger) and study its effects on LPS-induced toxicity and transfection activity. PBN has been used in previous studies as a scavenger of ROS (Gossart et al., 1996). Our results show that PBN effectively inhibited LPS-induced toxicity (Fig. 4A) and restored transfection activity (Fig. 4B). Thus, our results support the role of ROS in the process. Subsequent studies using specific ROS scavengers (see below) further confirm these results.

\section{Hydroxyl Radical $(\mathrm{OH})$ is the Primary Reactive Species Responsible for LPS-Induced Effects}

Since PBN is a non-specific ROS scavenger, the identity of specific oxygen species involved in this process is not known. To identify such species, we used specific ROS inhibitors, including SOD $\left(\mathrm{O}_{2}^{-}\right.$scavenger), catalase $\left(\mathrm{H}_{2} \mathrm{O}_{2}\right.$ scavenger $)$, and sodium formate ( $\cdot \mathrm{OH}$ scavenger) to study the effects on LPS. $\mathrm{O}_{2} \cdot \mathrm{H}_{2} \mathrm{O}_{2}$, and $\cdot \mathrm{OH}$ are three major reactive species produced by macrophages (Drath and Karnovsky, 1975; Gee et al., 1970; Rojanasakul et al., 1993) and thus are the primary focus of our investigation. Figs. 5A and $5 \mathrm{~B}$ show that all three scavengers had an inhibitory effect on cellular toxicity and 
transfection activity. However, the effects were more pronounced in the case of catalase and sodium formate and lesser effects were observed with SOD. It should be noted that all three scavengers were tested at different concentrations, however only optimal concentrations of each scavenger are presented here. The results obtained suggest that multiple ROS are involved in the toxicological process and that $\mathrm{H}_{2} \mathrm{O}_{2}$ and $\mathrm{OH}$ play a greater role. Since $\mathrm{H}_{2} \mathrm{O}_{2}$ has been reported to be a major source of $\mathrm{OH}$ formation in macrophages, i.e., via metal-catalyzed Fenton reaction $\left[\mathrm{M}^{\mathrm{nt}}+\mathrm{H}_{2} \mathrm{O}_{2}->\mathrm{M}^{(\mathrm{n}+1)+}+\mathrm{OH}^{-}+\mathrm{OH}\right.$ ] (Rojanasakul et al., 1993), and since $\cdot \mathrm{OH}$ is known to be highly reactive, we suggest that $\mathrm{OH}$ may be the primary oxidative species responsible for the observed effects induced by LPS. Supporting this notion is the fact that sodium formate, a scavenger of $\mathrm{OH}$ radicals, was equally effective in decreasing toxicity and restoring transfection as catalase, and that catalase can inhibit $\mathrm{OH}$ radicals in macrophages as further demonstrated in our ESR studies (see below).

To confirm that $\mathrm{OH}$ radicals were actually formed during LPS activation, ESR studies using the spin trap DMPO were carried out. Cells were treated with LPS in the presence or absence of ROS scavengers. Fig. 6 shows that in the presence of LPS, an ESR spectrum consisting of a 1:2:2:1 quartet pattern, which is characteristic of DMPO-OH adduct (Oberly, 1984), was observed. Addition of the $\mathrm{OH}$ scavenger sodium formate to the system decreased the intensity of the DMPO-OH signal, thus confirming the formation of $\mathrm{OH}$ induced by LPS. Interestingly, catalase whose function is to scavenge $\mathrm{H}_{2} \mathrm{O}_{2}$ also inhibited $\mathrm{OH}$ formation. These results are consistent with previous studies by our group which demonstrated that $\mathrm{H}_{2} \mathrm{O}_{2}$ can react with endogenous metal ions to form $\mathrm{OH}$ via the Fenton reaction (Rojanasakul et al., 1993). The results also explain the observed comparable effects of catalase and sodium formate in our toxicity and transfection studies. 


\section{III.5. DISCUSSION}

Transfection of macrophages represents a significant challenge in gene regulation studies that utilize these cells. Because of their crucial function in a variety of biological processes and pathologies, these cells also represent important targets for gene therapies. Using liposome-based gene transfection assay, we have shown that macrophages are difficult to transfect when compared to other cell types. Macrophages are sensitive to the content of contaminating endotoxin and hence are sensitive to the method of DNA preparation.

Previous studies have shown that the presence of contaminating endotoxin in plasmid preparations can reduce gene transfection efficiency in other cell types (Weber et al., 1995). However, this effect is generally observed at high levels of endotoxin, i.e., $>100$ $\mathrm{EU} / \mathrm{ml}$. In this study, we found that macrophages are susceptible to endotoxin at very low levels $(0-5 \mathrm{EU} / \mathrm{ml})$. At these concentrations, gene transfection was greatly diminished in macrophages but was relatively unaffected in other cell types. These results indicated that macrophages are particularly sensitive to endotoxin contamination and that this increased susceptibility may be responsible for their poor transfection efficiency.

The mechanism by which endotoxin decreases gene transfection in macrophages is not known. We suggest that this decreased efficiency may be associated with cellular toxicity induced by endotoxin. Supporting this notion is the evidence that endotoxin induced cellular toxicity and also decreased gene transfection in macrophages, the effects that were not observed in other cell types tested. The role of cellular toxicity in decreasing transfection efficiency is confirmed by treatment of cells with polymyxin B during transfection. Polymyxin $B$ is a polycationic antibiotic that has been widely used to neutralize the effects of LPS. Polymyxin B is known to bind lipid A portion of LPS with high affinity (Morrison and Jacobs, 1976). The lipid A portion has also been shown to be responsible for most of the biological activities of LPS (Morrison and Ryan, 1987; Raetz, 1990). We have observed in this study that the addition of polymyxin $B$ to the transfection medium effectively inhibited the cytotoxic effect of endotoxin and restored gene transfection efficiency of macrophages.

Endotoxin is known to activate macrophages and induce the production of various cellular mediators including ROS (Guthrie et al., 1984; Raetz, 1990). Consistent with these 
studies, our ESR and ROS scavenging studies indicated the formation of ROS in our system. To test whether the ROS generated are responsible for the decreased transfection induced by LPS, we treated the cells with different ROS scavengers during transfection. All scavengers increased gene transfection efficiency, thus supporting the role of ROS in this process. These scavengers also decreased cellular toxicity induced by LPS, further substantiating the relationship between these two processes. The observation that all ROS scavengers exhibited LPS inhibitory effects and that PBN, a general ROS scavenger, was more effective than other scavengers in neutralizing the LPS effects also indicated that multiple ROS are involved in the process. Careful analysis of the test results further showed that $\mathrm{O}_{2}^{-}$radicals play a less significant role and $\mathrm{OH}$ radicals formed by $\mathrm{H}_{2} \mathrm{O}_{2}$-dependent, metal-catalyzed Fenton reaction play a major role in the process.

The conclusions of this study are: 1) LPS decreases transfection efficiency in macrophages due to its toxic effect; 2) LPS-induced ROS generation is involved in this process; 3 ) inactivating LPS by addition of polymyxin B or addition of ROS scavengers decreases the toxicity associated with LPS; and 4) $\mathrm{OH}$ radicals appear to be the major reactive species responsible for LPS-induced toxicity and reduced transfection. We report here, for the first time, the role of ROS in causing decreased transfection in macrophages. The results of this study should provide useful information concerning the design of safe and effective gene delivery systems for macrophages. 


\section{III.6. FIGURES}

Figure 1

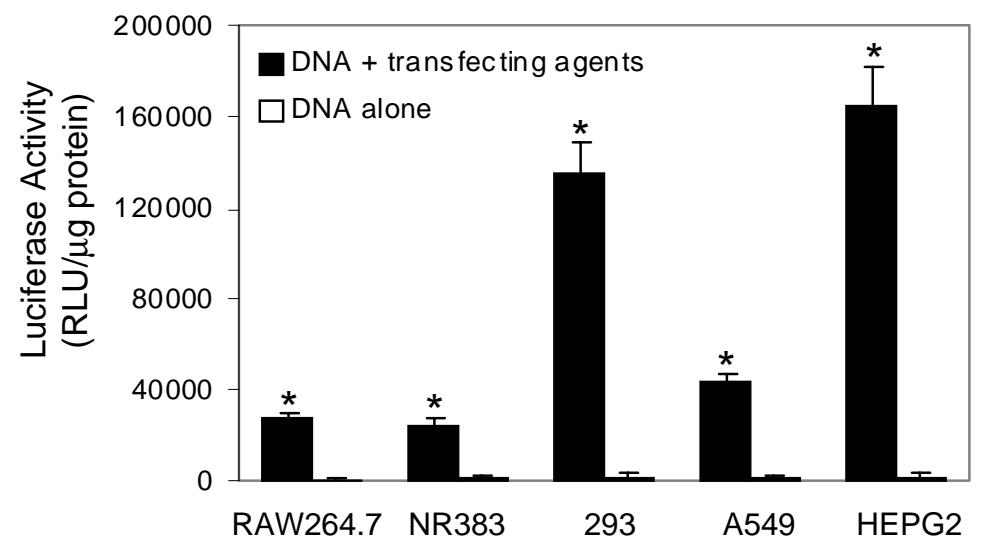

Fig. 1. Comparison of Gene Transfection in Different Cell Lines. Cells $\left(1 \times 10^{6} / \mathrm{ml}\right)$ were transfected with the reporter plasmid CMV-luciferase $(1 \mu \mathrm{g} / \mathrm{ml})$ in the presence or absence of transfecting agents (LipofectAMINE, $12 \mu \mathrm{g} / \mathrm{ml}$; protamine, $1 \mu \mathrm{g} / \mathrm{ml}$ ) for $4 \mathrm{~h}$ at $37^{\circ} \mathrm{C}$. The transfection conditions were optimized for maximum transfection of macrophages. Two days post-transfection, the cells were washed, lysed, and measured for luciferase activity. Data are normalized to protein content. Values are means $\pm \mathrm{SD} ; n=4 .{ }^{*} p<0.05$ vs. free DNA control. 
Figure 2

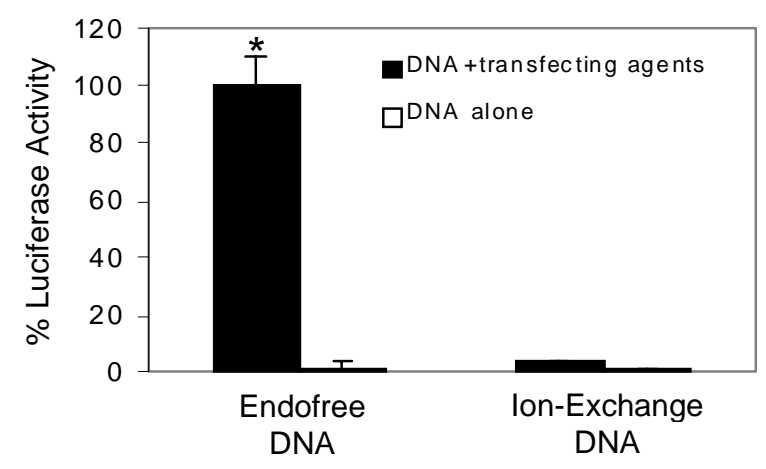

Fig. 2. Effect of DNA Preparation on Gene Transfer Efficiency. Macrophage RAW 264.7 cells $\left(1 \times 10^{6} / \mathrm{ml}\right)$ were transfected with either Endofree or anion-exchange plasmid CMVluciferase $(1 \mu \mathrm{g} / \mathrm{ml})$ in the presence or absence of transfecting agents (LipofectAMINE, 12 $\mu \mathrm{g} / \mathrm{ml}$; protamine, $1 \mu \mathrm{g} / \mathrm{ml}$ ) for $4 \mathrm{~h}$ at $37^{\circ} \mathrm{C}$. Two days post-transfection, the cells were washed, lysed, and measured for luciferase activity. Values are means $\pm \mathrm{SD} ; n=4$. ${ }^{*} p<$ 0.05 vs. ion-exchange treatment. 
Figure 3
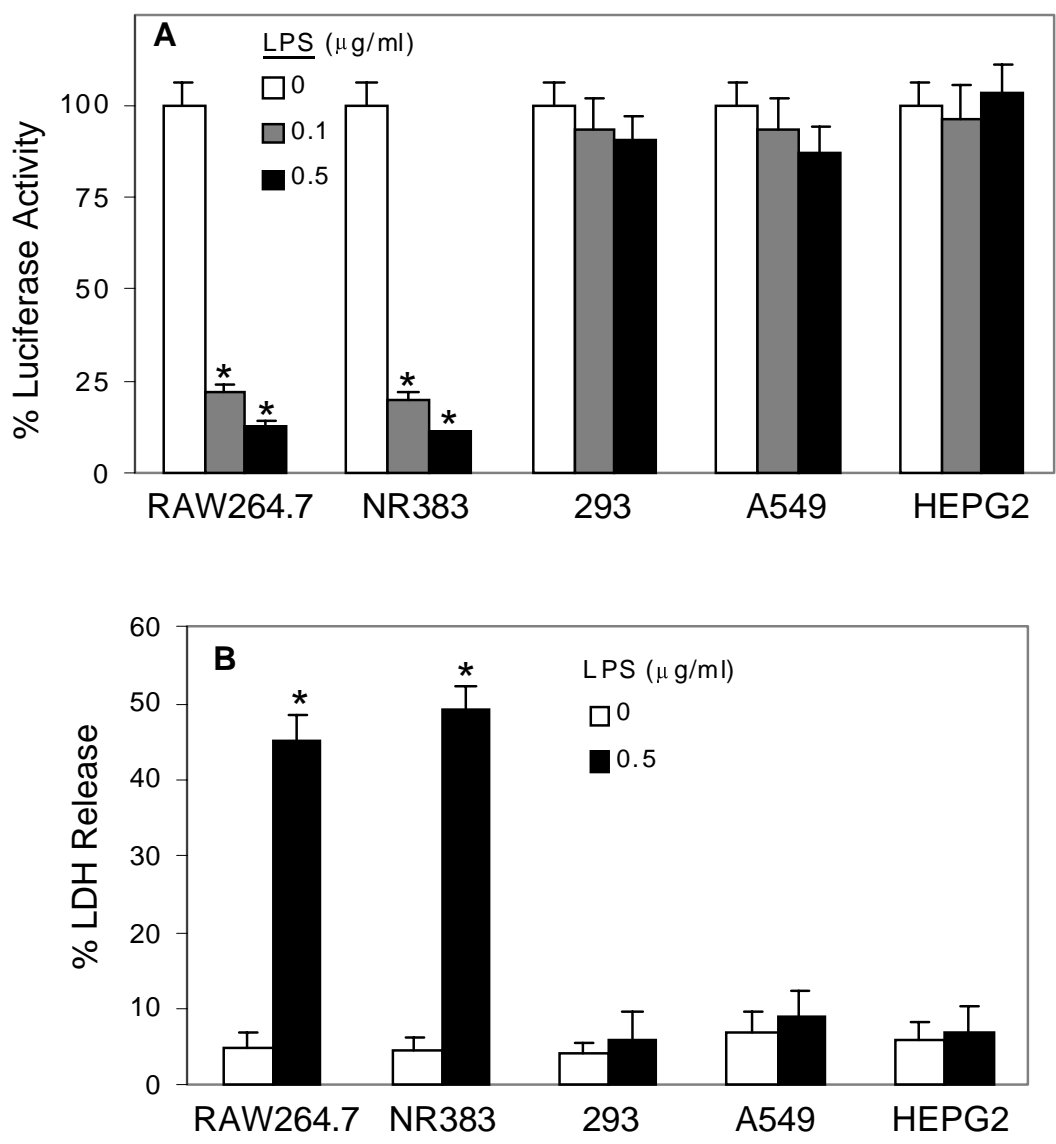

Fig. 3. Effects of Endotoxin on Transfection Efficiency $(A)$ and Cellular Toxicity $(B)$ in Different Cell Lines. Cells $\left(1 \times 10^{6} / \mathrm{ml}\right)$ were transfected with Endofree CMV-luciferase (1 $\mu \mathrm{g} / \mathrm{ml}$ ) in the presence of transfecting agents (LipofectAMINE, $12 \mu \mathrm{g} / \mathrm{ml}$; protamine, $1 \mu \mathrm{g} / \mathrm{ml}$ ) for $4 \mathrm{~h}$ at $37^{\circ} \mathrm{C}$. Varying amounts of LPS $(0-0.5 \mu \mathrm{g} / \mathrm{ml})$ were also added to the transfection medium during transfection. Two days post-transfection, the cells and supernatants were collected and analyzed for luciferase and LDH activities. Values are means $\pm \mathrm{SD} ; n=4 .{ }^{*} p$ $<0.05$ vs. LPS non-treated control. 
Figure 4
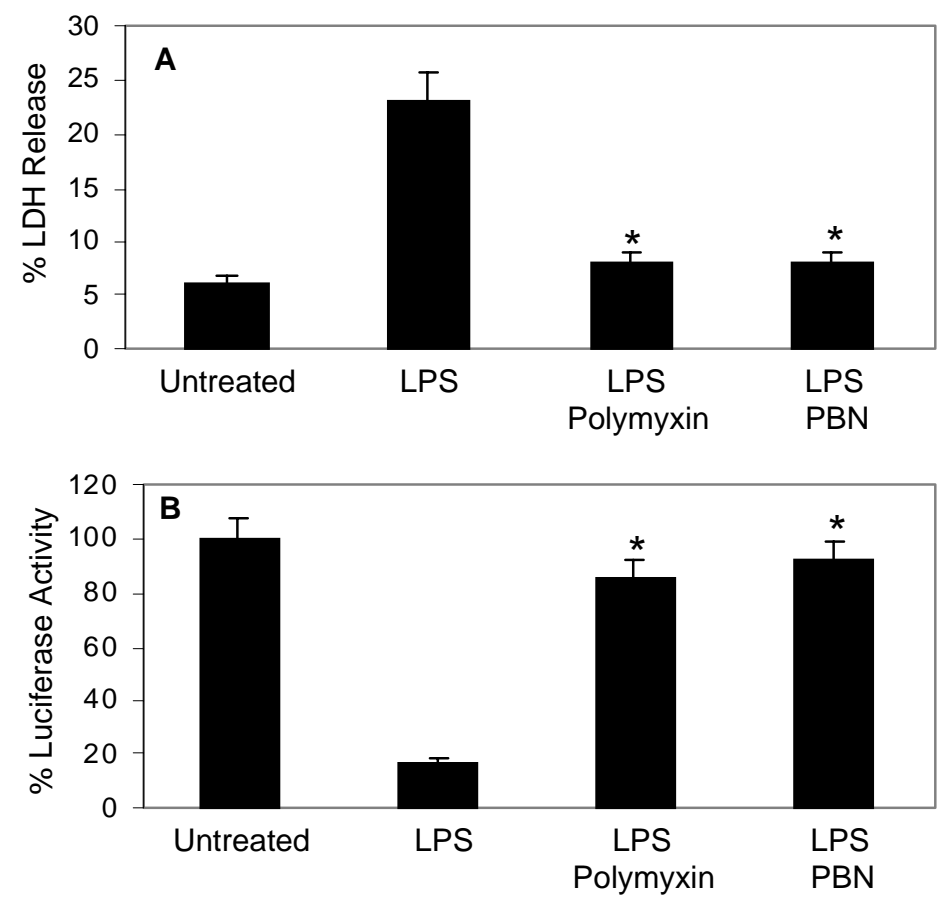

Fig. 4. Effects of Polymyxin $B$ and PBN on LPS-Induced Toxicity $(A)$ and Transfection Efficiency (B). Cells $\left(1 \times 10^{6} / \mathrm{ml}\right)$ were transfected with CMV-luciferase $(1 \mu \mathrm{g} / \mathrm{ml})$ in the presence of transfecting agents (LipofectAMINE, $12 \mu \mathrm{g} / \mathrm{ml}$; protamine, $1 \mu \mathrm{g} / \mathrm{ml}$ ) for $4 \mathrm{~h}$ at $37^{\circ} \mathrm{C}$. Polymyxin B $(1 \mu \mathrm{g} / \mathrm{ml})$ and PBN $(2 \mathrm{mM})$ were added to the transfection medium in different treatment groups. Two days post-transfection, the cells and supernatants were collected and analyzed for luciferase and LDH activities. Values are means \pm SD; $n=4$. ${ }^{*} p$ $<0.05$ vs. LPS-treated control. 
Figure 5
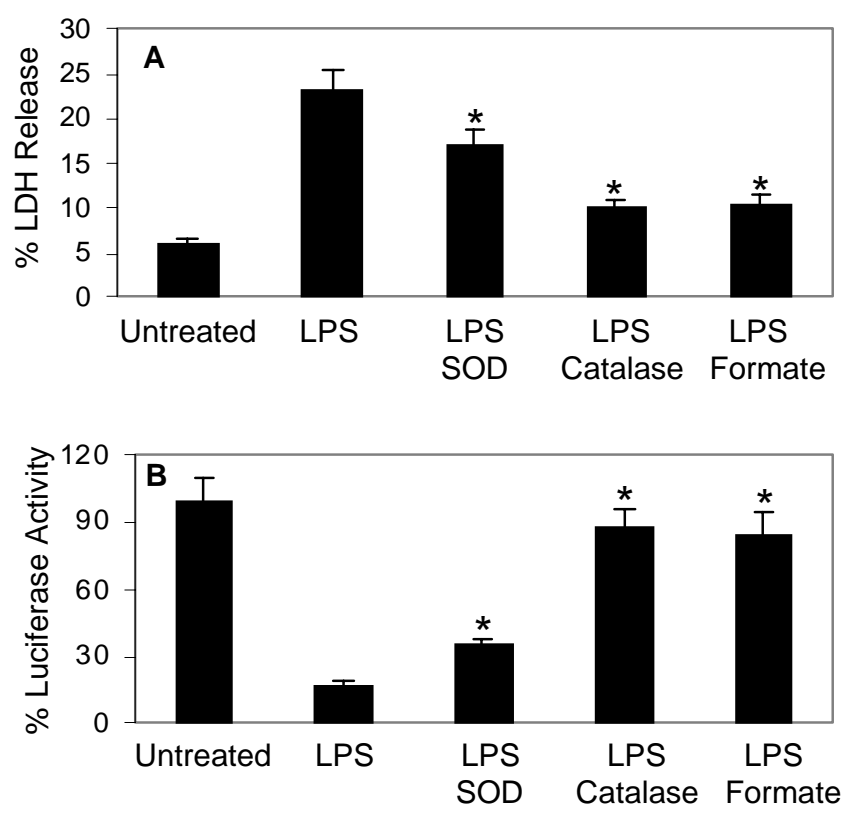

Fig. 5. Effects of ROS Scavengers on LPS-Induced Toxicity $(A)$ and Transfection Efficiency $(B)$. Cells $\left(1 \times 10^{6} / \mathrm{ml}\right)$ were transfected with CMV-luciferase $(1 \mu \mathrm{g} / \mathrm{ml})$ in the presence of transfecting agents (LipofectAMINE, $12 \mu \mathrm{g} / \mathrm{ml}$; protamine, $1 \mu \mathrm{g} / \mathrm{ml}$ ) for $4 \mathrm{~h}$ at $37^{\circ} \mathrm{C}$. SOD $(100 \mu \mathrm{g} / \mathrm{ml})$, catalase $(100 \mathrm{u} / \mathrm{ml})$, and sodium formate $(5 \mathrm{mM})$ were added to the transfection medium in different treatment groups. Two days post-transfection, the cells and supernatants were collected and analyzed for LDH and luciferase activities. Values are means $\pm \mathrm{SD} ; n=4 .{ }^{*} p<0.05$ vs. LPS-treated control. 
Figure 6

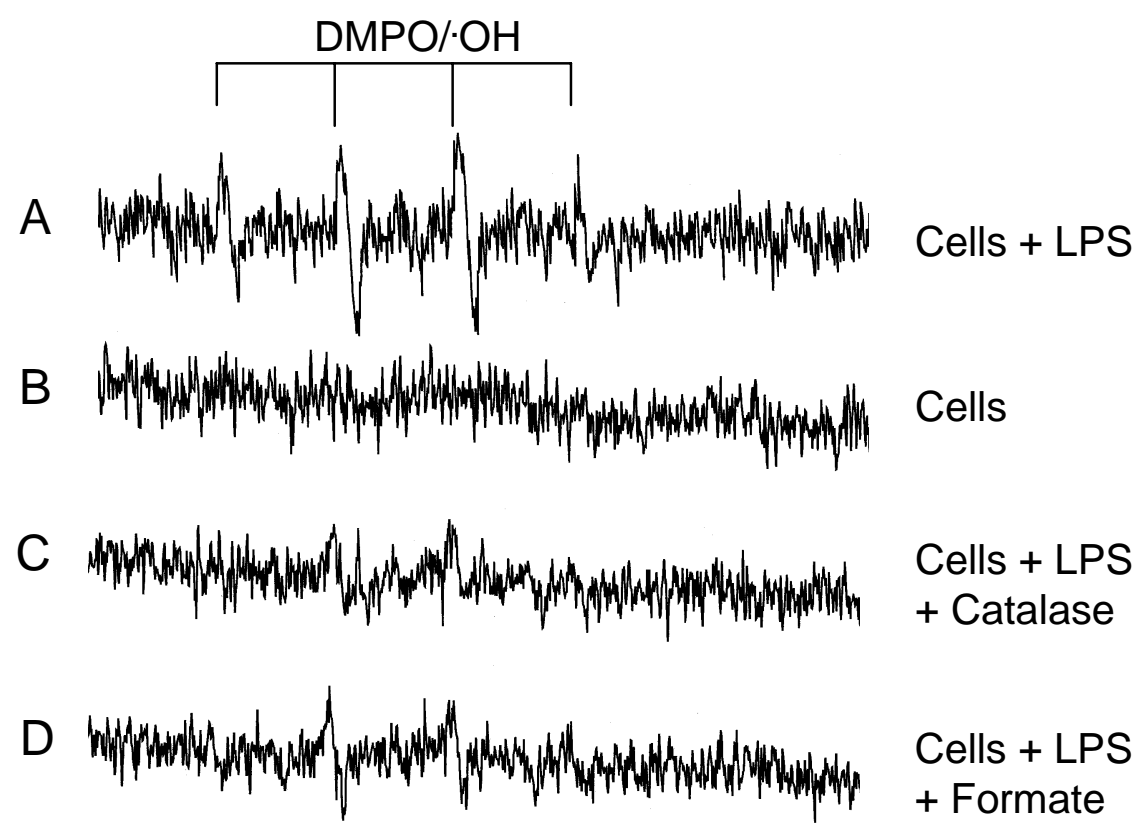

Fig. 6. ESR Measurements of LPS-Induced ROS Generation. A: ESR spectrum recorded $1 \mathrm{~h}$ after an addition of LPS $(10 \mu \mathrm{g} / \mathrm{ml})$ to macrophage RAW 264.7 cells $\left(1 \times 10^{6} / \mathrm{ml}\right)$ in the presence of spin trapper DMPO $(100 \mathrm{mM})$. $B$ : same as $A$ but with no LPS treatment. $C$ : same as $A$ but with catalase $(100 \mathrm{u} / \mathrm{ml})$ added. $D$ : same as $A$ but with sodium formate (5 $\mathrm{mM}$ ) added. The spectrometer settings were as follows: receiver gain, $1.5 \times 10^{5}$; time constants $0.3 \mathrm{sec}$; modulation amplitude, $1.0 \mathrm{G}$; scan time, $4 \mathrm{~min}$; magnetic field, $3470 \pm 100$ G. 


\section{III.7. REFERENCES}

Burkholder, J.K., Decker, J., and Yang, N.S. (1993) Rapid transgene expression in lymphocyte and macrophage primary cultures after particle bombardment-mediated gene transfer. J Immunol Meth 165, 149-156.

Cotten, M., Baker, A., Saltik, M., Wagner, E., and Buschle, M. (1994) Lipopolysaccharide is a frequent contaminant of plasmid DNA preparations and can be toxic to primary human cells in the presence of adenovirus. Gene Ther 1, 239-246.

Daumler, R. and Zimmermann, U. (1989) High yields of stable transformants by hypoosmolar plasmid electroinjection. J Immunol Meth 122, 203-210.

Drath, D.B. and Karnovsky, M.L. (1975) Superoxide production by phagocytic leukocytes. J Exp Med 141, 257-262.

Gee, J.B., Vassallo, C.L., Bell, P., Kaskin, J., Basford, R.E., and Field, J.B. (1970) Catalasedependent peroxidative metabolism in the alveolar macrophage during phagocytosis. J Clin Invest 49, 1280-1287.

Gossart, S., Cambon, C., Orfila, C., Seguelas, M.H., Lepert, J.C., Rami, J., Carre, P., and Pipy, B. (1996) Reactive oxygen intermediates as regulators of TNF-alpha production in rat lung inflammation induced by silica. J Immunol 156, 1540-1548.

Guthrie, L.A., McPhail, L.C., Henson, P.M., and Johnston, R.B.J. (1984) Priming of neutrophils for enhanced release of oxygen metabolites by bacterial lipopolysaccharide. Evidence for increased activity of the superoxide-producing enzyme. J Exp Med 160, 1656-1671.

Lewis, C.E. and McGee, J.O.D. (1992) The Macrophages. IRL Press, New York.

Mack, K.D., Wei, R., Elbagarri, A., Abbey, N., and McGrath, M.S. (1998) A novel method for DEAE-dextran mediated transfection of adherent primary cultured human macrophages. J Immunol Meth 211, 79-86.

Meyer, M., Pahl, H.L., and Baeuerle, P.A. (1994) Regulation of the transcription factors NFkappa B and AP-1 by redox changes. Chem Biol Interact 91, 91-100. 
Morrison, D.C. and Jacobs, D.M. (1976) Binding of polymyxin B to the lipid A portion of bacterial lipopolysaccharides. Immunochem 13, 813-818.

Morrison, D.C. and Ryan, J.L. (1987) Endotoxins and disease mechanisms. Annu Rev Med 38, 417-432.

Oberly, L.W. (1984) Superoxide Dismutase. CRC Press, Boca Raton. 63-81.

Raetz, C.R. (1990) Biochemistry of endotoxins. Annu Rev Biochem 59, 129-170.

Remacle, J., Raes, M., Toussaint, O., Renard, P., and Rao, G. (1995) Low levels of reactive oxygen species as modulators of cell function. Mutat Res 316, 103-122.

Rojanasakul, Y., Wang, L., Hoffman, A.H., Shi, X., Dalal, N.S., Banks, D.E., and Ma, J.H.K. (1993) Mechanisms of hydroxyl free radical-induced cellular injury and calcium overloading in alveolar macrophages. Am J Respir Cell Mol Biol 8, 377-383.

Rupprecht, A.P. and Coleman, D.L. (1991) Transfection of adherent murine peritoneal macrophages with a reporter gene using DEAE-dextran. J Immunol Meth 144, 157163.

Storm, D.R., Rosenthal, K.S., and Swanson, P.E. (1977) Polymyxin and related peptide antibiotics. Annu Rev Biochem 46, 723-763.

Weber, M., Moller, K., Welzeck, M., and Schorr, J. 1995) Short technical reports. Effects of lipopolysaccharide on transfection efficiency in eukaryotic cells. Biotechniques 19, 930-940.

Wright, S.D. (1991) Multiple receptors for endotoxin. Curr Opin Immuno/ 3, 83-90. 


\section{SECTION IV}

Mechanism of Interleukin-10-Mediated Inhibition of Nuclear Factor kB Activation in Macrophages 


\section{IV.1. ABSTRACT}

Interleukin-10 (IL-10) is a pleiotropic cytokine that controls inflammatory processes by suppressing the production of proinflammatory cytokines which are known to be transcriptionally regulated by nuclear factor $\kappa B(N F-\kappa B)$. Although still controversial, IL-10 has been shown to inhibit NF-kB activation through a process that involves proteolytic degradation of inhibitory subunit $1 \kappa B \alpha$. What is not known however is the mechanism by which IL-10 exerts its effect on I $\mathrm{KB} \alpha$ degradation. The present study investigates the possible role of reactive oxygen species (ROS) and their inhibition by IL-10 in NF-kB activation and $1 \kappa \mathrm{B} \alpha$ degradation in macrophages. Treatment of the cells with lipopolysaccharide (LPS) caused activation of $\mathrm{NF}-\kappa \mathrm{B}$ and rapid proteolysis of $\mathrm{I} \kappa \mathrm{B} \alpha$, as determined by the electrophoretic mobility shift assay (EMSA), gene transfection and Western blot. IL-10 pretreatment inhibited both NF- $\kappa B$ activation and $1 \kappa B \alpha$ degradation. Both these processes were also inhibited by ROS scavengers, catalase $\left(\mathrm{H}_{2} \mathrm{O}_{2}\right.$ scavenger) and sodium formate ( $\mathrm{OH}$ scavenger), but were minimally affected by superoxide dismutase (SOD) $\left(\mathrm{O}_{2}^{-}\right.$scavenger). These results suggests that $\mathrm{OH}$ radicals, formed by $a \mathrm{H}_{2} \mathrm{O}_{2}-$ dependent, metal-catalyzed Fenton reaction, play a major role in this process. Electron spin resonance (ESR) studies confirmed the formation of $\mathrm{OH}$ radicals in LPS-treated cells. Addition of IL-10 inhibited both $\mathrm{I} \kappa \mathrm{B} \alpha$ degradation and generation of $\mathrm{OH}$ radicals in response to LPS stimulation. These results demonstrate, for the first time, direct evidence for the role of IL-10 in ROS-dependent NF- $\mathrm{KB}$ activation. 


\section{IV.2. INTRODUCTION}

Advances in molecular and cellular biology have identified the cellular mediators that regulate many disease processes. One such mediator, IL-10, has been identified as an important regulator of the immune and inflammatory systems (Moore et al., 1993; de Vries, 1995). IL-10 is an anti-inflammatory cytokine that is regularly produced during inflammatory processes in vivo, usually by the same cells that release inflammatory mediators (e.g., monocytes, macrophages, T cells). It inhibits the production of inflammatory cytokines such as IL-1, IL-6, and tumor necrosis factor (TNF $\alpha$ ) by macrophages stimulated with LPS and interferon (Fiorentino et al., 1991).

In animal models of sepsis, IL-10, given before or soon after Gram-negative bacterial endotoxin has reduced TNF $\alpha$ production, hypothermia, and death (Howard et al., 1993). It was found that mice are more sensitive to LPS-induced shock by treatment with anti-IL-10 antibodies (Ishida et al., 1994). It was also found that IL-10 deficient mice developed severe enterocolitis and that IL-10 is an essential immunoregulator in the intestinal tract (Kuhn et al., 1993). Because of its potent anti-inflammatory effects, IL-10 has been implicated in a number of inflammatory conditions such as sepsis, chronic arthritis, and inflammatory bowel disease.

$\mathrm{NF}-\mathrm{KB}$ is a transcription factor that regulates gene transcription of many of the proinflammatory cytokines that are suppressed by IL-10 (Baldwin, 1996). NF-kB is a ubiquitous transcription factor that plays a central role in regulating gene expression of a number of proinflammatory cytokines that are released as a consequence of macrophage activation [reviewed in (Baeuerle and Henkel, 1994)]. Thus, suppression of NF-KB activity is potentially a mechanism for regulating inflammatory responses. NF- $\mathrm{kB}$ is most frequently composed of two DNA-binding subunits, p50 and p65 (Baeuerle and Henkel, 1994) and is present cytoplasmically in an inactive form in resting cells. The nuclear translocation and DNA binding of NF-KB dimers is tightly controlled by accessory proteins called IKB subunits (Baldwin, 1996). NF-kB is activated by a diverse range of stimulants including LPS, UV light, $\mathrm{H}_{2} \mathrm{O}_{2}$, and inflammatory cytokines such as IL-1 and TNF $\alpha$ (Baldwin, 1996; Baeuerle, 1995). When cells are treated with NF-kB inducers, rapid proteolysis of $I \kappa B \alpha$ proteins occurs and NF-kB dimers dissociate from the NF-kB//kB complex (Henkel et al., 1993; Whiteside and Israel, 1997). NF-kB inducers cause rapid phosphorylation of $I \kappa B \alpha$ on two 
serine residues (Brown et al., 1995; Traenckner et al., 1995) after which it is ubiquitinated and finally degraded by the proteosomes (Chen et al., 1995). Recently, the I $\mathrm{kB} \alpha$ kinases (IKK) responsible for the phosphorylation have been identified (Stancovski and Baltimore, 1997). The release of $I K B \alpha$ exposes the nuclear localization sequence of NF- $\mathrm{KB}$, and as a result, NF-kB dimers rapidly appear in the nucleus where they bind DNA (Baeuerle and Henkel, 1994). A number of genes contain NF-kB binding sites that might control their inducible expression (Lenardo et al., 1989). Thus, certain genes regulated by NF-kB can be transcriptionally activated within minutes after being exposed to the inducer.

The overall objective of this study is to investigate the effect of IL-10 on NF-kB activation in macrophages and to elucidate the molecular mechanism involved in this process. Macrophages play an important role in host defense against noxious substances and are involved in a variety of disease processes including autoimmune diseases, infections and inflammatory disorders (Pierce, 1990). While the role of IL-10 as an antiinflammatory molecule has been well established (Moore et al., 1993), the mechanism by which it exerts its action is still not completely understood and the experimental results are controversial. While most studies have shown that IL-10 inhibits NF-kB activation (Romano et al., 1996; Wang et al., 1995), there are others that report quite the opposite (Dokter et al., 1996; Takeshita et al., 1996). Similarly, the data on the effect of IL-10 on IKB $\alpha$ degradation are contradictory (Clarke et al., 1998; Schottelius et al., 1999). These differences can be reasonably explained by the fact that IL-10 has a great diversity of action and the effect of IL-10 on each cell is dependent on many factors, not all of which are understood.

Because macrophages are known to generate ROS in response to stimuli and because ROS have been implicated as the common messenger involved in NF-kB activation by diverse stimuli (Bonizzi et al., 2000; Bowie and O'Neill, 2000), we hypothesized that IL-10 may exert its effect on NF-KB activation by changing the redox status of stimulated cells through an ROS-dependent pathway. The specific questions being addressed in this study are: 1) Do ROS play a role in IL-10-mediated NF-KB signaling pathway? 2) What are the effects of IL-10 on NF-kB activation and I $\mathrm{KB} \alpha$ degradation in macrophages? 3) What are the key reactive species involved in the process? This is the first study that directly demonstrates the inhibitory effect of IL-10 on ROS production. 


\section{IV.3. MATERIALS AND METHODS}

\section{Cell Culture}

The macrophage cell line RAW 264.7 was obtained from the American Type Cell Culture Collection (Rockville, MD). The cells were grown in DMEM (GIBCO BRL Life Technologies) supplemented with 10\% fetal bovine serum (FBS), 2 mM L-glutamine, and $100 \mathrm{U} / \mathrm{ml}$ penicillin-streptomycin. They were maintained at $37^{\circ} \mathrm{C}$ in a humidified atmosphere containing $5 \% \mathrm{CO}_{2}$. Prior to use, cells were briefly trypsinized or mechanically scraped and centrifuged. They were plated at $\sim 1 \times 10^{6} \mathrm{cells} / \mathrm{ml}$ in 12-well tissue culture plates one day before transfection studies.

\section{Liposomal Transfection}

Approximately $1 \times 10^{6}$ cells were plated on a 12-well plate and allowed to grow for 24 hours before the transfection. The plasmid DNA NF- $\kappa B$ luciferase $(1 \mu \mathrm{g} / \mathrm{ml})$ was diluted in $200 \mu \mathrm{l}$ of DMEM and the DNA condensing agent protamine sulfate $(1 \mu \mathrm{g} / \mathrm{ml})$ (Sigma, St. Louis, MO) was added to the DNA. The liposome (LipofectAMINE, GIBCO BRL Life Technologies) $(12 \mu \mathrm{g} / \mathrm{ml})$ was diluted in $200 \mu \mathrm{l}$ of DMEM. The diluted DNA and liposome samples were combined and incubated at room temperature for 15-20 min. Cells with transfection reagents were incubated for 4 hours. Transfection medium was then replaced with growth medium containing $10 \%$ FBS. Thirty six hours after transfection the cells were stimulated with LPS either in the presence or absence of other test agents. Twelve hours after stimulation, luciferase activity was measured as described below. To account for the potential cytotoxic effect caused by the transfecting agent, LPS, or other test agents during the experiments, total cell protein was determined and used to normalize the measured luciferase activity. All transfections were conducted under sterile conditions and duplicate plates were tested for each condition.

\section{Stable Transfection}

Cells were transfected with $1 \mu \mathrm{g}$ of both CMV-mIL-10 (a kind gift from Dr. Tahara, University of Pittsburgh) and $\mathrm{pCDNA}_{3}$ using the protocol above for transient transfection. Two days after transfection, the medium was replaced with fresh complete medium containing $20 \mu \mathrm{l}$ of $75 \mu \mathrm{g} / \mathrm{ml} \mathrm{G} 418$ solution. Every two days the medium was changed and 
fresh G418 was added and this was cultured for 2 weeks. Survived colonies were picked and tested for their ability to produce IL-10 as determined by ELISA. To ensure a homogenous population of cells, positive colonies were subcloned and rescreened. Control cell line (RAW-control) was prepared the same way except that a control CMV plasmid lacking IL-10 was used.

\section{Measurement of Luciferase Activity}

Luciferase synthesized during the in vitro translation was quantitated by the assay of enzyme-dependent light production using a luciferase assay kit (Promega, Madison, WI). Cells were washed twice with PBS and incubated at room temperature for $10 \mathrm{~min}$ in the presence of $250 \mu \mathrm{l}$ of lysis buffer (Promega) and then centrifuged at $12000 \mathrm{~g}$. Ten microliters of each sample was placed in a 5-ml polystyrene test tube and the tubes were then loaded into an automated luminometer (BioRad, Hercules, CA). At the time of measurement, $100 \mu \mathrm{l}$ of luciferase substrate was automatically injected into each sample, and total luminescence was measured over a $20-\mathrm{sec}$ time interval. Output is quantitated as relative light units $(R L U)$. Protein content in the supernatant was determined by BCA protein assay reagent (Pierce, Rockford, IL). Luminescence detected was standardized per $\mu \mathrm{g}$ protein present in the supernatant.

\section{Determination of TNF $\alpha$ Protein}

In experiments where inhibition of TNF $\alpha$ produced by LPS stimulation had to be studied, cells were stimulated with the indicated amount of LPS for $6 \mathrm{~h}$ at $37^{\circ} \mathrm{C}$. Cell-free supernatants were then collected and assayed for cytokines by enzyme-linked immunosorbent assay (ELISA) kits specific for murine TNF $\alpha$ and protein levels were measured as specified by the manufacturer (Endogen). The sensitivity of the assays ranged from 15 to $31 \mathrm{pg} / \mathrm{ml}$. The coefficient of variation for all cytokine assays was $<10 \%$.

\section{Oligonucleotides}

Oligonucleotides (ON) were purchased from GIBCO BRL Life Technologies. The synthesized single-stranded $\mathrm{ON}$ were deprotected and desalted, and complementary strands were denatured at $80^{\circ} \mathrm{C}$ for $5 \mathrm{~min}$ and annealed at room temperature. The doublestranded ON were labeled with $\left({ }^{32} \mathrm{P}\right)$ dCTP (Amersham, Arlington Heights, IL) by using 
Klenow fragment (Bethesda Research Laboratories, Gaithersburg, MD), and the labeled ON were used as probes in the electrophoretic mobility shift assay (EMSA). The ON used in this study contained the NF-kB sequence of IL-6 gene promoter (74TGGGATTTTCCCATGAGTCT-54).

\section{Nuclear Extraction}

Nuclear extracts were prepared as follows; $5 \times 10^{7}$ cells were treated with $500 \mu$ lysis buffer ( $50 \mathrm{mM} \mathrm{KCl}, 0.5 \%$ Nonidet P-40, 25 mM HEPES, $1 \mathrm{mM}$ phenylmethylsulfonyl fluoride, $10 \mu \mathrm{g} / \mathrm{ml}$ leupeptin, $20 \mu \mathrm{g} / \mathrm{ml}$ aprotinin, $100 \mu \mathrm{M}$ dithiothreitol) and kept on ice for $4 \mathrm{~min}$. Nuclei were pelleted by centrifugation at 20,000 RCF for $1 \mathrm{~min}$ and supernatants were discarded. The nuclei were washed once with the same buffer without Nonidet P-40 and the nuclei were extracted in $300 \mu$ lextraction buffer $(500 \mathrm{mM} \mathrm{KCl}, 10 \%$ glycerol, $25 \mathrm{mM}$ HEPES, $1 \mathrm{mM}$ PMSF, $10 \mu \mathrm{g} / \mathrm{ml}$ leupeptin, $20 \mu \mathrm{g} / \mathrm{ml}$ aprotinin, $100 \mu \mathrm{M} \mathrm{DTT})$. After centrifugation at 20,000 RCF for $5 \mathrm{~min}$, the supernatants were harvested. The protein concentration of the resulting nuclear protein extract were determined by BCA protein assay reagent (Pierce, Rockford, IL) and the samples were diluted to $1 \mu \mathrm{g} / \mu \mathrm{l}$ with extraction buffer. The nuclear proteins were stored at $-70^{\circ} \mathrm{C}$.

\section{Electrophoretic Mobility Shift Assay}

The DNA-protein binding reaction was conducted in a $24-\mu$ l reaction mixture including $3 \mu \mathrm{g}$ nuclear protein extract, $1 \mu \mathrm{g}$ poly dl.dC (Sigma), $3 \mu \mathrm{g} \mathrm{BSA}$, and $12 \mu \mathrm{l}$ of $2 \mathrm{xY}$ buffer. The mixture was incubated on ice for $10 \mathrm{~min}$. A total of $10^{5} \mathrm{cpm}$ of ${ }^{32} \mathrm{P}$-labeled oligonucleotide probe was added, and the mixture was incubated for an additional $20 \mathrm{~min}$ at room temperature and then loaded on a $5 \%$ acrylamide gel (GIBCO BRL) that had been prerun at $110 \mathrm{~V}$ for $30 \mathrm{~min}$ with $0.5 \mathrm{x}$ Tris-borate-EDTA buffer. The loaded gel was run at $200 \mathrm{~V}$ for $90 \mathrm{~min}$, then dried, and exposed to X-OMAT film overnight (Eastman Kodak, Rochester, NY) for autoradiography. The film was developed after overnight exposure at $70^{\circ} \mathrm{C}$.

\section{Western Blots}

For intracellular $\mathrm{I} \mathrm{kB} \alpha$ degradation studies, whole-cell proteins were extracted. Whole cell extracts were subjected to $12 \%$ SDS-polyacrylamide gel electrophoresis (SDS- 
PAGE). Resolved proteins were transferred to a nitrocellulose membrane and incubated with affinity-purified rabbit polyclonal anti- $\kappa \mathrm{KB} \alpha$ serum raised against a peptide corresponding to amino acids 297-317 (mapping within the carboxyl-terminal domain of human $1 \kappa B \alpha$ molecule). After three 10-min washes with PBS/Tween-20, the membranes were incubated with peroxidase-conjugated anti-rabbit immunoglobulin, and the antigenantibody complexes were detected using ECL Western blotting detection reagents according to the manufacturer's instructions.

\section{Free Radical Measurements}

The ESR spin trapping technique was used to detect short-lived free radical intermediates (Wang et al., 1999). All measurements were conducted with a Varian E9 ESR spectrometer and a flat cell assembly. Hyperfine splittings were measured (to $0.1 \mathrm{G}$ ) directly from magnetic field separations using potassium tetraperoxochromate $\left(\mathrm{K}_{3} \mathrm{CrO}_{8}\right)$ and 1,1diphenyl-2-picrylhydrazyl (DPPH) as standards. Reactants were mixed in test tubes in a total volume of $0.5 \mathrm{ml}$. The reaction mixture was then transferred to a flat cell for ESR measurement. All measurements were carried out using 5,5-dimethyl-1-pyrroline- $N$-oxide (DMPO)(Aldrich) as a spin trap. 


\section{IV.4. RESULTS}

\section{Inhibition of LPS-Induced TNF $\alpha$ Production by IL-10}

It has been suggested that the nuclear factor NF- $\mathrm{KB}$ mediates the transcriptional activation of TNF $\alpha$ (Baeuerle and Henkel, 1994). We tested whether IL-10 could inhibit NFאB-dependent TNF $\alpha$ expression. RAW 264.7 macrophages were stimulated with LPS (10 $\mathrm{ng} / \mathrm{ml}$ ) for $6 \mathrm{~h}$ and cell culture supernatants were then assayed by ELISA for TNF $\alpha$ released. Stimulation of cells with LPS resulted in the release of high concentrations of TNF $\alpha$. Pretreatment of cells with recombinant mouse IL-10 ( $\mathrm{rmlL}-10)(1-50 \mathrm{ng} / \mathrm{ml}) 2 \mathrm{~h}$ prior to stimulation with LPS $(10 \mathrm{ng} / \mathrm{ml})$ resulted in a dose-dependent inhibition (50-72\%) in TNF $\alpha$ production (Fig. 1A). We also tested the inhibitory effect of IL-10 on TNF $\alpha$ production in a stably transfected cell line (RAW IL-10) that constitutively expresses IL-10 protein. Stimulation of RAW IL-10 with LPS showed much lower levels of TNF $\alpha$ compared to the regular (RAW 264.7) or control cell line (RAW-control) (Fig. 1B).

\section{Effect of IL-10 on NF-אB Binding Activity and IאB $\alpha$ Degradation}

EMSA studies were performed on stably transfected cells to study the effect of IL-10

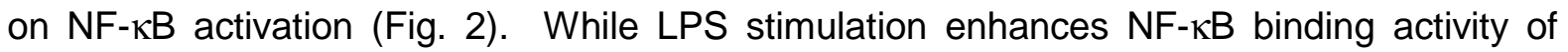
RAW 264.7 and RAW-control cells, this LPS-induced NF- $\kappa B$ activity was inhibited in RAW IL-10 cell line. This suggests that IL-10 is responsible for NF- $\kappa B$ inhibition.

To determine if IL-10 inhibited the transcriptional activation of NF- $\mathrm{kB}$, RAW 264.7 cells were transiently transfected with an expression plasmid containing luciferase gene transcribed from the NF-kB dependent promoter. The transfected cells were treated with LPS in the presence or absence of IL-10. Fig. 3A shows that LPS treatment caused a 10fold increase in luciferase activity, which was inhibited by IL-10 in a dose-dependent manner. This data suggests that IL-10 not only prevents NF-KB-DNA binding but also inhibits NF-KB induced transcription and hence, gene expression.

Since the activity of $\mathrm{NF}-\kappa \mathrm{B}$ is controlled by its interaction with $I \kappa \mathrm{B} \alpha$, the next logical step would be to test if IL-10 inhibits NF- $\mathrm{KB}$ activation via its effect on $\mathrm{I} \kappa \mathrm{B} \alpha$ degradation. To 
determine if the decreased DNA binding activity of NF-KB is due to inhibition of $1 \kappa B \alpha$ proteolysis, we performed Western blot analysis on either RAW-control or RAW-IL-10 cells stimulated with LPS (Fig. 3B). Cell lysates were collected and immunoblotting for $1 \kappa B \alpha$ was performed. In the control cell line, LPS stimulation caused complete proteolysis of $I \kappa B \alpha$ by 30 min. RAW-control cells behave very similarly to regular RAW 264.7 cells. This degradation of $\mathrm{I}_{\mathrm{K} B} \alpha$ is not seen in LPS-stimulated RAW-IL10 cells. These results suggest that IL-10 inhibits IK-B $\alpha$ degradation.

\section{Role of Reactive Oxygen Species in LPS-Stimulated Macrophages}

The role of free radical reactions in LPS-induced NF-KB activation was examined using specific ROS inhibitors, including $\operatorname{SOD}\left(\mathrm{O}_{2}{ }^{-}\right.$scavenger $)$, catalase $\left(\mathrm{H}_{2} \mathrm{O}_{2}\right.$ scavenger), and sodium formate ( $\mathrm{OH}$ scavenger). Macrophages are known to generate free radicals in response to stimuli. $\mathrm{O}_{2}-\mathrm{H}_{2} \mathrm{O}_{2}$, and $\mathrm{OH}$ are three major reactive species produced by macrophages (Drath and Karnovsky, 1975; Gee et al., 1970) and thus are the primary focus of our investigation. As shown in Fig. 4A, cells treated with catalase and sodium formate prior to LPS stimulation exhibited a decrease in NF-KB activity, while SOD pretreatment had no effect on LPS-induced NF-kB activity. It should be noted that all three scavengers were tested at different concentrations, however only optimal concentrations of each scavenger are presented here.

Western blots were employed to determine if these ROS scavengers inhibited NF- $\mathrm{KB}$ activation due to the stabilization of $I \kappa B \alpha$. RAW 264.7 cells were treated with the same specific ROS scavengers SOD, catalase, and sodium formate before stimulation with LPS. Consistent with the results above, addition of catalase and sodium formate inhibited LPSinduced IKB $\alpha$ degradation, while SOD was not effective (Fig. 4B). It must be noted that pretreatment of cells with IL-10 also inhibited IאB $\alpha$ degradation (Fig. 4B).

The results obtained above suggest that ROS are involved in the process and that $\mathrm{H}_{2} \mathrm{O}_{2}$ and $\mathrm{OH}$ play a major role. Since $\mathrm{H}_{2} \mathrm{O}_{2}$ has been reported to be a major source of $\mathrm{OH}$ formation in macrophages, i.e., via metal-catalyzed Fenton reaction $\left[\mathrm{M}^{\mathrm{n+}}+\mathrm{H}_{2} \mathrm{O}_{2} \rightarrow \mathrm{M}^{(\mathrm{n}+1)+}+\right.$ $\mathrm{OH}^{-}+\mathrm{OH}$, and since $\mathrm{OH}$ is known to be highly reactive, we suggest that $\mathrm{OH}$ may be the primary oxidative species responsible for the observed effects induced by LPS. Supporting 
this notion is the fact that sodium formate was equally effective as catalase in inhibiting NF$\kappa \mathrm{B}$ activity and $\mathrm{I} \kappa \mathrm{B} \alpha$ degradation.

\section{Effect of IL-10 on Hydroxyl Radical Generation}

Our results suggest that $\mathrm{OH}$ radical may be the key species involved in NF-kB activation. To confirm that $\mathrm{OH}$ radicals were actually formed during LPS activation, ESR studies using the spin trap DMPO were carried out. ESR spin trapping is a method that is specific and sensitive and is considered to be the best technique for detection and identification of free radical generation (Wang et al., 1999). Cells were treated with LPS in the presence or absence of IL-10 and ROS scavengers. Fig. 5 shows that in the presence of LPS, an ESR spectrum consisting of a 1:2:2:1 quartet pattern, which is characteristic of DMPO-OH adduct (Buettner, 1984), was observed. LPS-induced adduct formation increased with time and reached a peak in an hour. Pretreatment of cells with IL-10 inhibited LPS induced free radical generation (Fig. 5). Addition of the $\mathrm{OH}$ scavenger sodium formate to the system decreased the intensity of the DMPO-OH signal, thus confirming the formation of $\mathrm{OH}$ induced by LPS. Interestingly, catalase whose function is to scavenge $\mathrm{H}_{2} \mathrm{O}_{2}$ also inhibited $\mathrm{OH}$ formation. These results are consistent with previous studies by our

group which demonstrated that $\mathrm{H}_{2} \mathrm{O}_{2}$ can react with endogenous metal ions to form $\mathrm{OH}$ via the Fenton reaction (Rojanasakul et al., 1993). It is interesting to note that when IL-10 was added to a chemical system (Fenton Reaction), it did not inhibit $\mathrm{OH}$ generation. These results suggest that $\mathrm{IL}-10$ is not a free radical scavenger. Instead, it interacts with the cellular machinery in such a way that free radical production is inhibited. 


\section{IV.5. DISCUSSION}

IL-10 is an anti-inflammatory cytokine that plays an important regulatory role in inflammatory diseases (Moore et al., 1993; de Vries, 1995). Studies with IL-10 knockout mice have shown that a key function of IL-10 is the control of inflammatory responses (Kuhn et al., 1993). In vitro and in vivo studies suggest that IL-10 could be a potentially useful therapeutic agent for the treatment of acute and chronic, systemic and localized inflammatory reactions.

Although numerous studies have been performed to identify the signaling pathways targeted to by IL-10, the mechanism is still not completely understood. We hypothesized that IL-10 mediates part of its inhibitory effects via its effect on ROS. Our studies show that IL-10 pretreatment inhibits TNF $\alpha$ production of stimulated macrophages due to its ability to

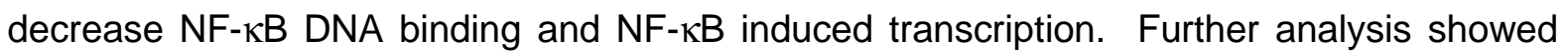
that IL-10 inhibits LPS-induced $I \kappa B \alpha$ degradation.

Macrophages provide an important line of host defense against noxious substances. One of the essential mechanisms by which this is accomplished is the production of reactive oxygen metabolites such as superoxide anion and hydrogen peroxide through the respiratory burst. Excessive production of these oxidative species, however, can also cause toxic reactions to the cell and potentiate several pathologic conditions. It has been suggested that the highly reactive hydroxyl radical $(\cdot \mathrm{OH})$ which is generated from $\mathrm{H}_{2} \mathrm{O}_{2}$ via the Fenton or Fenton-like reactions, is the major oxidant species that causes cellular injury (Rojanasakul et al., 1993). Hydroxyl radicals are known to induce lipid peroxidation which causes damage to the cell membrane.

NF- $\mathrm{KB}$ inducers produce ROS (Baeuerle and Henkel, 1994) and the observation that antioxidants and radical scavengers inhibit the activation of $\mathrm{NF}-\kappa \mathrm{B}$, strongly supports the idea that oxygen radicals are involved in the release of $I \kappa B \alpha$ from the NF- $\kappa B-I \kappa B$ complex. Recent studies have indicated that ROS can activate a number of cytokine genes including the TNF $\alpha$ gene. It has also been speculated that the protease activities involved with $I \kappa B \alpha$ are under the control of the cell's redox status (Baeuerle and Henkel, 1994). This speculation is strengthened by the observation that the antioxidant PDTC prevents inducible decay of $I_{\kappa} \mathrm{B} \alpha$ in response to PMA (Beg et al., 1993; Henkel et al., 1993; Sun et al., 1993). 
Oxygen free radicals are known to facilitate the progress of inflammatory reactions. Since NF-kB has been identified as an oxidative stress-responsive transcription factor that is activated by a diverse range of inducers, it has been postulated that ROS may be the common messenger involved in the signal transduction pathway leading to NF- $\mathrm{kB}$ activation (Baeuerle and Henkel, 1994). Our results show that ROS are involved in NF-kB activation and $\mathrm{I} \mathrm{KB} \alpha$ degradation. Specifically, $\mathrm{OH}$ seems to be the key player in ROS mediated I $\mathrm{KB} \alpha$ degradation. $\mathrm{OH}$ radicals in macrophages are generated via metal-catalyzed Fenton reaction $\left[\mathrm{M}^{\mathrm{n}+}+\mathrm{H}_{2} \mathrm{O}_{2}->\mathrm{M}^{(\mathrm{n}+1)+}+\mathrm{OH}^{-}+\mathrm{OH}\right]$ using $\mathrm{H}_{2} \mathrm{O}_{2}$ as the source (Rojanasakul et al., 1993). These results are consistent with those observed by Schreck et al. (1992). They observed that $\mathrm{H}_{2} \mathrm{O}_{2}$ on its own does not activate the purified NF-kB-IKB complex and therefore it appears that a metabolite of $\mathrm{H}_{2} \mathrm{O}_{2}$ caused the release of $\mathrm{I} \mathrm{B} \alpha$. This metabolite is probably the $\mathrm{OH}$ radical.

Since IL-10 inhibits IKB $\alpha$ degradation, we tested the effect of IL-10 on $\mathrm{OH}$ radical generation. IL-10 inhibits LPS-induced $\mathrm{OH}$ radical generation as demonstrated by ESR. The fact that IL-10 does not inhibit $\mathrm{OH}$ radicals in a chemical system suggests that IL-10 does not act as free radical scavenger. Instead it probably induces signals that interface with the cellular signals that generate ROS in response to LPS-stimulation. A recent study by Schottelius et al. (1999) has shown that IL-10 inhibits TNFo-induced activation of IKK which is responsible for phosphorylation and subsequent degradation of IкB $\alpha$. Bonizzi et al. (2000) have suggested that ROS generation may be required for cell-specific kinase activity. Based on our results and those reported earlier, we propose the following mechanism of action for IL-10. IL-10 inhibits ROS production which in turn inhibits IKK activity and hence, $\mid \kappa B \alpha$ degradation. This results in a decrease in NF- $\kappa B$ activity and hence, decreases the expression of inflammatory cytokines such as TNF $\alpha$. This whole cascade of events is responsible for the anti-inflammatory properties of IL-10 in macrophages.

In conclusion, IL-10 inactivates macrophage production of reactive oxygen radicals, thereby decreasing inflammation. The results in this study provide a new light into the action of IL-10. Finally, the mechanism of IL-10 in this cell type may not be reflective of its action in other cell types. As rightly discussed by Bowie et al. (2000), signal transduction pathways in different cell types need to be addressed individually. 


\section{6. FIGURES}

Figure 1
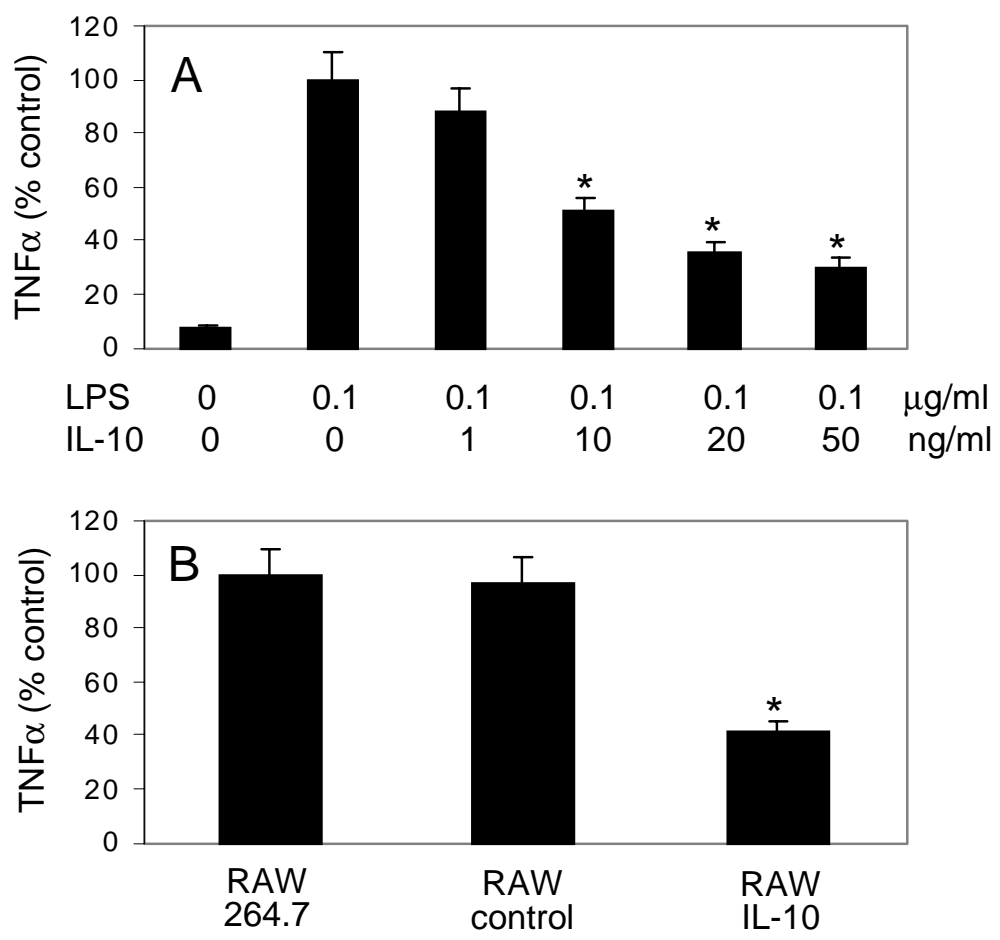

Fig. 1. Inhibition of TNF $\alpha$ Production by IL-10. (A) RAW 264.7 cells $\left(10^{6} / \mathrm{ml}\right)$ were pretreated with varying concentrations of rmlL-10 (1-50 $\mathrm{ng} / \mathrm{ml})$ for $2 \mathrm{~h}$ at $37^{\circ} \mathrm{C}$, after which they were treated with LPS $(0.1 \mu \mathrm{g} / \mathrm{ml})$ for $6 \mathrm{~h}$ at $37^{\circ} \mathrm{C}$. The supernatants were collected at the end of $6 \mathrm{~h}$ and assayed for TNF $\alpha$ by ELISA. (B) Two stable cell lines were generated. RAW IL-10 was stably transfected with IL-10-containing plasmid and RAW control was transfected with control plasmid. The cells $\left(10^{6} / \mathrm{ml}\right)$ were stimulated with LPS $(0.1 \mu \mathrm{g} / \mathrm{ml})$ for $6 \mathrm{~h}$ at $37^{\circ} \mathrm{C}$ after which the supernatants were collected and assayed for TNF $\alpha$ by ELISA. * indicates a significant decrease from LPS-treated control $(p<0.05)$. 
Figure 2

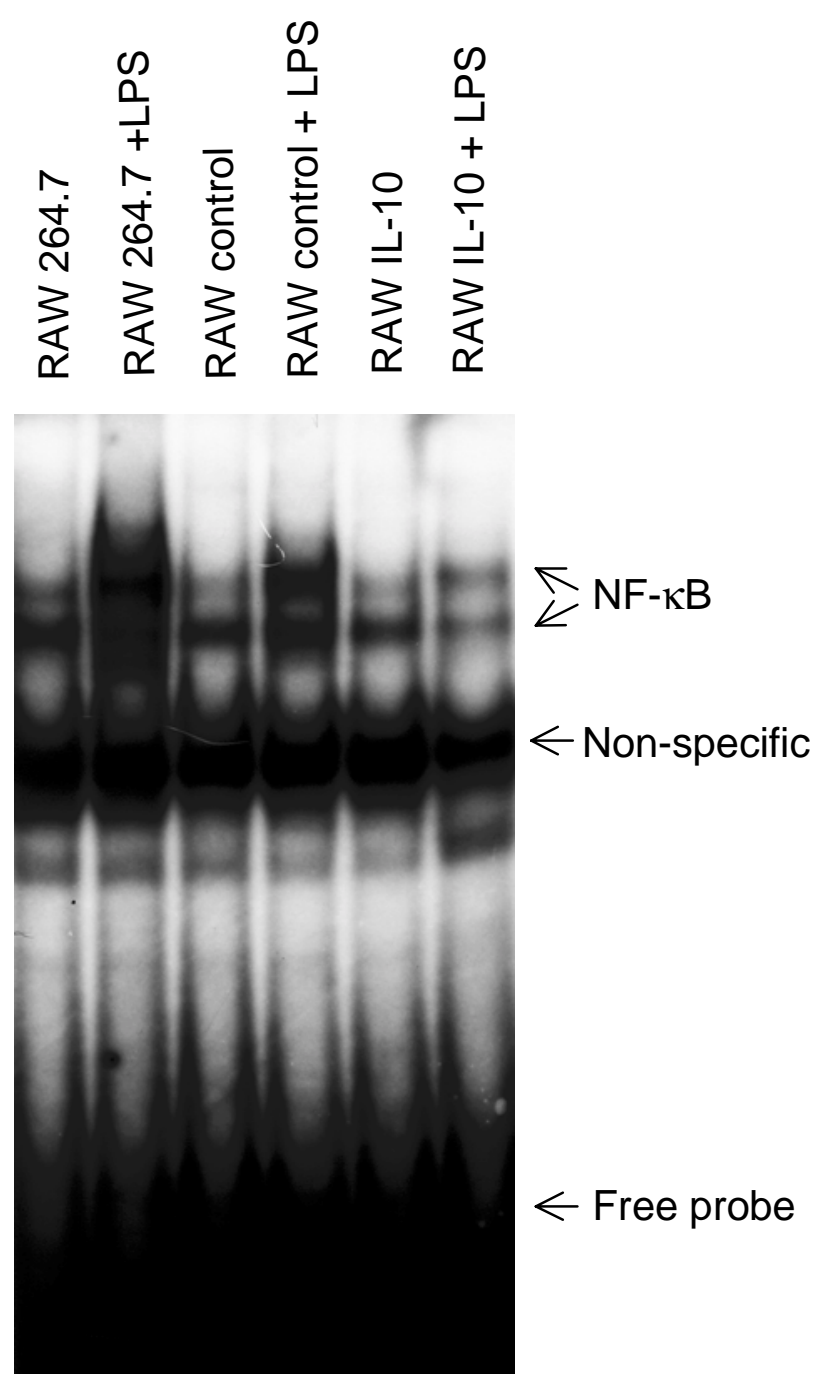

Fig. 2. EMSA Studies of NF-kB Binding Activity in LPS-Treated Macrophages. DNA binding activity of NF-kB was determined using the nuclear extract of macrophages treated with LPS $(0.1 \mu \mathrm{g} / \mathrm{ml})$ for $1 \mathrm{~h}$ at $37^{\circ} \mathrm{C}$. Lane 1: RAW 264.7 with no LPS, Lane 2: RAW 264.7 with LPS $(0.1 \mu \mathrm{g} / \mathrm{ml})$, Lane 3: RAW control with no LPS, Lane 4: RAW control with LPS $(0.1$ $\mu \mathrm{g} / \mathrm{ml})$, Lane 5: RAW IL-10 with no LPS, Lane 6: RAW IL-10 with LPS $(0.1 \mu \mathrm{g} / \mathrm{ml})$ 
Figure 3
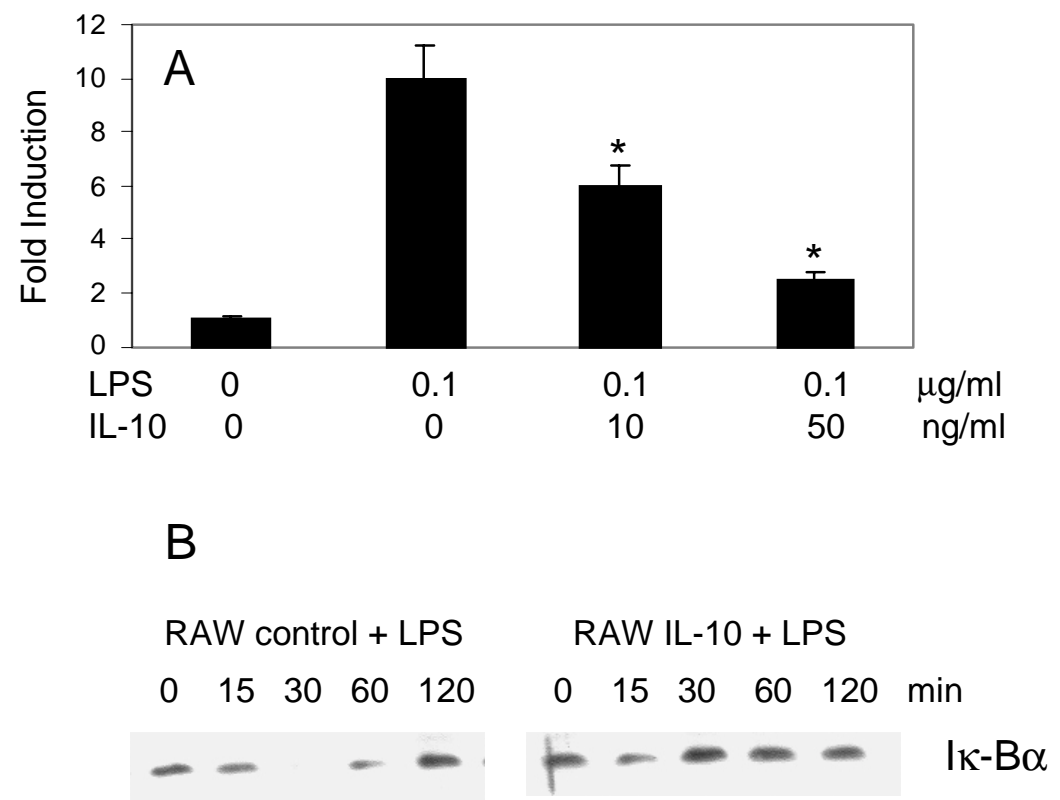

Fig. 3. Effect of IL-10 on NF-kB-Dependent Gene Expression and IkB $\alpha$ Degradation. (A) RAW 264.7 cells were transiently transfected with an expression plasmid containing luciferase gene transcribed from the NF-kB-dependent promoter. Thirty-six hours after transfection, the cells were pretreated with varying concentrations of IL-10 $(10-50 \mathrm{ng} / \mathrm{ml})$ before stimulation with LPS $(0.1 \mu \mathrm{g} / \mathrm{ml})$ for $12 \mathrm{~h}$ at $37^{\circ} \mathrm{C}$. Luciferase activity was then measured by luminescence. (B) Western blots were performed to determine effect of IL-10 on IKB $\alpha$. RAW control and RAW IL-10 cells $\left(10^{6} / \mathrm{ml}\right)$ were treated with LPS $(0.1 \mu \mathrm{g} / \mathrm{ml})$ for the different time points and $\mathrm{I} \mathrm{KB} \alpha$ protein was measured by Western blots. * indicates a significant decrease from LPS-treated control $(p<0.05)$. 
Figure 4
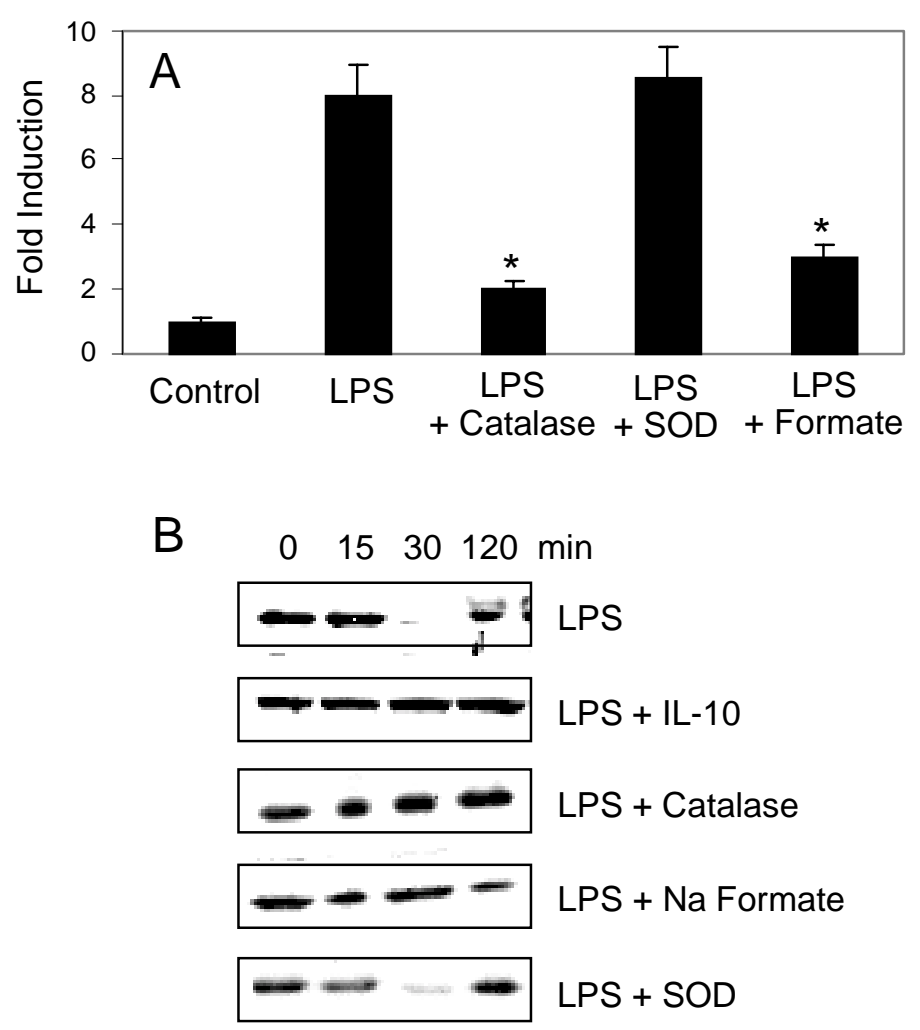

Fig. 4. Effect of Oxygen Radical Scavengers on NF-kB-Dependent Gene Expression and IKB $\alpha$ Degradation. (A) RAW 264.7 cells were transiently transfected with an expression plasmid containing luciferase gene transcribed from the NF-KB-dependent promoter. Thirty-six hours after transfection, the cells were pretreated with the different oxygen radical scavengers, SOD $(500 \mathrm{U} / \mathrm{ml})$, catalase $(500 \mathrm{U} / \mathrm{ml})$, and sodium formate $(5$ $\mathrm{mM})$ for $4 \mathrm{~h}$ before stimulation with LPS $(0.1 \mu \mathrm{g} / \mathrm{ml})$ for $12 \mathrm{~h}$ at $37^{\circ} \mathrm{C}$. Luciferase activity was then measured by luminescence. (B) Western blots were performed to determine the effect of ROS on IKB $\alpha$. RAW 264.7 cells $\left(10^{6} / \mathrm{ml}\right)$ were pretreated with the different ROS scavengers, SOD $(500 \mathrm{U} / \mathrm{ml})$, catalase $(500 \mathrm{U} / \mathrm{ml})$, and sodium formate $(5 \mathrm{mM})$ for $4 \mathrm{~h}$ before stimulation with LPS $(0.1 \mu \mathrm{g} / \mathrm{ml})$ for the different time points. ${ }^{*}$ indicates a significant decrease from LPS-treated control $(p<0.05)$. 


\section{Figure 5}
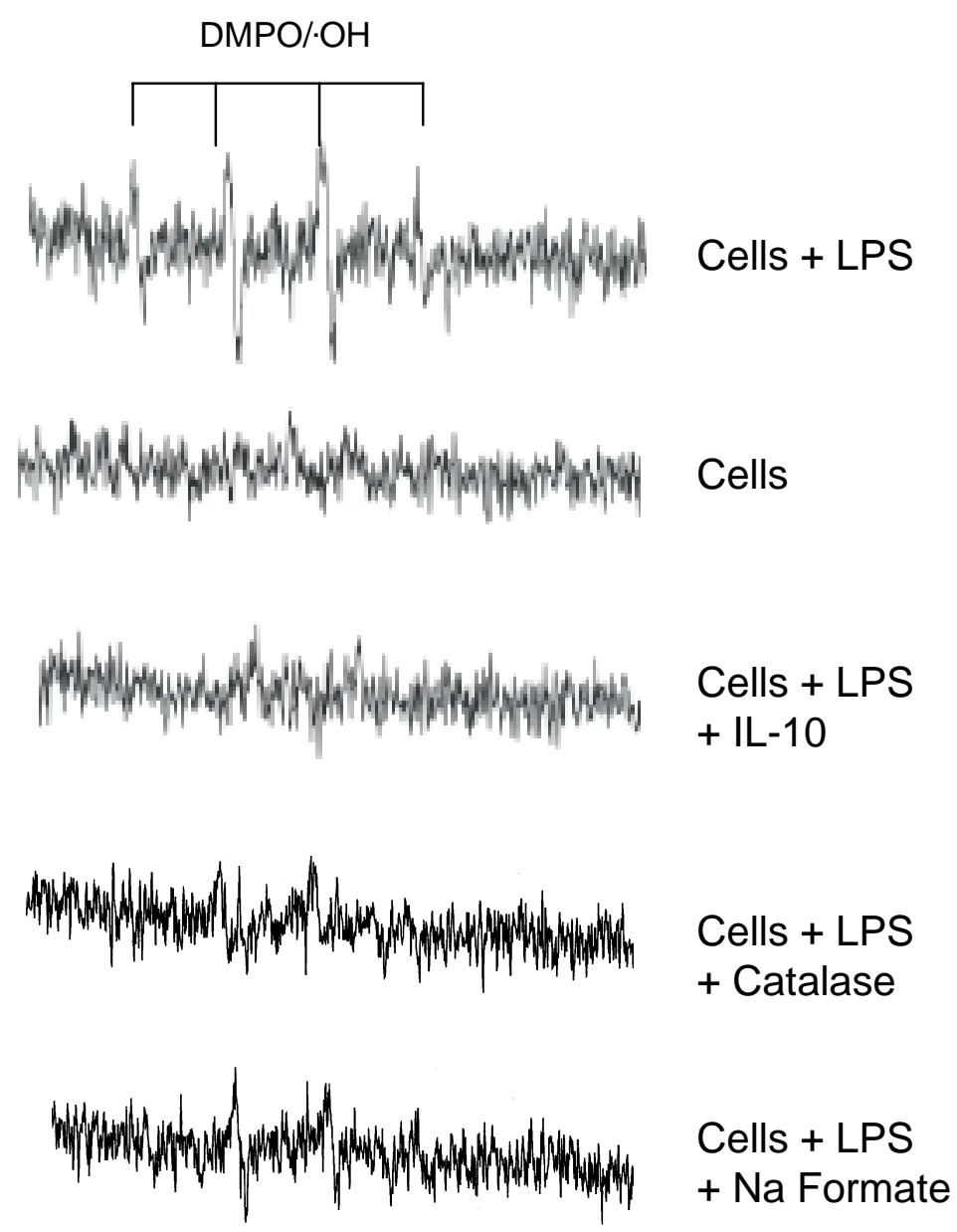

Fig. 5. ESR Measurements of LPS-Induced ROS Generation. (A) ESR spectrum recorded $1 \mathrm{~h}$ after an addition of LPS $(1 \mu \mathrm{g} / \mathrm{ml})$ to macrophage RAW 264.7 cells $\left(10^{6} / \mathrm{ml}\right)$ in the presence of spin trapper DMPO (100 mM). (B) same as (A) but with no LPS treatment. (C) same as (A) but with IL-10 $(0.1 \mu \mathrm{g} / \mathrm{ml})$ added. (D) same as (A) but with catalase (500 $\mathrm{U} / \mathrm{ml}$ ) added. (E) same as (A) but with sodium formate $(5 \mathrm{mM})$ added. The spectrometer settings were as follows: receiver gain, $1.5 \times 10^{5}$; time constants $0.3 \mathrm{sec}$; modulation amplitude, $1.0 \mathrm{G}$; scan time, $4 \mathrm{~min}$; magnetic field, $3470 \pm 100 \mathrm{G}$. 


\section{IV.7. REFERENCES}

Baeuerle, P.A. (1995) Transcriptional activators. Enter a polypeptide messenger. Nature 373, 661-662.

Baeuerle, P.A. and Henkel, T. (1994) Function and activation of NF-kappa B in the immune system. Annu Rev Immunol 12, 141-179.

Baldwin, A.S.J. (1996) The NF-kappa B and I kappa B proteins: new discoveries and insights. Annu Rev Immunol 14, 649-683.

Beg, A.A., Finco, T.S., Nantermet, P.V., and Baldwin, A.S.J. (1993) Tumor necrosis factor and interleukin-1 lead to phosphorylation and loss of I kappa B alpha: a mechanism for NF-kappa B activation. Mol Cell Biol 13, 3301-3310.

Bonizzi, G., Piette, J., Merville, M.P., and Bours, V. (2000) Cell type-specific role for reactive oxygen species in nuclear factor-kappaB activation by interleukin-1. Biochem Pharmacol 59, 7-11.

Bowie, A. and O'Neill, L.A. (2000) Oxidative stress and nuclear factor-kappaB activation: a reassessment of the evidence in the light of recent discoveries. Biochem Pharmacol 59, $13-23$.

Brown, K., Gerstberger, S., Carlson, L., Franzoso, G., and Siebenlist, U. (1995) Control of I kappa B-alpha proteolysis by site-specific, signal-induced phosphorylation. Science 267, 1485-1488.

Buettner, G.R. (1984) Superoxide Dismutase (Oberly, L.W., Ed.) CRC Press, Boca Raton. 63-81.

Chen, Z., Hagler, J., Palombella, V.J., Melandri, F., Scherer, D., Ballard, D., and Maniatis, T. (1995) Signal-induced site-specific phosphorylation targets I kappa B alpha to the ubiquitin-proteasome pathway. Genes Dev 9, 1586-1597.

Clarke, C.J., Hales, A., Hunt, A., and Foxwell, B.M. (1998) IL-10-mediated suppression of TNF-alpha production is independent of its ability to inhibit NF kappa B activity. Eur J Immunol 28, 1719-1726. 
de Vries, J.E. (1995) Immunosuppressive and anti-inflammatory properties of interleukin 10. Ann Med 27, 537-541.

Dokter, W.H.A., Koopmans, S.B., and Vellenga, E. (1996) Effects of IL-10 and IL-4 on LPSinduced transcription factors (AP-1, NF-IL6 and NF-kappa B) which are involved in IL-6 regulation. Leukemia 10, 1308-1316.

Drath, D.B. and Karnovsky, M.L. (1975) Superoxide production by phagocytic leukocytes. $J$ Exp Med 141, 257-262.

Fiorentino, D.F., Zlotnik, A., Mosmann, T.R., Howard, M., and O'Garra, A. (1991) IL-10 inhibits cytokine production by activated macrophages. J Immunol 147, 3815-3822.

Gee, J.B., Vassallo, C.L., Bell, P., Kaskin, J., Basford, R.E., and Field, J.B. (1970) Catalasedependent peroxidative metabolism in the alveolar macrophage during phagocytosis. J Clin Invest 49, 1280-1287.

Henkel, T., Machleidt, T., Alkalay, I., Kronke, M., Ben-Neriah, Y., and Baeuerle, P.A. (1993) Rapid proteolysis of I kappa B-alpha is necessary for activation of transcription factor NF-kappa B. Nature 365, 182-185.

Howard, M., Muchamuel, T., Andrade, S., and Menon, S. (1993) Interleukin 10 protects mice from lethal endotoxemia. J Exp Med 177, 1205-1208.

Ishida, H., Muchamuel, T., Sakaguchi, S., Andrade, S., Menon, S., and Howard, M. (1994) Continuous administration of anti-interleukin 10 antibodies delays onset of autoimmunity in NZB/W F1 mice. J Exp Med 179, 305-310.

Kuhn, R., Lohler, J., Rennick, D., Rajewsky, K., and Muller, W. (1993) Interleukin-10deficient mice develop chronic enterocolitis. Cell 75, 263-274.

Lenardo, M.J., Fan, C.M., Maniatis, T., and Baltimore, D. (1989) The involvement of NFkappa $B$ in beta-interferon gene regulation reveals its role as widely inducible mediator of signal transduction. Cell 57, 287-294.

Moore, K.W., O'Garra, A., de Waal, M., Vieira, P., and Mosmann, T.R. (1993) Interleukin-10. Annu Rev Immunol 11, 165-190. 
Pierce, G.F. (1990) Macrophages: important physiologic and pathologic sources of polypeptide growth factors. Am J Respir Cell Mol Biol 2, 233-234.

Rojanasakul, Y., Wang, L., Hoffman, A.H., Shi, X., Dalal, N.S., Banks, D.E., and Ma, J.H.K. (1993) Mechanisms of hydroxyl free radical-induced cellular injury and calcium overloading in alveolar macrophages. Am J Respir Cell Mol Biol 8, 377-383.

Romano, M.F., Lamberti, A., Petrella, A., Bisogni, R., Tassone, P.F., Formisano, S., Venuta, S., and Turco, M.C. (1996) IL-10 inhibits nuclear factor-kappa B/Rel nuclear activity in CD3- stimulated human peripheral T lymphocytes. J Immunol 156, 2119-2123.

Schottelius, A.J., Mayo, M.W., Sartor, R.B., and Baldwin, A.S.J. (1999) Interleukin-10 signaling blocks inhibitor of kappaB kinase activity and nuclear factor kappaB DNA binding. J Biol Chem 274, 31868-31874.

Schreck, R., Meier, B., Mannel, D.N., Droge, W., and Baeuerle, P.A. (1992) Dithiocarbamates as potent inhibitors of nuclear factor kappa $B$ activation in intact cells. J Exp Med 175, 1181-1194.

Stancovski, I. and Baltimore, D. (1997) NF-kappaB activation: The I kappaB kinase revealed? Cell 91, 299-302.

Sun, S.C., Ganchi, P.A., Ballard, D.W., and Greene, W.C. (1993) NF-kappa B controls expression of inhibitor I kappa B alpha: evidence for an inducible autoregulatory pathway. Science 259, 1912-1915.

Takeshita, S., Gage, J.R., Kishimoto, T., Vredevoe, D.L., and Martinez-Maza, O. (1996) Differential regulation of IL-6 gene transcription and expression by IL- 4 and IL-10 in human monocytic cell lines. J Immunol 156, 2591-2598.

Traenckner, E.B., Pahl, H.L., Henkel, T., Schmidt, K.N., Wilk, S., and Baeuerle, P.A. (1995) Phosphorylation of human I kappa B-alpha on serines 32 and 36 controls I kappa Balpha proteolysis and NF-kappa B activation in response to diverse stimuli. EMBO J $14,2876-2883$.

Wang, P., Wu, P., Siegel, M.I., Egan, R.W., and Billah, M.M. (1995) Interleukin (IL)-10 inhibits nuclear factor kappa B (NF kappa B) activation in human monocytes. IL-10 
and IL-4 suppress cytokine synthesis by different mechanisms. J Biol Chem 270, 9558-9563.

Wang, S., Leonard, S.S., Castranova, V., Vallyathan, V., and Shi, X. (1999) The role of superoxide radical in TNF-alpha induced NF-kappaB activation. Ann Clin Lab Sci 29, 192-199.

Whiteside, S.T. and Israel, A. (1997) I kappa B proteins: structure, function and regulation. Semin Cancer Biol 8, 75-82. 


\section{SECTION V}

\section{Oxygen Radical-Mediated Pulmonary}

Toxicity Induced by Cationic Liposomes 


\section{V.1. ABSTRACT}

Cationic liposomes represent a class of nonviral vectors that hold great promise as gene delivery vehicles. However, recent studies have shown that they may be associated with some toxicity. The objectives of this study are to investigate the toxicity associated with polycationic liposomes and to elucidate the underlying mechanism. We tested the hypothesis that the positive charge of liposomes is a key determinant of toxicity by testing differently charged liposomes in mice. Differently charged liposomal systems including cationic liposomes, LipofectAMINE and DOTAP, and neutral and negative liposomes were evaluated for their toxicity after pulmonary administration in mice. LDH assay and differential cell counts were performed to measure toxicity and pulmonary inflammation, respectively. Reactive oxygen species (ROS) were assessed by luminol-dependent chemiluminescence. Instillation of cationic liposomes elicited dose-dependent toxicity and pulmonary inflammation. This effect was more pronounced with the multivalent cationic liposome LipofectAMINE as compared to the monovalent cationic DOTAP. Neutral and negative liposomes did not exhibit lung toxicity. Toxicity associated with cationic liposomes correlated with the oxidative burst induced by the liposomes. LipofectAMINE induced a dose-dependent increase in zymosan-stimulated production of ROS. This effect was less

pronounced with DOTAP and absent with neutral and negative liposomes. ROS play a key role in cationic lipid-mediated toxicity. Polyvalent cationic liposomes cause a release of ROS which are responsible for the pulmonary toxicity. 


\section{V.2. INTRODUCTION}

With our increasing knowledge of human inherited and acquired diseases at a molecular level, the use of gene therapy to restore a missing function or to treat certain diseases has become a clinical reality. Currently, however, the rate-limiting step in its successful application is the development of safe and efficient gene delivery vehicles. Vectors proposed for gene delivery fall into two categories, viral and nonviral. Viral vectors have achieved best results as far as transfection efficiency is concerned. However, the safety concerns and the immunological profile of viral vectors have steered research towards the development of efficient non-viral carriers. Cationic lipids represent a class of nonviral vectors that have shown the greatest success and promise so far. Their lack of immunogenicity, simplicity and ease of production make them attractive vectors for gene therapy (Gao and Huang, 1995). Cationic liposomes have been reported to successfully transfect genes both in vitro (Behr et al., 1989; Felgner and Holm, 1989; Gao and Huang, 1991; Lee et al., 1996) and in vivo (Brigham et al., 1989; Lee et al., 1996). Cationic lipid based gene delivery protocols have also been used in clinical trials (Caplen et al., 1995; Chadwick et al., 1997; Nabel et al., 1993). However, their relatively low transfection efficiency compared to that of the viral vectors makes them far from ideal.

Another concern regarding the use of cationic liposomes is their toxicity. Cationic lipids were considered to be safe initially, however, increasing evidence has suggested that they may cause some toxic effects in vivo (Freimark et al., 1998; Scheule et al., 1997; Song et al., 1997). Experimental data indicate that in vivo toxicity does not correlate well with in vitro toxicity. In general, cationic liposomes are better tolerated in vitro suggesting that other factors involved in vivo are responsible for the toxicity. Scheule et al. (1997) have shown significant lung toxicity following a nasal instillation of up to $300 \mathrm{nmol}$ of lipid complexed with $400 \mathrm{nmol}$ of pDNA. They observed a dose-dependent lung inflammation associated with the cationic lipid. Song et al. (1997) have demonstrated acute toxicity at high positive charge ratios of cationic lipid to plasmid DNA. Freimark et al. (1998) reported that intratracheal instillation of lipid alone or plasmid/lipid complex induced cytokine production and cellular influx in the lung airway. We have also found in this study that cationic liposomes cause an inflammatory response in a dose-dependent manner when administered intratracheally. This inflammation is seen as early as $6 \mathrm{~h}$ after instillation. 
The mechanism by which cationic liposomes facilitate gene transfection is still not completely understood. Since biological membranes are negatively charged, it has been suggested that liposomes interact with cells through a nonspecific charge interaction. Cationic liposomes form complexes with DNA through electrostatic interactions. The excess positive charge of the complexes allows non-specific interactions with cell membranes. This property which results in efficient transfection, may be also responsible for causing cellular toxicity. Cationic lipids are also excellent surfactants with a potential of causing membrane solubilization, poration, and lysis. They can also change the membrane properties by interacting with membrane proteins such as protein kinase C (Bottega and Epand, 1992) which play an important role in signal transduction and gene regulation.

The origin of toxicity caused by cationic liposomes is not well understood. We hypothesized that the positive charge of liposomes plays an important role in lung toxicity. Using differently charged liposomes, we found that the multivalent cationic liposome LipofectAMINE was much more toxic than the monovalent cationic liposome DOTAP, and that neutral and negative liposomes were not toxic at the relevant concentrations.

ROS have been identified as key mediators of pulmonary damage induced by various stimuli (Janssen et al., 1993; Gossart et al., 1996). To further identify the cause of toxicity, we studied the effect of different liposomes on free radical generation. We observed that the highly charged cationic liposome LipofectAMINE caused a marked inflammatory response as determined by neutrophil influx and oxidative burst of lung lavaged cells. This effect is charge related and can be reversed by pretreatment of mice with the free radical scavenger N-ter-butyl- $\alpha$-phenylnitrone (PBN). Hence, our results suggest that ROS play a key role in cationic lipid-mediated toxicity. 


\section{V.3. METHODS}

\section{Animals}

Healthy male Balb/c mice, 4-6 weeks old, were obtained from Jackson Laboratories (Bar Harbor, ME). They were acclimated in an AAALAC-approved facility for at least a week before use. The mice were fed food and water ad libitum. Intratracheal instillations into mice were performed by anesthetizing them with a mixture of ketamine and xylazine ( 45 and $8 \mathrm{mg} / \mathrm{kg}$, i.p., respectively) and challenged by aspiration. The animals were placed on a board in a supine position. The animal's tongue was extended with lined forceps and 50$100 \mu \mathrm{l}$ of the test solution was placed on the back of the tongue.

\section{Liposomes}

Cationic liposomes used in this study were LipofectAMINE (Gibco BRL, Gaithersburg, MD) and DOTAP (Boehringer Mannheim, Indianapolis, IN). LipofectAMINE is a 3:1 mixture of cationic lipid DOSPA and neutral lipid DOPE. The neutral liposome used in this study was palmitoyl-oleoyl phosphatidylcholine (POPC) (Sigma, St. Louis, MO) and the negative liposome was a mixture of palmitoyl-oleoyl phosphatidylcholine (POPC) and dioleoyl phosphatidylglcyerol (DOPG) (Sigma). The neutral and negative liposomes were reconstituted in sterile water according the manufacturer's instructions. The neutral and negative liposomes were extruded through polycarbonate membranes to achieve the same size as that of LipofectAMINE and DOTAP. Briefly, the lipid solution was briefly vortexed, followed by incubation at $50^{\circ} \mathrm{C}$ for $10 \mathrm{~min}$ and then sequentially extruded through polycarbonate membranes with the following pore sizes: 1.0, 0.6 and $0.2 \mu \mathrm{m}$. The size of the liposomes were measured by dynamic laser scattering using Coulter N4SD particle sizer (Hialeah, FL, USA). The mean particle size of different liposomes are as follows: LipofectAMINE, $160 \mathrm{~nm}$; DOTAP, 189 nm; neutral, $171 \mathrm{~nm}$; and negative, $174 \mathrm{~nm}$.

\section{Bronchoalveolar Lavage}

At selected time intervals, treated mice were euthanized with an intraperitoneal injection of $0.25 \mathrm{~mL}$ sodium pentobarbital (EUTHA-6, Western Medical Supply Inc., Arxadia, CA). A tracheal canula was inserted and the lungs were lavaged through the canula using 
ice-cold PBS. Five lavages of $0.8 \mathrm{ml}$ each were collected. The first lavage was separated from the consecutive lavages. Bronchoalveolar lavage cells (BALC) were isolated by centrifugation $\left(500 \mathrm{~g}, 10 \mathrm{~min}, 4^{\circ} \mathrm{C}\right)$. The cell free supernatants were collected and used for biochemical measurements. For each animal, the cell pellet was resuspended in $1 \mathrm{~mL}$ of HEPES buffer (10 mM N-2-hydroxyethylpiperazine-N'-1-ethanesulfonic acid, $145 \mathrm{mM} \mathrm{NaCl}$, $5.0 \mathrm{mM} \mathrm{KCl}, 1.0 \mathrm{mM} \mathrm{CaCl}$, $5.5 \mathrm{mM}$ D-glucose; $\mathrm{pH} 7.4)$, centrifuged (500g, $10 \mathrm{~min}, 4^{\circ} \mathrm{C}$ ), and the supernatant was decanted and discarded. The BALC pellet was then resuspended in $1 \mathrm{~mL}$ HEPES buffer and placed on ice. Cell counts and differentials were determined using a Coulter Multisizer II and AccuComp software (Coulter Electronics, Hialeah, FL).

\section{LDH Activity}

Lactate dehydrogenase (LDH) assay was performed to assess the effect of liposomes on cellular toxicity. Mice were instilled with the test agents. After the treatments, bronchoalveolar lavage was performed and the supernatant from the first lavage was assayed for LDH activity. LDH activity was determined by monitoring the oxidation of pyruvate coupled with the reduction of NAD at $340 \mathrm{~nm}$ using an LDH assay kit (Roche Diagnostic Systems, Montclair, NJ). The assay was performed on Cobas Fara II Analyzer (Roche Diagnostic Systems). One unit per liter of LDH activity is defined as the amount of enzyme that converts $1 \mu \mathrm{mol}$ of lactate to $1 \mu \mathrm{mol}$ of pyruvate with the concomitant reduction of $1 \mu \mathrm{mol}$ of NAD to $1 \mu \mathrm{mol}$ of NADH per minute per liter of sample in the assay procedure.

\section{Administration of PBN}

For this procedure, the spin trapping agent, PBN, was administered in vivo by i.p. injection at a dose of $300 \mathrm{mg} / \mathrm{kg}, 20 \mathrm{~min}$ before instillation of liposomes after dissolving it in PBS.

\section{Chemiluminescence}

Chemiluminescence (CL) assay of bronchoalveolar lavage cells (BALC) was conducted in a total volume of $0.25 \mathrm{~mL}$ HEPES buffer. Resting BALC CL was determined by incubating $0.25 \times 10^{6} \mathrm{BALC}$ at $37^{\circ} \mathrm{C}$ for $5 \mathrm{~min}$ with $0.04 \%(\mathrm{w} / \mathrm{v}$ ) luminol (Sigma) followed by the measurement of $\mathrm{CL}$ for $15 \mathrm{~min}$. To determine zymosan-stimulated BALC CL, the assay 
was modified to include $1 \mathrm{mg}$ unopsonized zymosan (Sigma), which was added to the assay immediately prior to measurement of CL. CL measurement was conducted with an automated luminometer (Berthold Autolumat LB 953, Wallace, Inc., Gaithersburg, MD) at 390-620 nm for $15 \mathrm{~min}$ and the integral of counts per minute (cpm) versus time calculated. Zymosan-stimulated CL was calculated as the cpm in the zymosan-stimulated assay minus the cpm in the resting assay. 


\section{V.4. RESULTS}

\section{Charge Dependent Toxicity of Liposomes}

To test the hypothesis that the charge of the liposome is responsible for toxicity, we tested differently charged liposomes on lung inflammation and damage. Cationic liposomes used in this study were LipofectAMINE and DOTAP. LipofectAMINE is a commercially available liposome that has been successfully used in vitro (Hawley-Nelson et al., 1993). In our experience, we have found that LipofectAMINE is superior to most other commercially available liposomes for in vitro gene transfection of lung cells. The cationic lipid present in LipofectAMINE has 4 protonatable amines on its headgroup at physiological pH. DOTAP is a monovalent cationic lipid. The neutral liposome used in this study is phosphatidylcholine and the negative liposome is a mixture of phosphatidylcholine and phosphatidylglycerol.

Intratracheal instillations of differently charged liposomes were performed in mice lungs. One day after instillation, mice were lavaged and bronchoalveolar lavage fluid (BALF) was tested for LDH activity and cell counts. LDH activity is a measure of toxicity. Inflammation is characterized by an increase in polymorphonuclear leukocytes (PMN) and hence, the cell counts are an indication of inflammation. There was a charge dependent toxicity of liposomes as determined by LDH (Fig. 1A). For a fair comparison, the dose of all liposomes was fixed at a dose that is commonly used in gene transfection protocols in vivo (Liu et al., 1999). The polycationic LipofectAMINE was found to be most toxic, followed by DOTAP, which is monocationic. Neutral and anionic liposomes did not exhibit significant toxicity over PBS control. This toxicity correlated with the inflammation induced. LipofectAMINE-induced inflammation, as determined by PMN count, was greater than that induced by other liposomes (Fig. 1B). Further studies have shown that there is a dose dependent increase in toxicity (Fig. 2A), as well as in the induction of inflammation (Fig. 2B) associated with instillation of LipofectAMINE. These results suggest that toxicity of liposomes is dependent on the charge of the liposome and that toxicity is seen only with cationic liposomes.

The positively charged headgroup of the liposome is responsible for its cationic nature. To identify whether this component of the cationic liposome is responsible for the observed toxicity, we instilled mice with relevant concentrations of spermine. Spermine is 
the headgroup of the cationic lipid present in LipofectAMINE. However, administration of spermine elicited neither a toxicity (Fig. 3A) nor an inflammatory response (Fig. 3B) in comparison to the administration of equivalent dose of cationic liposome. These results suggest that both the cationic headgroup and lipophilic tail of the liposome are required for toxicity induction, presumably through its surfactant action.

\section{Oxygen Radical-Mediated Toxicity of Cationic Liposomes}

ROS have been identified as key mediators of pulmonary damage (Gossart et al., 1996; Janssen et al., 1993). We hypothesized that the cationic liposome mediated toxicity was in part due to the production of ROS by lung cells. To study the effect of liposomal charge on ROS production, we instilled mice with differently charged liposomes and lavaged the animals $24 \mathrm{~h}$ after instillation. The lavaged cells were then tested for their basal and zymosan-induced oxidative burst. Consistent with our toxicity data, we observed that cationic liposomes triggered an oxidative burst (Fig. 4A). Neutral and negative liposomes did not exhibit a zymosan-induced $C L$ response. Multivalently charged cationic liposome, LipofectAMINE, showed a greater induction of ROS than the monovalently charged DOTAP. LipofectAMINE-induced ROS production was found to be dose dependent (Fig. 4B). Stimulation of lavaged cells with zymosan in cationic liposome-instilled mice resulted in about 25-100 times enhancement of zymosan-triggered peak CL intensity over the controls.

The role of ROS in cationic lipid-mediated toxicity was further studied by administering a free radical trapper, PBN. PBN has been used in previous studies as a spin trap for ROS (Gossart et al., 1996). It would be reasonable to assume that if oxygen radicals produced by LipofectAMINE are responsible for the toxicity, then scavenging these radicals would reverse the toxicity. To test this hypothesis, we pretreated the mice with PBN (i.p., $300 \mathrm{mg} / \mathrm{kg}$ ) $20 \mathrm{~min}$ before liposomal instillation. One day after instillation, mice trachea were lavaged and the lavaged cells were tested for oxidative burst, toxicity and inflammation. As can be seen in Fig. 5A, PBN decreases oxidative burst induced by liposome treatment. PBN by itself does not cause any production of ROS. It also decreases the toxicity (Fig. 5B) and inflammation (Fig. 5C) induced by LipofectAMINE. These results support the role of ROS in LipofectAMINE-mediated lung toxicity. 


\section{V.5. DISCUSSION}

Cationic lipids have been used successfully in both in vitro and in vivo gene transfer (Behr et al., 1989; Brigham et al., 1989; Felgner and Holm, 1989; Gao and Huang, 1991; Lee et al., 1996). However, there have been some recent reports of toxicity associated with their use in vivo (Freimark et al., 1998; Scheule et al., 1997). The principle objective of this study is to understand the influence of charge of the liposome on its in vivo toxicity profile. We have tested the toxicity of differently charged liposomes in vivo in mice. This study has revealed four significant observations: (1) charge of liposome is a key determinant of toxicity; (2) cationic liposomes are more toxic than neutral/negative liposomes and multivalent cationic liposomes are more toxic than monovalent cationic liposomes; (3) the cationic headgroup of liposome by itself is not toxic but its presence in the cationic liposome causes toxicity; and (4) ROS are responsible for cationic liposome-mediated toxicity.

Cationic lipids are composed of a hydrophilic anchor connected via a linker to a positively charged headgroup (Gao and Huang, 1991; Gao and Huang, 1995). It has been shown that although all components of the cationic lipid contribute to its transfection efficiency, the nature of the headgroup plays a major role in transfection efficiency of the lipid. The positively charged headgroup of most cationic lipids consists of one or more amine groups with various degrees of substitution. This domain facilitates both electrostatic interactions with negatively charged DNA to form the lipoplex as well as interactions with target cells. Polyvalent headgroups have been reported to be superior to their monovalent counterparts due to their capacity for greater DNA compaction (Behr et al., 1989; HawleyNelson et al., 1993; Remy et al., 1994) and non-specific cell interactions. However, for the same reason, they are also toxic. We and others (Freimark et al., 1998; Scheule et al., 1997) have observed that direct instillation of cationic lipid into the lungs elicits an inflammatory response which is dose-dependent. Forming a complex with plasmid DNA did not decrease the toxicity even when the net charge of pDNA/lipid complexes was neutral.

The mechanism of toxicity of cationic liposomes has not been well characterized. It has been suggested that the amphipathic nature of cationic lipid is responsible for toxicity because they are excellent detergents. This hypothesis is supported by our results. Spermine, the headgroup of lipid responsible for the positive charge, is not toxic by itself at the relevant concentrations. Scheule et al. (Scheule et al., 1997) have suggested that 
introducing a larger headgroup increases water solubility resulting in a greater tendency to form micelles and hence, a potential for greater toxicity.

Cationic liposomes have been associated in the induction of cytokines (Freimark et al., 1998), cellular influx and pulmonary inflammation (Scheule et al., 1997). Inflammation is characterized and triggered by several mediators, especially those produced by macrophages such as cytokines and ROS. Positively charged liposomes caused an increase in inflammatory cells which are responsible for the release of inflammatory mediators such as cytokines and ROS. We assessed ROS production by luminol dependent CL (Antonini et al., 1994). This method allowed measurement of the cellular and tissue events related to the oxidative process. We have shown that treatment with positively charged liposomes increased the ability of lung cells to release ROS in response to various stimuli such as zymosan.

To confirm the role of ROS in the development of pulmonary inflammation and toxicity, we used the spin trapping agent PBN. PBN has been shown to reduce endotoxininduced rat mortality through its ability to trap intermediate oxygen and carbon-centered radicals (Pogrebniak et al., 1992). We have shown here that in vivo pretreatment with PBN decreases the ability of lung cells to release ROS in response to stimuli. This pretreatment also decreased pulmonary inflammation and toxicity induced by cationic liposomes.

We report here, for the first time, the role of ROS in cationic lipid mediated toxicity. The data presented here suggest that cationic liposomes cause inflammation and toxicity via a pathway that involves the generation of oxygen free radicals because scavenging these radicals decreases toxicity. 


\section{V.6. FIGURES}

\section{Figure 1}
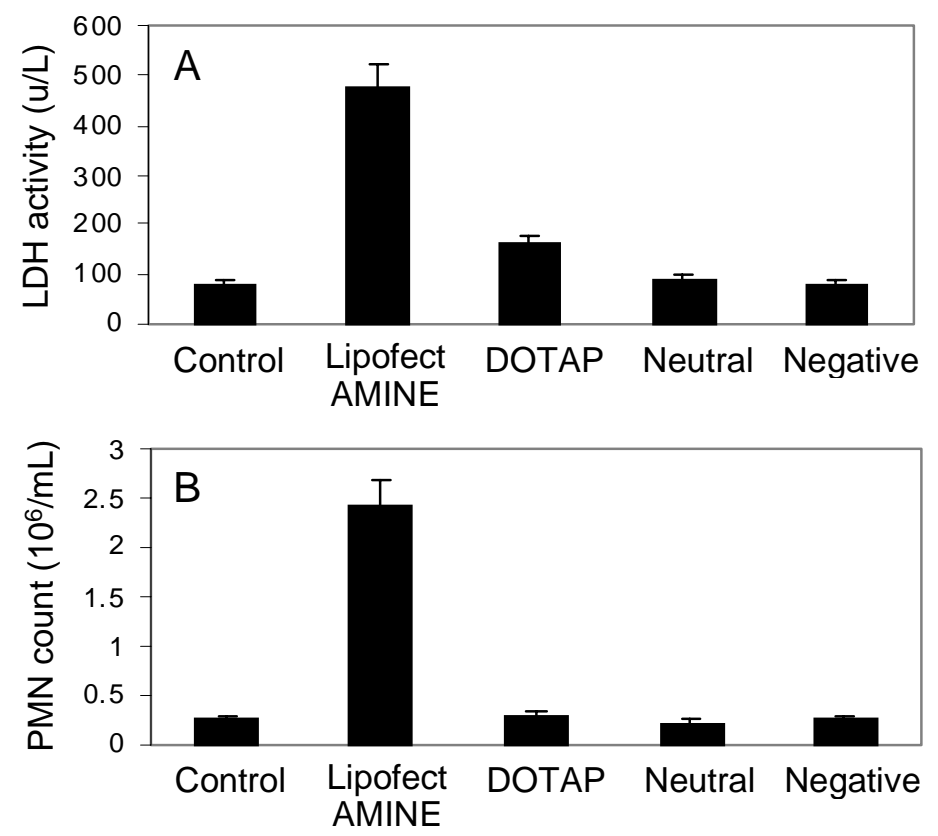

Fig. 1. Comparison of Toxicity Induced by Differently Charged Liposomes. Intratracheal instillations were performed on mice with LipofectAMINE, DOTAP, neutral and negative liposomes at a fixed dose of $200 \mathrm{nmol} /$ mouse. Bronchoalveolar lavage was performed $24 \mathrm{~h}$ after instillation. The BAL was tested for (A) LDH activity and (B) PMN cell count as described in the Methods section. The values are the mean \pm SD of 3 animals. 
Figure 2
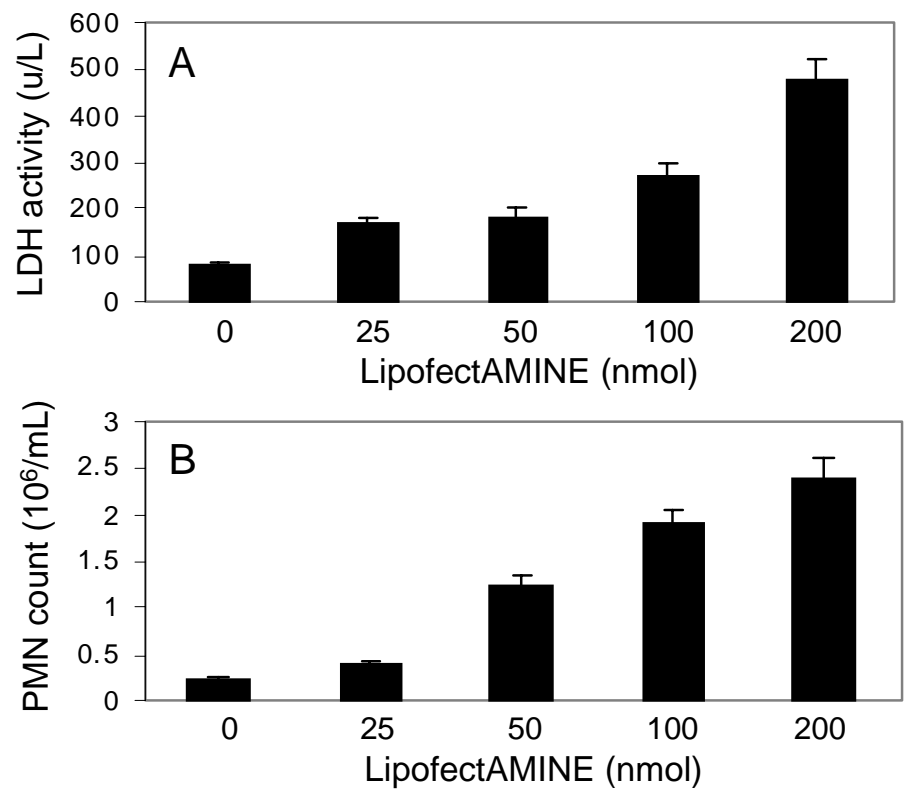

Fig. 2. Dose-Dependent Toxicity Induced by LipofectAMINE. Intratracheal instillations were performed on mice with different concentrations of LipofectAMINE (0-200 $\mathrm{nmol} /$ mouse). Bronchoalveolar lavage was performed $24 \mathrm{~h}$ after instillation. The BAL was tested for (A) LDH activity and (B) PMN cell count as described in the Methods section. The values are the mean \pm SD of 3 animals. 


\section{Figure 3}
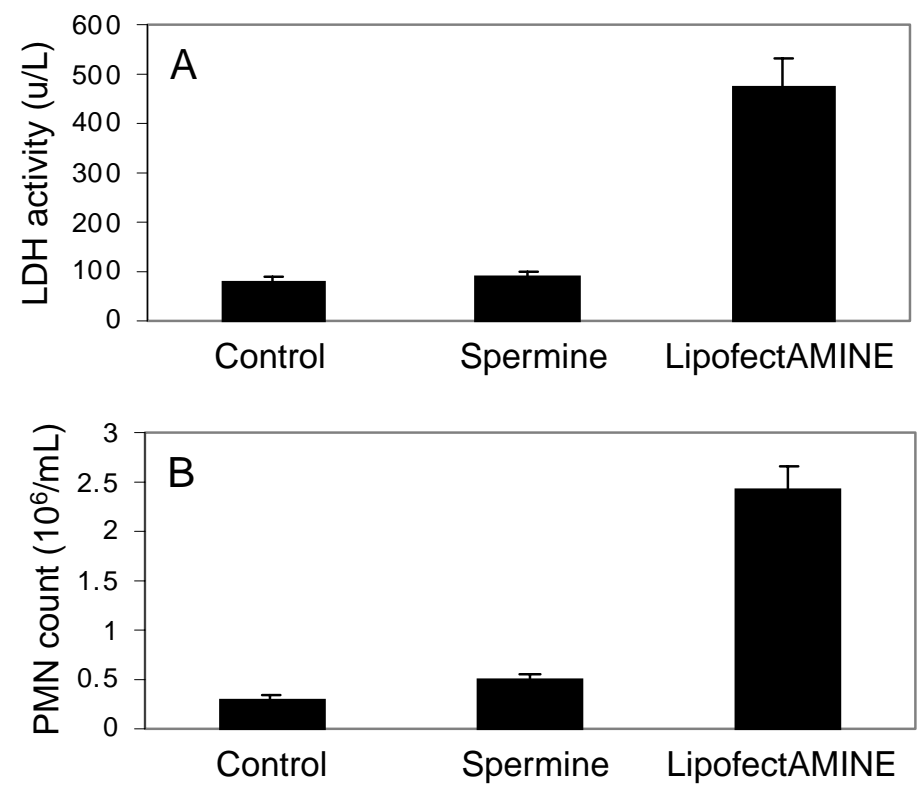

Fig. 3. Role of the Headgroup Spermine in LipofectAMINE-Induced Lung Toxicity. Intratracheal instillations were performed on mice with spermine and LipofectAMINE (200 $\mathrm{nmol} /$ mouse). Bronchoalveolar lavage was performed $24 \mathrm{~h}$ after instillation. The BAL was tested for (A) LDH activity and (B) cell count as described in the Methods section. The values are the mean \pm SD of 3 animals. 
Figure 4
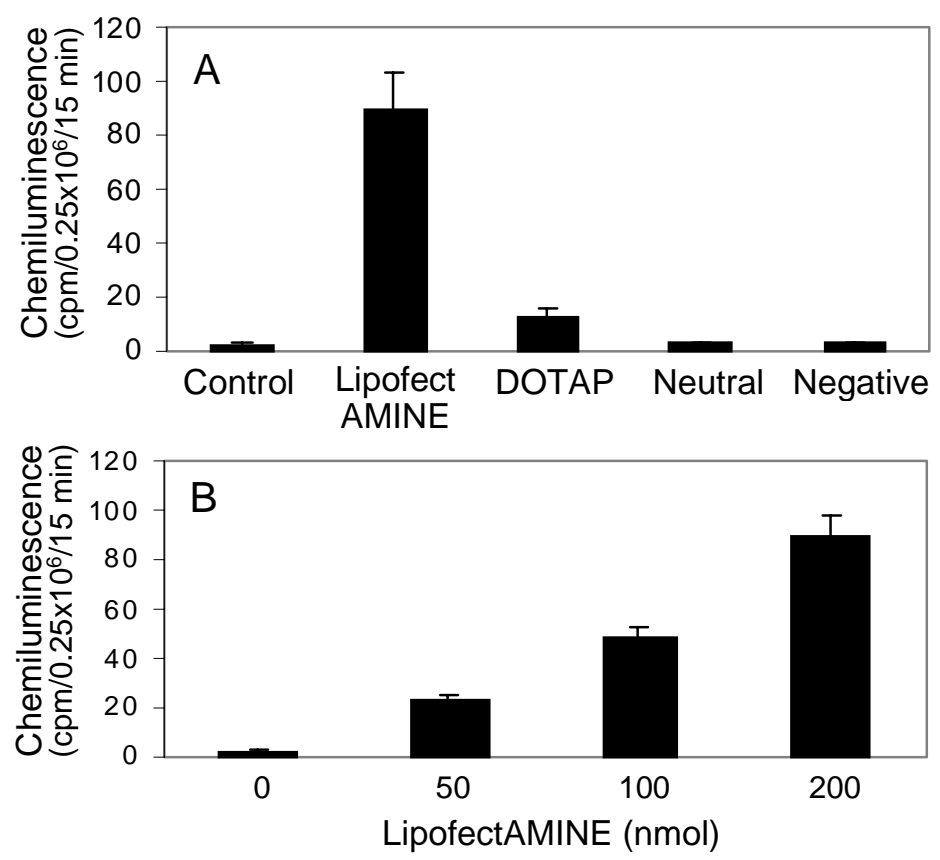

Fig. 4. (A) Comparison of ROS Production by Differently Charged Liposomes. (B) Dose-Dependent Induction of ROS by LipofectAMINE. Intratracheal instillations were performed on mice with LipofectAMINE, DOTAP, neutral and negative liposomes (200 $\mathrm{nmol} /$ mouse). Bronchoalveolar lavage was performed $24 \mathrm{~h}$ after instillation. Chemiluminescence assay was performed as described in the Methods section. The values are the mean \pm SD of 3 animals. 


\section{Figure 5}
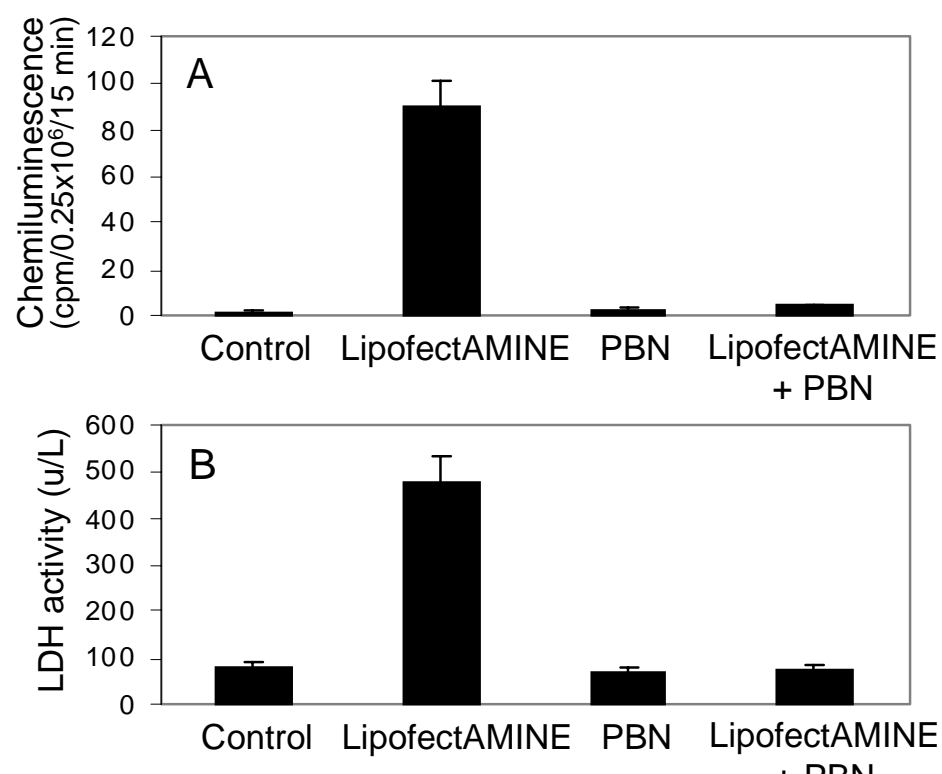

$+\mathrm{PBN}$

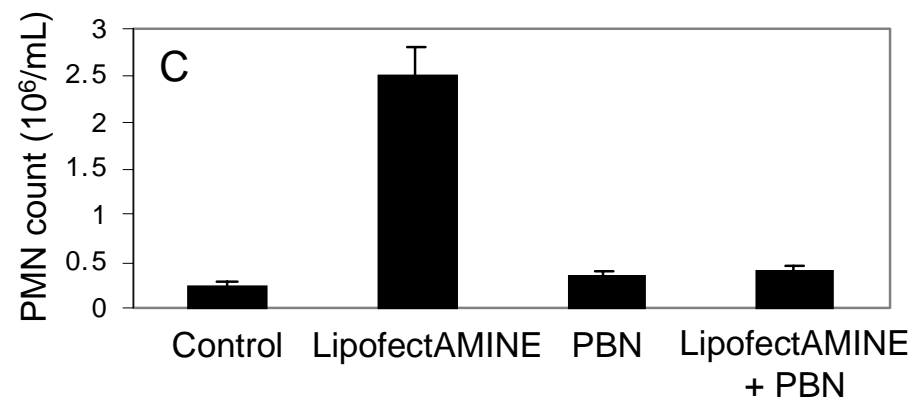

Fig. 5. Effect of Pretreatment of Mice with PBN before Instillation with LipofectAMINE. Mice were pretreated with free radical scavenger, PBN, (i.p., $300 \mathrm{mg} / \mathrm{kg}$ ) $20 \mathrm{~min}$ before intratracheal instillations with LipofectAMINE (200 nmol/mouse). Bronchoalveolar lavage was performed $24 \mathrm{~h}$ after instillation. The BAL was tested for (A) chemiluminescence, $(B)$ LDH activity and (C) cell count as described in the Methods section. The values are the mean \pm SD of 3 animals. 


\section{V.7. REFERENCES}

Antonini, J.M., Van Dyke, K., Ye, Z., DiMatteo, M., and Reasor, M.J. (1994) Introduction of luminol-dependent chemiluminescence as a method to study silica inflammation in the tissue and phagocytic cells of rat lung. Environ Health Perspect 102 Suppl 10, 37-42.

Behr, J.P., Demeneix, B., Loeffler, J.P., and Perez-Mutul, J. (1989) Efficient gene transfer into mammalian primary endocrine cells with lipopolyamine-coated DNA. Proc Natl Acad Sci USA 86, 6982-6986.

Bottega, R. and Epand, R.M. (1992) Inhibition of protein kinase C by cationic amphiphiles. Biochemistry 31, 9025-9030.

Brigham, K.L., Meyrick, B., Christman, B., Magnuson, M., King, G., and Berry, L.C.J. (1989) In vivo transfection of murine lungs with a functioning prokaryotic gene using a liposome vehicle. Am J Med Sci 298, 278-281.

Caplen, N.J., Alton, E.W., Middleton, P.G., Dorin, J.R., Stevenson, B.J., Gao, X., Durham, S.R., Jeffery, P.K., Hodson, M.E., and Coutelle, C. (1995) Liposome-mediated CFTR gene transfer to the nasal epithelium of patients with cystic fibrosis [published erratum appears in Nat Med 1995 Mar;1(3):272]. Nat Med 1, 39-46.

Chadwick, S.L., Kingston, H.D., Stern, M., Cook, R.M., O'Connor, B.J., Lukasson, M., Balfour, R.P., Rosenberg, M., Cheng, S.H., Smith, A.E., Meeker, D.P., Geddes, D.M., and Alton, E.W.(1997). Safety of a single aerosol administration of escalating doses of the cationic lipid GL-67/DOPE/DMPE-PEG5000 formulation to the lungs of normal volunteers [published erratum appears in Gene Ther 1998 Apr;5(4):569]. Gene Ther 4, 937-942.

Felgner, P. and Holm, M. (1989) Cationic-liposome-mediated transfection. Focus 11, 21-25.

Freimark, B.D., Blezinger, H.P., Florack, V.J., Nordstrom, J.L., Long, S.D., Deshpande, D.S., Nochumson, S., and Petrak, K.L. (1998) Cationic lipids enhance cytokine and cell influx levels in the lung following administration of plasmid: cationic lipid complexes. J Immunol 160, 4580-4586. 
Gao, X. and Huang, L. (1991) A novel cationic liposome reagent for efficient transfection of mammalian cells. Biochem Biophys Res Commun 179, 280-285.

Gao, X. and Huang, L. (1995) Cationic liposome-mediated gene transfer. Gene Ther 2, 710-722.

Gossart, S., Cambon, C., Orfila, C., Seguelas, M.H., Lepert, J.C., Rami, J., Carre, P., and Pipy, B. (1996) Reactive oxygen intermediates as regulators of TNF-alpha production in rat lung inflammation induced by silica. $J$ Immunol 156, 1540-1548.

Hawley-Nelson, P., Ciccarone, V., Gebeyehu, G., and Jessee, J. (1993) Lipofectamine reagent: A new, higher efficiency polycationic liposome transfection reagent. Focus 15, 73-79.

Janssen, Y.M., Van Houten, B., Borm, P.J., and Mossman, B.T. (1993) Cell and tissue responses to oxidative damage. Lab Invest 69, 261-274.

Lee, E.R., Marshall, J., Siegel, C.S., Jiang, C., Yew, N.S., Nichols, M.R., Nietupski, J.B., Ziegler, R.J., Lane, M.B., Wang, K.X., Wan, N.C., Scheule, R.K., Harris, D.J., Smith, A.E., and Cheng, S.H. (1996) Detailed analysis of structures and formulations of cationic lipids for efficient gene transfer to the lung. Hum Gene Ther 7, 1701-1717.

Liu, D., Knapp, J.E., and Song, Y.K. (1999) Nonviral Vectors for Gene Therapy (Huang, L., Hung, M.C., and Wagner, E., Eds.) Academic Press, New York. 313-335.

Nabel, G.J., Nabel, E.G., Yang, Z.Y., Fox, B.A., Plautz, G.E., Gao, X., Huang, L., Shu, S., Gordon, D., and Chang, A.E. (1993) Direct gene transfer with DNA-liposome complexes in melanoma: expression, biologic activity, and lack of toxicity in humans. Proc Natl Acad Sci USA 90, 11307-11311.

Pogrebniak, H.W., Merino, M.J., Hahn, S.M., Mitchell, J.B., and Pass, H.I. (1992) Spin trap salvage from endotoxemia: the role of cytokine down- regulation. Surgery 112, 130139.

Remy, J.S., Sirlin, C., Vierling, P., and Behr, J.P. (1994) Gene transfer with a series of lipophilic DNA-binding molecules. Bioconjug Chem 5, 647-654. 
Scheule, R.K., St George, J.A., Bagley, R.G., Marshall, J., Kaplan, J.M., Akita, G.Y., Wang, K.X., Lee, E.R., Harris, D.J., Jiang, C., Yew, N.S., Smith, A.E., and Cheng, S.H. (1997) Basis of pulmonary toxicity associated with cationic lipid-mediated gene transfer to the mammalian lung. Hum Gene Ther 8, 689-707.

Song, Y.K., Liu, F., Chu, S., and Liu, D. (1997) Characterization of cationic liposomemediated gene transfer in vivo by intravenous administration. Hum Gene Ther 8 , 1585-1594. 


\section{SECTION VI}

\section{Inhibition of Endotoxin-Induced Lung Inflammation by Interleukin-10 Gene Transfer in Mice}




\section{VI.1. ABSTRACT}

Interleukin-10 (IL-10) is an anti-inflammatory cytokine that has great potential to be used for the treatment of inflammatory and immune illnesses. Gene transfer technology now permits directed expression of exogenous genes within specific organs (e.g., lung) of intact animals. In the present study, gene transfer was used to induce IL10 transgene expression in mice lungs for a possible treatment of endotoxin-induced lung inflammation. Gene transfer was performed using CMV-IL-10 plasmid with the aid of liposomal transfecting agents, LipofectAMINE and DOTAP. Administration of endotoxin caused a marked increase in lung inflammation as indicated by increased tumor necrosis factor (TNF)- $\alpha$ release and neutrophil cell count. Pretreatment of the mice with IL-10 plasmid, either alone or in combination with LipofectAMINE, had no inhibitory effect on lung inflammation and did not induce IL-10 protein expression. LipofectAMINE by itself was found to be toxic and cause lung inflammation, the effect that was not observed with DOTAP. IL-10 plasmid, when co-delivered with DOTAP, expressed biologically active IL-10 protein (150-700 pg/ml) and caused a reduction in lung inflammation induced by endotoxin. Maximum transgene expression was observed when a dose of $12 \mathrm{nmol}$ of DOTAP per $\mu \mathrm{g}$ DNA was used. This expression was seen as early as $3 \mathrm{~h}$ after administration, peaked at $12 \mathrm{~h}$, and declined thereafter. We conclude that IL-10 gene transfer is a feasible approach for the treatment of lung inflammation. However, the efficacy of this treatment is dependent on the appropriate use of gene delivery systems. 


\section{VI.2. INTRODUCTION}

IL-10 is an anti-inflammatory cytokine that is regularly produced during inflammatory processes in vivo, usually by the same cells that release inflammatory mediators (e.g., monocytes, macrophages, $\mathrm{T}$ cells). It inhibits the production of inflammatory cytokines, e.g., IL-1, IL-6, and TNF- $\alpha$, by inflammatory cells stimulated with endotoxin and interferon (Fiorentino et al., 1991). IL-10 has been implicated in a number of inflammatory disorders such as sepsis, chronic arthritis, and inflammatory bowel diseases (Goldman et al., 1996; Moore et al., 1993). In animal models of sepsis, IL-10, given before or soon after Gram-negative bacterial endotoxin reduces TNF- $\alpha$ production, hypothermia, and death (Howard et al., 1993; Kuhn et al., 1993). It was found that mice are more sensitive to LPS-induced shock by treatment with anti-IL-10 antibodies (Ishida et al., 1994). It was also found that IL-10 deficient mice developed severe enterocolitis and that IL-10 is an essential immunoregulator in the intestinal tract (Kuhn et al., 1993). In an experimental model of lung inflammation, IL-10 has been shown to inhibit lung inflammation induced by lgG immune complexes (Lentsch et al., 1997; Mulligan et al., 1993). Because of its potent anti-inflammatory effects, IL-10 has been investigated as a potential therapeutic agent for inflammatory disorders.

Most IL-10 studies to date have been carried out using recombinant IL-10 protein (Howard et al., 1993; Kuhn et al., 1993; Mulligan et al., 1993; Tumpey et al., 1994; Kuhn et al., 1993; Mulligan et al., 1993; Tumpey et al., 1994). However, recombinant protein has the disadvantage of being short-lived, poorly accessible to tissue interstitium, and expensive. In the present study, we propose to use gene transfer strategy to deliver the therapeutic IL-10 gene to the lung for the possible treatment of lung inflammation. Gene transfer technology offers the potential advantage of prolonged expression. In addition, because of the amplification process associated with gene expression, i.e., a single gene copy can express numerous copies of protein, this method is therefore potentially more effective than the protein delivery method. However, the use of gene transfer method has been hindered by inefficient gene expression in vivo. The present study investigated the effect of naked DNA and various DNA-liposome complexes on IL-10 gene expression. The specific aims of this study are 1) to determine whether IL-10 gene transfer can be used to produce therapeutically relevant levels of IL-10 protein in mice lungs, 2) to determine whether the transgene expression can result in reduced lung 
inflammation caused by endotoxin, 3) to evaluate the efficacy and safety of gene delivery systems in transferring the IL-10 gene to lung cells. 


\section{VI.3. MATERIALS AND METHODS}

\section{Animals}

Healthy male Balb/c mice, 4-6 weeks old, were obtained from Jackson Laboratories (Bar Harbor, ME). They were acclimated in an AAALAC-approved facility for at least a week before use. The mice were fed food and water ad libitum. Intratracheal instillations into mice were performed by anesthetizing them with a mixture of ketamine and xylazine (45 and $8 \mathrm{mg} / \mathrm{kg}$, i.p., respectively) and challenged by aspiration. The animals were placed on a board in a supine position. The animal's tongue was extended with lined forceps and $50-100 \mu \mathrm{l}$ of the test solution was placed on the back of the tongue.

\section{Preparation of Liposome-DNA Complexes}

Plasmid CMV-mIL-10, which contains mIL-10 cDNA driven by a cytomegalovirus immediate-early promoter, was amplified in $\mathrm{DH} 5 \alpha$ strain of $E$. coli and isolated and purified according to the manufacturer's instructions (Qiagen, Chatsworth, CA). Endotoxin-free plasmid was used for all experiments. Cationic liposomes used in this study were LipofectAMINE (Gibco BRL, Gaithersburg, MD) and DOTAP (Boehringer Mannheim, Indianapolis, IN). For the preparation of DNA-liposome complexes, an indicated amount of LipofectAMINE or DOTAP was added to the diluted DNA in distilled water and the mixture was incubated for 10 min before use.

\section{Bronchoalveolar Lavage}

At selected time intervals, treated mice were euthanized with an intraperitoneal injection of $0.25 \mathrm{ml}$ sodium pentobarbital (EUTHA-6, Western Medical Supply Inc., Arxadia, CA). A tracheal canula was inserted and the lungs were lavaged through the canula using ice-cold PBS. Five lavages of $0.8 \mathrm{ml}$ each were collected. The first lavage was separated from the consecutive lavages. Bronchoalveolar lavage cells (BALC) were isolated by centrifugation $\left(500 \mathrm{~g}, 10 \mathrm{~min}, 4^{\circ} \mathrm{C}\right)$. The cell-free supernatants were

collected and used for biochemical measurements. For each animal, the cell pellet was resuspended in $1 \mathrm{ml}$ of HEPES buffer (10 mM N-2-hydroxyethylpiperazine-N'-1- 
ethanesulfonic acid, $145 \mathrm{mM} \mathrm{NaCl}, 5.0 \mathrm{mM} \mathrm{KCl}, 1.0 \mathrm{mM} \mathrm{CaCl}$, $5.5 \mathrm{mM}$ D-glucose; $\mathrm{pH}$ 7.4), centrifuged ( $500 \mathrm{~g}, 10 \mathrm{~min}, 4^{\circ} \mathrm{C}$ ), and the supernatant was decanted and discarded. The BALC pellet was then resuspended in $1 \mathrm{ml} \mathrm{HEPES}$ buffer and placed on ice. Cell counts and differentials were determined using a Coulter Multisizer II and AccuComp software (Coulter Electronics, Hialeah, FL).

\section{LDH Activity}

Lactate dehydrogenase (LDH) assay was performed to assess the effect of liposomes on cellular toxicity. Mice were instilled with the test agents. After the treatments, bronchoalveolar lavage was performed and the supernatant from the first lavage was assayed for LDH activity. LDH activity was determined by monitoring the oxidation of pyruvate coupled with the reduction of NAD at $340 \mathrm{~nm}$ using an LDH assay kit (Roche Diagnostic Systems, Montclair, NJ). The assay was performed on Cobas Fara II Analyzer (Roche Diagnostic Systems). One unit per liter of LDH activity is defined as the amount of enzyme that converts $1 \mu \mathrm{mol}$ of lactate to $1 \mu \mathrm{mol}$ of pyruvate with the concomitant reduction of $1 \mu \mathrm{mol}$ of NAD to $1 \mu \mathrm{mol}$ of NADH per minute per liter of sample in the assay procedure.

\section{Cytokine Determination}

Supernatants from the first bronchoalveolar lavage were assayed for cytokines using enzyme-linked immunosorbent assay (ELISA) kits specific for murine TNF- $\alpha$ or IL10 according to the manufacture's instructions (Endogen). The sensitivity of the assays ranged from 15 to $31 \mathrm{pg} / \mathrm{ml}$. The coefficient of variation for all cytokine assays was $<10 \%$. 


\section{VI.4. RESULTS}

\section{Endotoxin-Induced Lung Inflammation and its Inhibition by IL-10 Protein}

Endotoxin-induced lung inflammation is associated with increased production of TNF- $\alpha$ and sequestered pulmonary neutrophils (Chang, 1994; Cirelli et al., 1995). In the present study, we utilized these two indices of inflammation as quantitative measures of lung inflammation. Lung inflammation was induced by an intratracheal instillation of LPS (30 $\mu \mathrm{g} /$ mouse) into mice lungs. At various time points after the instillation, TNF- $\alpha$ level and PMN cell count were measured. Fig. 1A shows that LPS stimulation caused a rapid but transient increase in TNF- $\alpha$ production. This increase in cytokine level occurred within an hour of stimulation and reached a maximum at $6 \mathrm{~h}$. By $24 \mathrm{~h}$, the TNF- $\alpha$ level already subsided. Fig. 1B shows that PMN cell count also increased in response to LPS stimulation. This effect was time-dependent and more sustained than the TNF- $\alpha$ level.

To study the effect of IL-10 gene transfer on lung inflammation, it is first necessary to test the anti-inflammatory effect of IL-10 protein in our lung inflammation model. Mice were pretreated with varying amounts of purified recombinant IL-10 (0-100 $\mathrm{ng} /$ mouse) $2 \mathrm{~h}$ before instillation with LPS (30 $\mu \mathrm{g} / \mathrm{mouse})$. Six hours after LPS treatment, the mice were lavaged and the BALF was assayed for TNF- $\alpha$ level and PMN cell count. Figs. $2 \mathrm{~A}$ and $2 \mathrm{~B}$ show that rlL-10 effectively inhibited LPS-induced TNF- $\alpha$ production and PMN count in a dose-dependent manner. Maximum inhibitory effects were observed at the $\mathrm{rlL}-10$ dose of $50 \mathrm{ng} / \mathrm{mouse}$. Increasing the dose of IL-10 beyond this point did not result in further inhibition of TNF- $\alpha$ level and PMN count. Thus, our results indicate that IL-10 protein is indeed a potent anti-inflammatory molecule in vivo.

\section{IL-10 Gene Transfer and the Delivery System}

Studies by Meyer et al. (1995) have shown that naked CMV-CAT plasmid when instilled intratracheally, expresses CAT protein in mice lungs. To test if naked DNA by itself can express IL-10 in the lungs, IL-10 plasmid was instilled and BALF was analyzed for IL-10 protein levels at different time points. Introduction of naked IL-10 plasmid (10$300 \mu \mathrm{g} /$ mouse) did not lead to any detectable expression of IL-10 protein in the BALF. 
Because our subsequent studies show that only $10 \mu \mathrm{g}$ of the plasmid was sufficient to induce IL-10 protein expression when an appropriate delivery system was used, we therefore concluded that naked IL-10 DNA by itself was ineffective and that there is a need for a delivery system for efficient gene transfection in vivo.

In a separate study, we have found that LipofectAMINE, a widely used transfecting agent, is one of the most effective agents in transfecting lung cells in vitro. Therefore, we attempted to use this agent to aid the transfection of IL-10 plasmid in vivo. Varying amounts of LipofectAMINE (20-100 nmol/mouse) were instilled with the plasmid DNA (10 $\mu \mathrm{g} /$ mouse) into mice lungs. Twelve hours after the treatment, the BALF was collected and analyzed for IL-10 protein, PMN cell count, and LDH activity. Our BALF analysis showed that there was no IL-10 expression (data not shown). Moreover, the PMN count was very high in mice treated with DNA-LipofectAMINE complex or LipofectAMINE alone (Fig. 3A). The measurement of LDH activity, which was used as an indication of lung toxicity, also showed that LipofectAMINE was very toxic at the concentrations used (Fig. 3B).

Since LipofectAMINE is very toxic by itself, we can not use this liposome to enhance DNA delivery. Further studies on the in vivo toxicity of cationic liposomes by our group (Dokka et al., 2000) revealed that LipofectAMINE due to its polycationic nature caused a release of highly reactive oxygen species by lung cells which is responsible for lung toxicity. To avoid this problem, a monovalent cationic liposome, DOTAP, was used to aid the delivery of DNA. DOTAP has been used as a gene delivery system in a number of in vivo applications (McLachlan et al., 1995; McLachlan et al., 1996; Porteous et al., 1997). Our results show that DOTAP was relatively non-toxic and was effective in promoting IL-10 gene expression in the lungs (see below).

\section{Optimization of Gene Delivery using DOTAP}

To optimize IL-10 gene transfer in the lung using DOTAP, we tested different DNA:DOTAP ratios on IL-10 gene expression (Fig. 4). As controls, animals were instilled with DOTAP alone or with free DNA alone. As might be expected, no transgene expression was observed in animals that received only DOTAP or DNA alone. Coinstillation of the DNA and DOTAP resulted in a dose-dependent expression of IL-10 in 
the mice lungs (Fig. 4A). Maximum expression was obtained when $12 \mathrm{nmol}$ of DOTAP per $\mu \mathrm{g}$ DNA was used. Beyond this ratio, the expression dropped significantly. PMN data showed that DOTAP, unlike LipofectAMINE, did not cause any significant effect on lung inflammation (Fig. 4B). Similarly, LDH data indicated that DOTAP was non-toxic except when the highest concentration (150 nmol/mouse) was used (Fig. 4C). Because at this concentration the level of IL-10 expression also decreased, it is therefore likely that the decreased expression may be a result of toxicity associated with highconcentration DOTAP. The kinetics of IL-10 expression following DNA-DOTAP administration was also studied (Fig. 5). IL-10 expression was seen to peak at $12 \mathrm{~h}$ after instillation and subsided by $24 \mathrm{~h}$.

\section{Effect of IL-10 Gene Transfer on LPS-Induced Lung Inflammation}

Since we developed a delivery system capable of expressing IL-10 in the lung, the next step was to study the functional effect of this expressed IL-10 on LPS-induced lung inflammation. Mice were instilled with IL-10-DNA/DOTAP complexes $12 \mathrm{~h}$ prior to LPS stimulation. Six hours after LPS stimulation, mice were sacrificed and BALF was tested for PMN count, IL-10 and TNF- $\alpha$ levels. As seen in Fig. 6A, DNA:DOTAP complexes when delivered either with or without LPS, expressed a high level of IL-10 protein. LPS by itself induced a modest but significant amount of IL-10 (Fig. 6A). At the dose of $30 \mu \mathrm{g} /$ mouse, LPS caused a dramatic increase in TNF- $\alpha$ production which was decreased ( 3-fold) by IL-10 gene expression (Fig. 6B). LPS (10 $\mu \mathrm{g} / \mathrm{mouse}$ ) caused a lower TNF- $\alpha$ response which was completely inhibited by IL-10 gene expression (Fig. $6 B)$. Treatment of the mice with DNA/DOTAP complexes similarly inhibited LPS-induced PMN cell count (Fig. 6C). Thus, our results indicate that the gene delivery system was effective in promoting IL-10 expression and subsequent reduction in lung inflammation induced by LPS. 


\section{VI.5. DISCUSSION}

IL-10 is a potent anti-inflammatory cytokine, which regulates the function of various cell types of the immune system (Moore et al., 1993). Its anti-inflammatory properties have been established in a number of in vivo models including sepsis, enterocolitis, and immune complex- or allergan-induced inflammation (Howard et al., 1993; Kuhn et al., 1993; Lentsch et al., 1997; Mulligan et al., 1993; Tumpey et al., 1994). Most of the in vivo studies to date have been carried out by using recombinant IL-10 protein (Howard et al., 1993; Kuhn et al., 1993; Lentsch et al., 1997; Mulligan et al., 1993; Tumpey et al., 1994). The present study investigated the feasibility of utilizing IL10 gene transfer for the treatment of lung inflammation. Gene transfer technology now permits directed expression of exogenous genes within specific organs (e.g., lung) of intact animals (Brigham et al., 1994).

There have been conflicting reports on the capability of naked DNA to express proteins when administered to the lung (Felgner and Holm, 1989; Li and Huang, 1997; Meyer et al., 1995). Meyer et al. (1995) have shown that transgene expression from naked DNA is as high as that seen when the DNA is co-administered with liposomes. On the other hand, Li et al. (1997) have shown that naked DNA alone did not express the gene in vivo. To test if naked DNA is effective in our system, we instilled naked DNA into mice lungs and tested for IL-10 gene expression. Consistent with the results of $\mathrm{Li}$ et al. (1997), we observed no gene expression with the naked DNA. Thus, we concluded that a delivery system is required for efficient IL-10 gene expression in the lung.

IL-10 gene transfer has been used with some success for the treatment of rheumatoid arthritis (Ghivizzani et al., 1998; Whalen et al., 1999) and endotoxemia (Drazan et al., 1996; Xing et al., 1997; Drazan et al., 1996; Whalen et al., 1999). However, in all these studies replication-defective viral vectors were used as a delivery system. Viral vectors, although more efficient than non-viral systems, are considered to be risky due to their potential for viral infection and immunogenicity. These potential deleterious side effects have steered gene transfer research toward developing non-viral delivery systems. Cationic liposome technology has become well established for introducing DNA into cells and these liposomes have been considered to be among the most promising carriers for gene therapy (Gao and Huang, 1995). In spite of the 
effectiveness of cationic liposomes in transfecting cells in vitro, their transfection efficiency in vivo is still fairly low compared to that of the viral vectors (Lee et al., 1996). DOTAP is a cationic liposome that has been used to transfect lung cells in vivo (McLachlan et al., 1995; McLachlan et al., 1996; Porteous et al., 1997). In our studies we found DOTAP to be relatively non-toxic and hence we chose this liposomal system for IL-10 gene transfer.

We have shown that it is possible to express IL-10 in the lung when delivered as a DNA-liposome complex. The expressed IL-10 is capable of suppressing endotoxininduced lung inflammation. Since endotoxin-induced lung inflammatory injury is a common cause of death in sepsis and respiratory distress syndrome, our findings strongly suggest the therapeutic potential of IL-10 gene transfer for the protection of endotoxic lung injury. Nonetheless, the expression of DNA plasmid from our delivery system is transitory and subsides by around $24 \mathrm{~h}$. These results are consistent with those observed by Li et al. (1997). They also observed that there was a rapid decline of gene expression in vivo in the lungs. They performed Southern blot analysis on DNA in the lungs and could detect DNA till around $6 \mathrm{~h}$, after which the level declined and was barely detectable at $24 \mathrm{~h}$ (Li and Huang, 1997). Meyer et al. (1995) also showed that there was a reduction in intact DNA as early as $5 \mathrm{~min}$ after instillation to the lungs. They concluded that DNA was rapidly eliminated from the lungs due to degradation since short DNA fragments were observed at early times in Southern blots.

Both the groups reported that cationic liposomes increase the extent and duration of plasmid DNA in the lungs ( $\mathrm{Li}$ and Huang, 1997; Meyer et al., 1995). Southern blot and PCR analysis demonstrated that rapid degradation of DNA is significantly slowed in the presence of cationic liposomes. Cationic liposomes assist in retaining DNA molecules in the lung for a time sufficient for gene transfer to be complete before they can be washed out of the capillary bed by normal blood flow. Thus, it appears that the retention time of the DNA molecules in the lung is likely to play a critical role in determining the level of gene expression. There could be a number of potential causes for this rapid decline in DNA expression including $A$ ) loss of plasmid DNA from the transfected cells, B) loss of transfected cells due to cell death, and C) loss of transgene expression due to promoter shut-off. Recently, it has been reported that the CMV promoter is suppressed by interferon- $\gamma$ (Harms and Splitter, 1995). Interferon is 
one of the inflammatory cytokines that is released in response to LPS stimulation (Sing et al., 2000). Since the IL-10 plasmid used in this study contains CMV promoter, it is possible that such inactivation may have caused a reduction in IL-10 expression.

We report here, for the first time, that intratracheal administration of DNA/liposome complexes results in clinically relevant concentrations of IL-10 protein. This IL-10 gene transfer can downregulate TNF- $\alpha$ expression and suppress lung inflammation induced by LPS. One of the goals of gene therapy is to provide a prolonged expression of therapeutic proteins over a period of time. This would eliminate the need for repeated administration of short-lived recombinant proteins. However, in our system we have shown that while gene delivery of IL-10 does inhibit LPS-induced inflammation, IL-10 expression does not last beyond $24 \mathrm{~h}$. While these results are encouraging, it is clear that there are still many hurdles to overcome before liposomemediated gene transfer can be regarded as a viable therapy for lung inflammation. Significant improvements in gene transfer efficiency and persistence of gene expression need to be attained. Development of better vectors would allow gene therapy to be a clinical reality.

\section{ACKNOWLEDGEMENTS}

This work was supported in part by the National Institutes of Health Grant HL62959 and by the National Institute for Occupational Safety and Health. 


\section{VI.6. FIGURES}

Figure 1
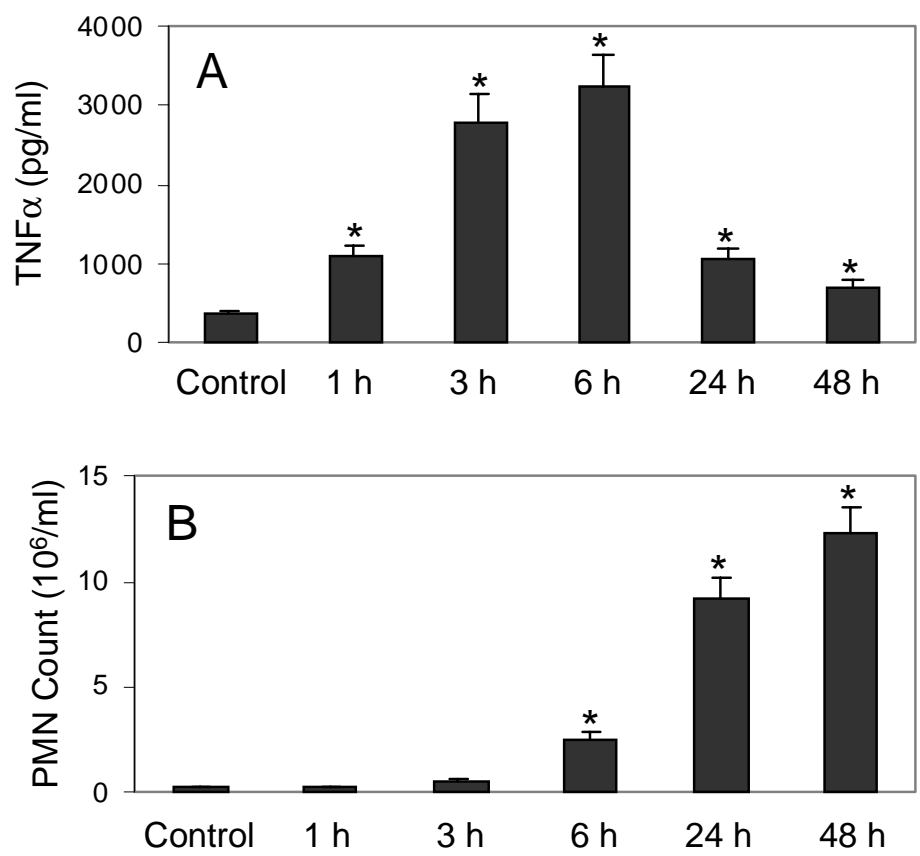

Fig. 1. LPS-Induced Lung Inflammation in Mice. Mice were instilled with LPS (0.03 $\mathrm{mg} /$ mouse) and bronchoalveolar lavage was performed 1, 3, 6, 24 and $48 \mathrm{~h}$ after instillation. The BAL was tested for A) TNF- $\alpha$ concentration and B) PMN cell count. Values are means $\pm \mathrm{SD} ; n=4$ mice/group. ${ }^{*} p<0.05$ vs. untreated control group. 
Figure 2
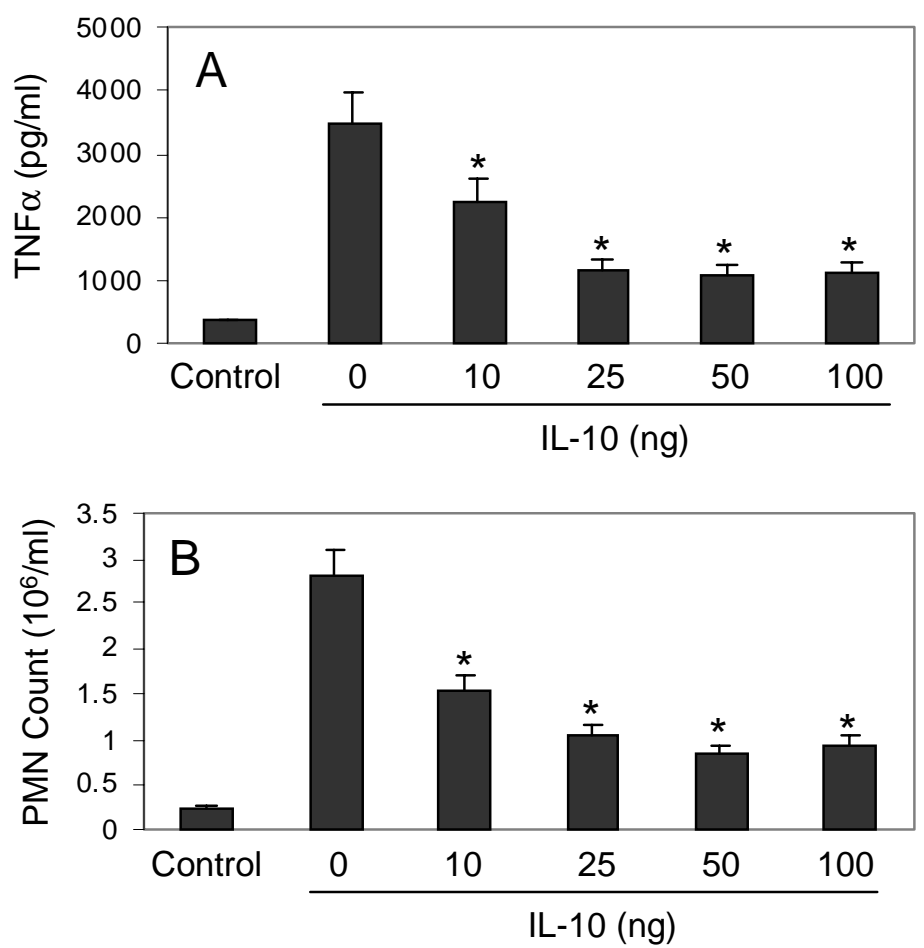

Fig. 2. Effect of Pretreatment of Mice with rIL-10 before instillation with LPS. Mice were preinstilled with different amounts of rlL-10 (0-100 ng/mouse) $2 \mathrm{~h}$ before LPS treatment $(0.03 \mathrm{mg} / \mathrm{mouse})$. Bronchoalveolar lavage was performed $6 \mathrm{~h}$ after instillation. The BAL was tested for $A$ ) TNF- $\alpha$ concentration and B) PMN cell count. Values are means $\pm \mathrm{SD} ; n=4$ mice/group. ${ }^{*} p<0.05$ vs. LPS-treated control group. 
Figure 3
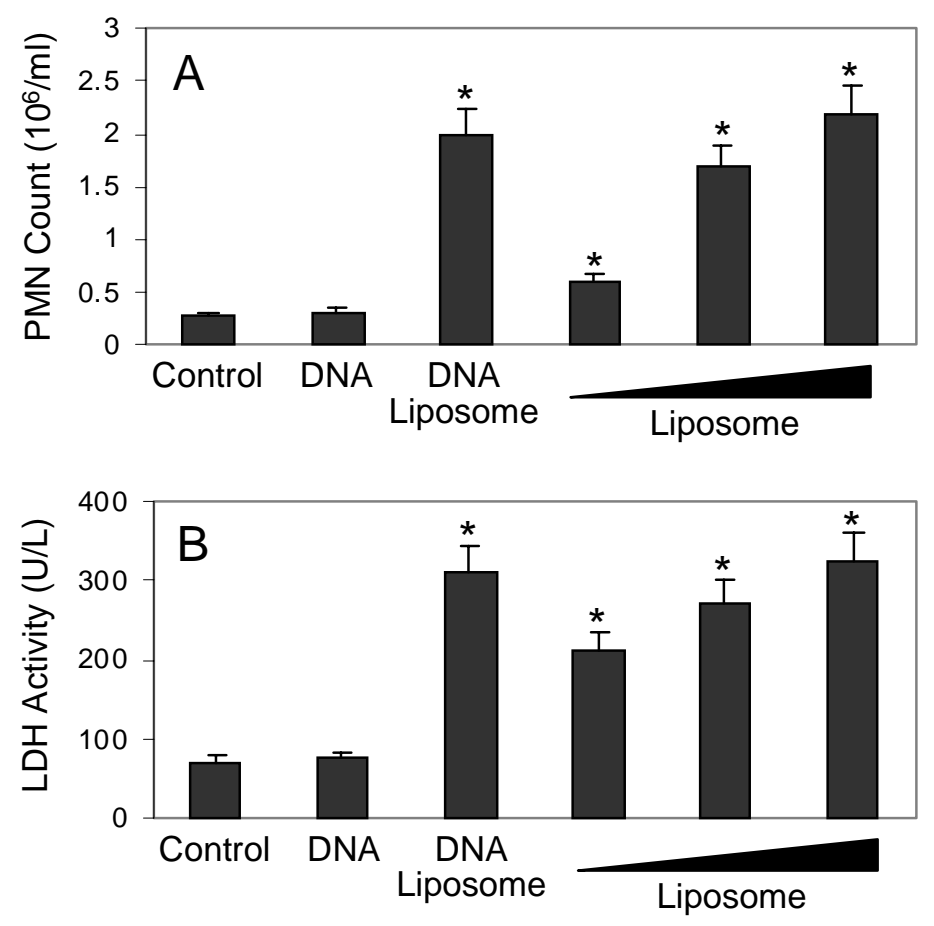

Fig. 3. Delivery of IL-10 Plasmid with LipofectAMINE. Mice were instilled with DNA (10 $\mu \mathrm{g} /$ mouse), DNA-LipofectAMINE complex (10 $\mu \mathrm{g}: 60 \mathrm{nmol} /$ mouse), or LipofectAMINE alone $(20,60,100 \mathrm{nmol} /$ mouse). Bronchoalveolar lavage was performed $12 \mathrm{~h}$ after instillation. The BAL was tested for $A$ ) PMN cell count and B) LDH activity. Values are means $\pm \mathrm{SD} ; n=4$ mice/group. ${ }^{*} p<0.05$ vs. untreated control group. 
Figure 4
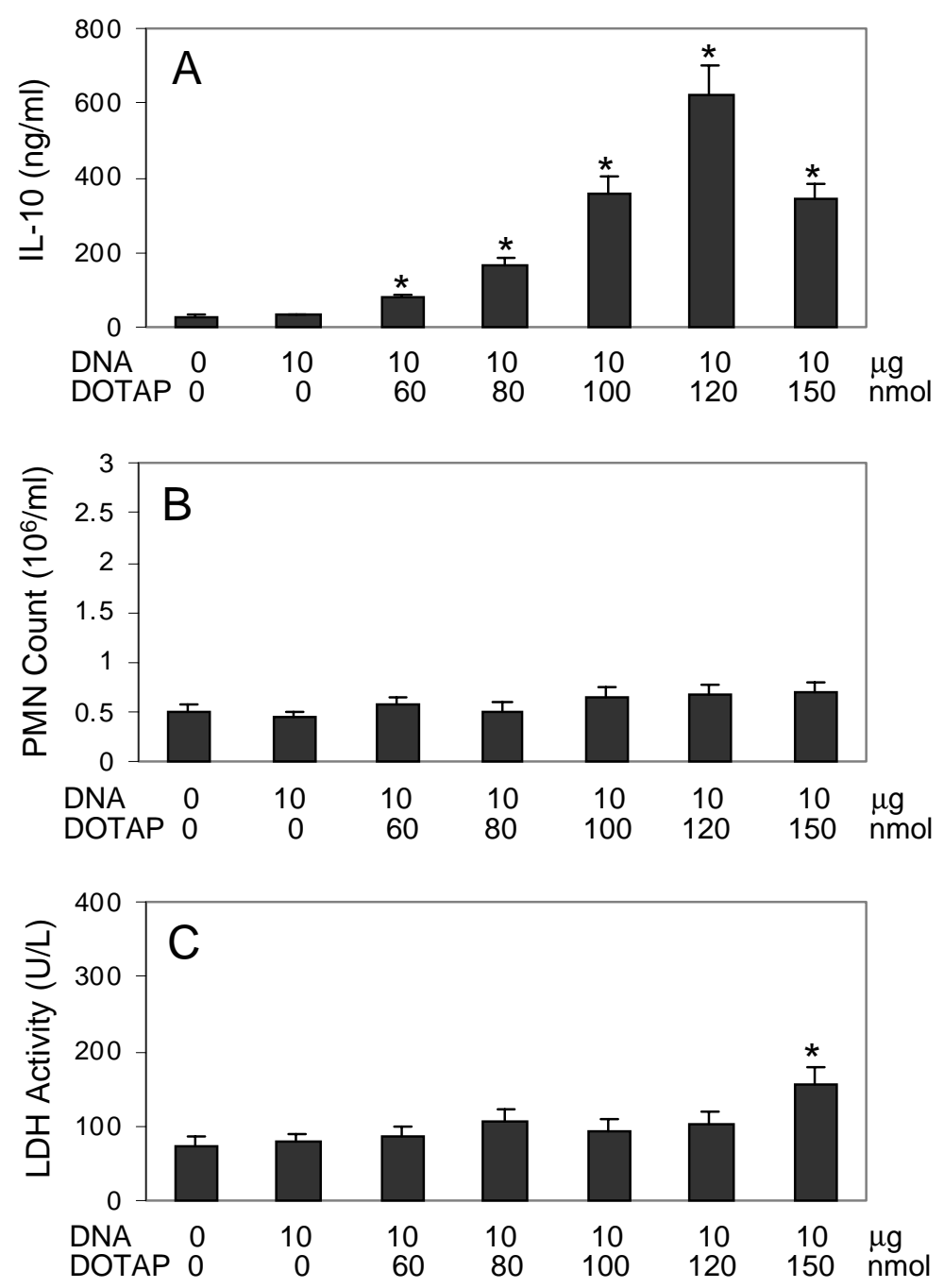

Fig. 4. Optimization of DNA-DOTAP Delivery System. Mice were instilled with DNA (10 $\mu \mathrm{g} /$ mouse) or DNA-DOTAP complexes (10 $\mu \mathrm{g}: 60-150 \mathrm{nmol} /$ mouse). Twelve hours after the instillation, bronchoalveolar lavage was performed and the BAL was tested for A) IL-10 level, B) PMN cell count, and C) LDH activity. Values are means \pm SD; $n=4$ mice/group. * $p<0.05$ vs. untreated control group. 
Figure 5

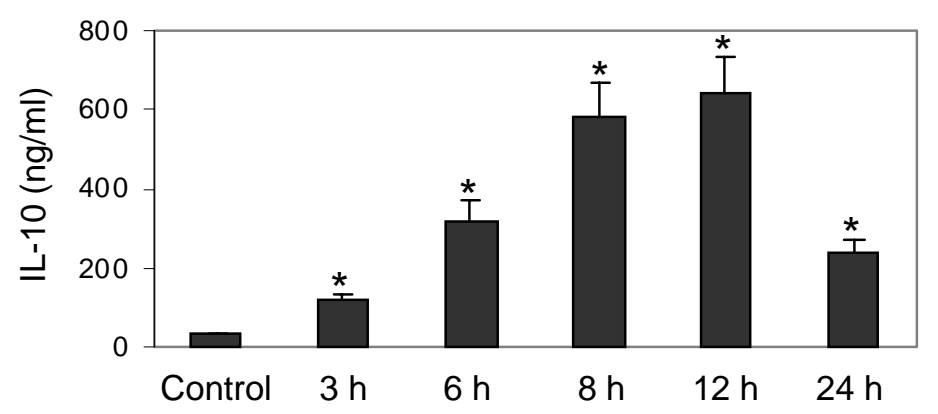

Fig. 5. Time Profile of IL-10 Expression Following DNA-DOTAP Administration. Mice were instilled with DNA-DOTAP (10 $\mu \mathrm{g}: 120 \mathrm{nmol} / \mathrm{mouse}$ ). Bronchoalveolar lavage was performed $3,6,8,12$, and $24 \mathrm{~h}$ after instillation, and the BAL was tested for IL-10 level. Values are means $\pm \mathrm{SD} ; n=4$ mice/group. ${ }^{*} p<0.05$ vs. untreated control group. 
Figure 6
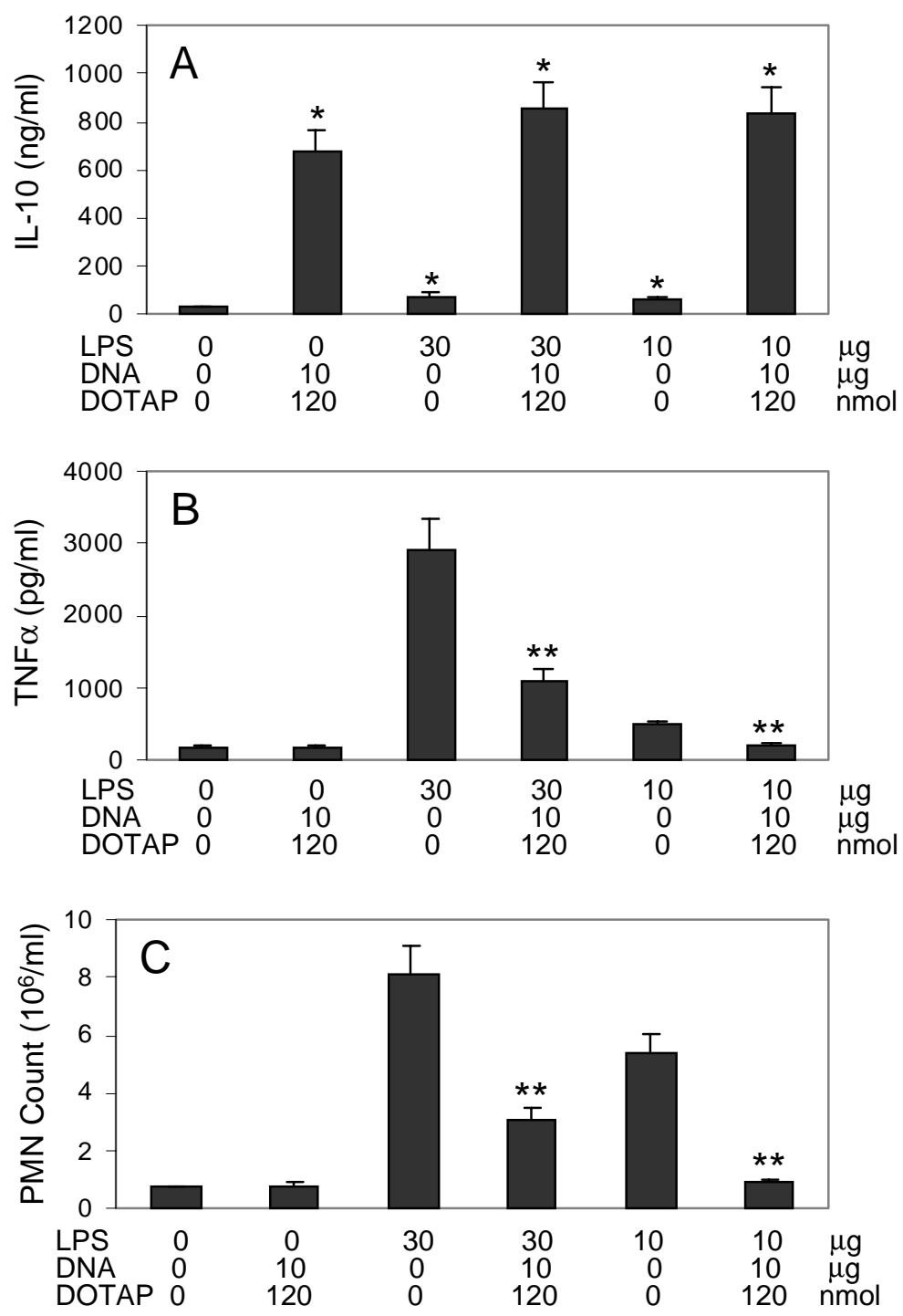

Fig. 6. Effect of IL-10 Gene Transfer on LPS-Induced Lung Inflammation. Mice were instilled with DNA-DOTAP (10 $\mu \mathrm{g}: 120 \mathrm{nmol} /$ mouse) $12 \mathrm{~h}$ before intratracheal instillation with LPS (10, $30 \mu \mathrm{g} /$ mouse). Bronchoalveolar lavage was performed $6 \mathrm{~h}$ after LPS instillation. The BAL was tested for $A$ ) IL-10 concentration, B) TNF- $\alpha$ concentration, and C) PMN cell count. Values are means $\pm \mathrm{SD} ; n=4$ mice/group. ${ }^{*} p<0.05$ vs. untreated control group. ${ }^{* *} p<0.05$ vs. LPS-treated control group. 


\section{VI.7. REFERENCES}

Brigham, K.L., Canonico, A.E., Meyrick, B.O., Schreier, H., Stecenko, A.A., and Conary, J.T. (1994) Gene therapy for inflammatory diseases. Prog Clin Biol Res 388, 361-365.

Chang, S.W. (1994) Endotoxin-induced pulmonary leukostasis in the rat: role of plateletactivating factor and tumor necrosis factor. J Lab Clin Med 123, 65-72.

Cirelli, R.A., Carey, L.A., Fisher, J.K., Rosolia, D.L., Elsasser, T.H., Caperna, T.J., Gee, M.H., and Albertine, K.H. (1995) Endotoxin infusion in anesthetized sheep is associated with intrapulmonary sequestration of leukocytes that immunohistochemically express tumor necrosis factor-alpha. J Leukoc Biol 57, 820-826.

Dokka, S., Leonard, S.S., Wang, L., Castranova, V., Shi, X., and Rojanasakul, Y. (2000) Oxygen Radical-Mediated Pulmonary Toxicity Induced by Cationic Liposomes. Pharm Res (in press)

Drazan, K.E., Wu, L., Bullington, D., and Shaked, A. (1996) Viral IL-10 gene therapy inhibits TNF-alpha and IL-1 beta, not IL-6, in the newborn endotoxemic mouse. $J$ Pediatr Surg 31, 411-414.

Felgner, P. and Holm, M. (1989) Cationic-liposome-mediated transfection. Focus 11, 2125.

Fiorentino, D.F., Zlotnik, A., Mosmann, T.R., Howard, M., and O'Garra, A. (1991) IL-10 inhibits cytokine production by activated macrophages. J Immunol 147, 38153822.

Gao, X. and Huang, L. (1995) Cationic liposome-mediated gene transfer. Gene Ther 2, $710-722$.

Ghivizzani, S.C., Lechman, E.R., Kang, R., Tio, C., Kolls, J., Evans, C.H., and Robbins, P.D. (1998) Direct adenovirus-mediated gene transfer of interleukin 1 and tumor necrosis factor alpha soluble receptors to rabbit knees with experimental arthritis has local and distal anti-arthritic effects. Proc Natl Acad Sci USA 95, 4613-4618. 
Goldman, M., Marchant, A., and Schandene, L. (1996) Endogenous interleukin-10 in inflammatory disorders: regulatory roles and pharmacological modulation. Ann NY Acad Sci 796, 282-293.

Harms, J.S. and Splitter, G.A. (1995) Interferon-gamma inhibits transgene expression driven by SV40 or CMV promoters but augments expression driven by the mammalian MHC I promoter. Hum Gene Ther 6, 1291-1297.

Howard, M., Muchamuel, T., Andrade, S., and Menon, S. (1993) Interleukin 10 protects mice from lethal endotoxemia. J Exp Med 177, 1205-1208.

Ishida, H., Muchamuel, T., Sakaguchi, S., Andrade, S., Menon, S., and Howard, M. (1994) Continuous administration of anti-interleukin 10 antibodies delays onset of autoimmunity in NZB/W F1 mice. J Exp Med 179, 305-310.

Kuhn, R., Lohler, J., Rennick, D., Rajewsky, K., and Muller, W. (1993) Interleukin-10deficient mice develop chronic enterocolitis. Cell 75, 263-274.

Lee, E.R., Marshall, J., Siegel, C.S., Jiang, C., Yew, N.S., Nichols, M.R., Nietupski, J.B., Ziegler, R.J., Lane, M.B., Wang, K.X., Wan, N.C., Scheule, R.K., Harris, D.J., Smith, A.E., and Cheng, S.H. (1996) Detailed analysis of structures and formulations of cationic lipids for efficient gene transfer to the lung. Hum Gene Ther 7, 1701-1717.

Lentsch, A.B., Shanley, T.P., Sarma, V., and Ward, P.A. (1997) In vivo suppression of NF-kappa B and preservation of I kappa B alpha by interleukin-10 and interleukin-13. J Clin Invest 100, 2443-2448.

$\mathrm{Li}$, S. and Huang, L. (1997) In vivo gene transfer via intravenous administration of cationic lipid- protamine-DNA (LPD) complexes. Gene Ther 4, 891-900.

McLachlan, G., Davidson, D.J., Stevenson, B.J., Dickinson, P., Davidson-Smith, H., Dorin, J.R., and Porteous, D.J. (1995) Evaluation in vitro and in vivo of cationic liposome-expression construct complexes for cystic fibrosis gene therapy. Gene Ther 2, 614-622. 
McLachlan, G., Ho, L.P., Davidson-Smith, H., Samways, J., Davidson, H., Stevenson, B.J., Carothers, A.D., Alton, E.W., Middleton, P.G., Smith, S.N., Kallmeyer, G., Michaelis, U., Seeber, S., Naujoks, K., Greening, A.P., Innes, J.A., Dorin, J.R., and Porteous, D.J. (1996) Laboratory and clinical studies in support of cystic fibrosis gene therapy using pCMV-CFTR-DOTAP. Gene Ther 3, 1113-1123.

Meyer, K.B., Thompson, M.M., Levy, M.Y., Barron, L.G., and Szoka, F.C.J. (1995) Intratracheal gene delivery to the mouse airway: characterization of plasmid DNA expression and pharmacokinetics. Gene Ther 2, 450-460.

Moore, K.W., O'Garra, A., de Waal, M., Vieira, P., and Mosmann, T.R. (1993) Interleukin-10. Annu Rev Immunol 11, 165-190.

Mulligan, M.S., Jones, M.L., Vaporciyan, A.A., Howard, M.C., and Ward, P.A. (1993) Protective effects of IL-4 and IL-10 against immune complex-induced lung injury. J Immunol 151, 5666-5674.

Porteous, D.J., Dorin, J.R., McLachlan, G., Davidson-Smith, H., Davidson, H., Stevenson, B.J., Carothers, A.D., Wallace, W.A., Moralee, S., Hoenes, C., Kallmeyer, G., Michaelis, U., Naujoks, K., Ho, L.P., Samways, J.M., Imrie, M., Greening, A.P., and Innes, J.A. (1997) Evidence for safety and efficacy of DOTAP cationic liposome mediated CFTR gene transfer to the nasal epithelium of patients with cystic fibrosis. Gene Ther 4, 210-218.

Sing, A., Merlin, T., Knopf, H.P., Nielsen, P.J., Loppnow, H., Galanos, C., and Freudenberg, M.A. (2000) Bacterial Induction of Beta Interferon in Mice Is a Function of the Lipopolysaccharide Component. Infect Immun 68, 1600-1607.

Tumpey, T.M., Elner, V.M., Chen, S.H., Oakes, J.E., and Lausch, R.N. (1994) Interleukin-10 treatment can suppress stromal keratitis induced by herpes simplex virus type 1. J Immunol 153, 2258-2265.

Whalen, J.D., Lechman, E.L., Carlos, C.A., Weiss, K., Kovesdi, I., Glorioso, J.C., Robbins, P.D., and Evans, C.H. (1999) Adenoviral transfer of the viral IL-10 gene periarticularly to mouse paws suppresses development of collagen-induced arthritis in both injected and uninjected paws. J Immunol 162, 3625-3632. 
Xing, Z., Ohkawara, Y., Jordana, M., Graham, F.L., and Gauldie, J. (1997) Adenoviral vector-mediated interleukin-10 expression in vivo: intramuscular gene transfer inhibits cytokine responses in endotoxemia. Gene Ther 4, 140-149. 


\section{OVERALL CONCLUSIONS}

1. Nuclear expression vectors were more effective at IL-10 expression than the cytoplasmic vectors tested. Hence, the nuclear expression plasmids were chosen for all further studies.

2. Macrophage transfection was maximal at the DNA:LipofectAMINE:protamine ratio of $1: 12: 1 \mu \mathrm{g} / \mathrm{ml}$. This transfection method showed minimal toxicity at the concentrations tested and was at least 20-25-fold superior to the most frequently used DEAEdextran method for macrophage transfection.

3. The presence of endotoxin in plasmid DNA preparations severely limited transgene expression in macrophages, but had little or no effect in other cell types tested. This decreased transfection was dependent on ROS-mediated cellular toxicity induced by endotoxin. Our results indicate that multiple oxidative species are involved in the transfection inactivation process, and that $\mathrm{OH}$ radicals, formed by $\mathrm{H}_{2} \mathrm{O}_{2}$-dependent, metal-catalyzed Fenton reaction, play a major role in this process.

4. IL-10 inactivates macrophage production of reactive oxygen radicals, thereby decreasing inflammation. Specifically, we propose that IL-10 inhibits ROS production which in turn inhibits IKK activity and hence, $1 \mathrm{~KB} \alpha$ degradation. This results in a decrease in NF-KB activity and hence, decreases the expression of inflammatory cytokines such as TNF $\alpha$. This whole cascade of events is responsible for the antiinflammatory properties of IL-10 in macrophages.

5. ROS play a key role in cationic lipid-mediated toxicity. The charge of a liposome is a key determinant of toxicity. Cationic liposomes cause inflammation and toxicity via a pathway that involves the generation of oxygen free radicals because scavenging these radicals decreases toxicity. Polyvalent cationic liposomes are more toxic than their monovalent counterparts.

6. IL-10 gene transfer can downregulate mouse lung inflammation and cell activation in response to LPS stimulation. 


\section{SUJATHA DOKKA}

\section{EDUCATION}

Ph. D., Pharmaceutical Sciences, West Virginia University (GPA 4.0) May 1997-May 2000 Area: Gene Based Therapeutics: Mechanism and Delivery M. S., Pharmaceutical Sciences, West Virginia University (GPA 3.9) Aug 1995- May 1997 Area: Novel delivery systems for antisense oligonucleotides B. S., Pharmacy, University of Bombay, India

(GPA 4.0) July 1991- July 1995

\section{HONORS \& ACTIVITIES}

Graduate Student Teaching Award, School of Pharmacy, West Virginia University, 1999.

Graduate Student Research Award, School of Pharmacy, West Virginia University, 1998.

Outstanding Graduate Student Award for Research Excellence, WVU Chapter of Sigma Xi, 1998.

Rho Chi Honor Society, Initiated into the Alpha Mu Chapter, 1997.

Merit Scholarship, Government of India Merit Scholarship, 1989-1995.

Graduate Student Representative, Basic Pharmaceutical Sciences, WVU, 98-99.

Vice President, Indian Students Association, WVU, 96-97.

\section{WORK EXPERIENCE}

GRADUATE RESEARCH ASSISTANT

Department of Basic Pharmaceutical Sciences, West Virginia University

Aug 1995-present

\section{CYTOKINE GENE THERAPEUTICS}

\section{Cytokine Delivery in vitro and in vivo}

- Established an optimized transfection protocol in macrophages and other cell types in vitro

- Investigated the potential causes of decreased transfection in macrophages

- Developed a non-viral gene delivery system for intratracheal instillations of plasmid IL-10 in mice lungs

- Pharmacology studies: Studied the anti-inflammatory effects of cytokine (IL-10) gene therapy in a lung inflammation model

- Toxicology studies: Investigated the relationship between charge of liposomes and toxicity in vivo

Results: Reported an in vitro transfection protocol, which is superior to previously established protocols in macrophages. Identified key factors affecting macrophage gene transfection.

\section{Mechanistic Studies}

- Studied the mechanism of anti-inflammatory effect of IL-10 at various steps in the signal transduction pathway

- Performed Gene Cloning, Electrophoretic Mobility Shift Assays, Western Blots, ESR to investigate the mechanism of IL-10 action on transcription factors and reactive oxygen species

Results: Demonstrated for the first time, the role of IL-10 in decreasing reactive oxygen species (ROS) production using ESR. Established a potential mechanism of IL-10 action. 


\section{MOLECULAR MODELING}

- Designed wild-type and mutated Nuclear Localization Sequence peptides using Sybyl

- Studied the effect of one amino acid substitution of the peptide on its ability to dock to its receptor and hence, on its function

\section{NOVEL OLIGONUCLEOTIDE DELIVERY SYSTEM}

- Designed a synthetic import peptide for potential use as a delivery system for oligonucleotides

- Evaluated the safety and efficacy of the delivery system in a number of cell types

- Illustrated nuclear localization of the oligonucleotide in the presence of the delivery system by employing Fluorescence and Confocal Microscopy

Results: Developed a novel delivery system, which enhanced nuclear uptake of oligonucleotides. This delivery system was superior to existing delivery systems for oligonucleotides.

\section{SUMMER RESEARCH}

Summer, 1997

\section{Dr. Leaf Huang's Laboratory of Drug Targeting, University of Pittsburgh}

- Developed cytoplasmic and nuclear expression vectors for IL-10 gene therapy

- Designed, constructed, and isolated plasmid DNA from bacterial cultures

- Performed a number of molecular biology techniques such as Northern Blots, RT-PCR, PCR, and Gene transfections

\section{Graduate Teaching Assistant}

Aug 1997- 1999

Department of Basic Pharmaceutical Sciences, West Virginia University

- Coordinated, designed, and planned experiments for an undergraduate level Pharmaceutics $\mathrm{Lab}$

- Facilitated interactive group discussions among students as a part of Problem Based Learning

- Graded lab assignments, examinations and homeworks

- Supervised and coached four undergraduate students in their research projects

- Won the "Graduate Student Teaching Award, 99".

\section{SUMMER INTERN}

Pfizer India Ltd., Bombay, India

Summer, 1994

- Worked in the Departments of Quality Control and Assurance, Research and Development, and Production.

\section{PUBLICATIONS}

Rojanasakul, Y., Luo, Q., Ye, J., Dokka, S., and Shi, X. (2000). Molecular Targeting of Nuclear Transcriptional Regulators. American Chemical Society Series Book (In Press).

Rojanasakul, Y., and Dokka, S. (1999). Tools for Molecular Analysis. In "Biopharmaceutical Drug Design and Development ", S. Wu-Pong and Y. Rojanasakul (Eds.), Humanna Press, Totowa, NJ, 37-49.

Dokka, S., Toledo-Velasquez, D., Shi, X., Wang, L., and Rojanasakul, Y. (1997). Cellular Delivery of Oligonucleotides by Synthetic Import Peptide Carrier. Pharm. Res., 14 (12): 17591764.

Dokka, S. (1997). Synthetic Import Peptides as a Drug Delivery System for Oligonucleotides. $M$. S. Thesis., West Virginia University. 
Dokka, $S$ and Rojanasakul, Y. (1999). Nonendocytic Routes of Oligonucleotide Delivery. Adv. Drug Del. Rev. (In press).

Dokka, $\boldsymbol{S}$ and Rojanasakul, Y. (1999). High-Efficiency Gene Transfection of Macrophages by Lipoplexes. J. Pharm. Sci. (Manuscript in Review).

Dokka, S., Toledo, D., Castronova, V., Shi, X., and Rojanasakul, Y. (1999). Oxygen RadicalMediated Pulmonary Toxicity Induced by Cationic Liposomes. Pharm. Res. (Accepted for Publication)

Dokka, S., Toledo, D., Wang, L., Shi, X., and Rojanasakul, Y. Mechanisms of EndotoxinInduced Inactivation of Transgene Expression in Macrophages. Am. J. Physiol. (Accepted for Publication)

Dokka, S., Rojanasakul, Y., Shi, X., Leonard, S., Ye, J. and Chen, F. (1999). Mechanism of Interleukin-10-Mediated Inhibition of Nuclear Factor Kappa B Activation in Macrophages (Manuscript in Review).

Dokka, S., Shi, X., Castronova, V., and Rojanasakul, Y. (1999). Inhibition of endotoxin-induced inflammation by IL-10 gene therapy (Manuscript in Review).

\section{AbStracts}

Dokka, $S$ and Rojanasakul, Y. Mechanism of IL-10 gene regulation and development of IL-10 gene therapeutics. Pharm Sci. 1(4), 4093, 1999.

Dokka, S., Fernando, S., Toledo, D., Rojanasakul, Y. Cytokine gene therapy in the treatment of lung inflammation. Pharm Sci. 1(4), 4134, 1999.

Dokka, S., Swaroop, N., Rojanasakul, Y. Gene transfection in macrophages. Pharm Sci. 1(4), 4135, 1999.

Dokka. S., Huang, L., Brisson, M. and Rojanasakul, Y. Development of IL-10 Gene Therapeutics. Pharm. Res., 1(1), S-288, 1998.

Dokka, $\boldsymbol{S}$ and Rojanasakul, Y. Optimization of Gene Transfection in Macrophages. Pharm. Res., 1(1), S-284, 1998.

Dokka, S., Tran, B. and Rojanasakul, Y. Cellular Oligonucleotide Delivery Using Synthetic Import Peptides and Liposomes. Pharm. Res., 1(1), S-289, 1998.

Rojanasakul, Y., Chen, N., Dokka, S., Luo, Q., and Shi, X. Abstract. Inhibition of NF-kB mediated cytokine gene expression by oligonucleotides. Pharm. Res., 14(11), S-59, 1997.

Dokka, S., Toledo-Velasquez, D., and Rojanasakul, Y. Synthetic Import Peptides as a Drug Delivery System for Oligonucleotides. Pharm. Res., 14(11): S-640, 1997.

Dokka, S., Liang, W., and Rojanasakul, Y. Selectivity of antisense action against point mutated Ki- ras oncogene in Human Lung Carcinoma cells. Pharm. Res., 13(9): S- 387, 1996.

\section{Presented AT THE FOLLOWING MEETINGS}

AAPS Annual Meeting and Exposition, Nov. 1999, New Orleans, LA. AAPS Annual Meeting and Exposition, Nov. 1998, San Fransisco, CA

PODIUM , AAPS Annual Meeting and Exposition, Nov. 1997, Boston, MA.

AAPS Annual Meeting and Exposition, Oct. 1996, Seattle, WA.

Post Graduate Students' Research Meeting, May 1996,University of Minnesota, Minneapolis.

WVU School of Medicine Research Day, March, 1999, Morgantown, WV.

\section{ProfessionAl MeMberships}

American Association of Pharmaceutical Scientists.

Alpha Mu Chapter of Rho-Chi Society.

West Virginia University Chapter of Sigma Xi, The Scientific Research Society. 